
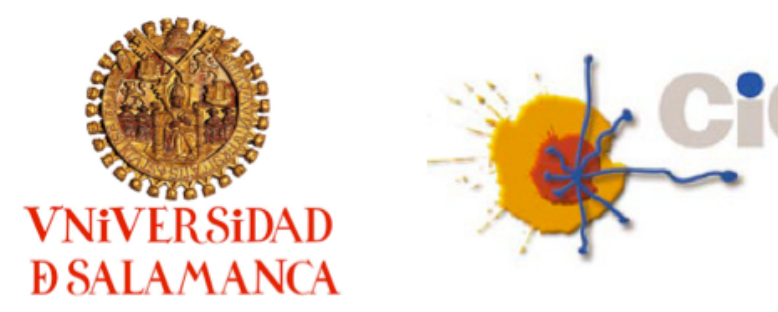

CENTRO DE INVESTIGACIÓN DEL CÁNCER

INSTITUTO DE BIOLOGÍA MOLECULAR Y CELULAR DEL CÁNCER

CSIC-UNIVERSIDAD DE SALAMANCA

\title{
NUEVOS MECANISMOS REGULADORES DE LA ACTIVACIÓN Y FUNCIONES EFECTORAS DE LA ONCOPROTEÍNA Vav1 EN LINFOCITOS
}

TESIS DOCTORAL

MARÍA BARREIRA GONZÁLEZ

Salamanca, 2013 


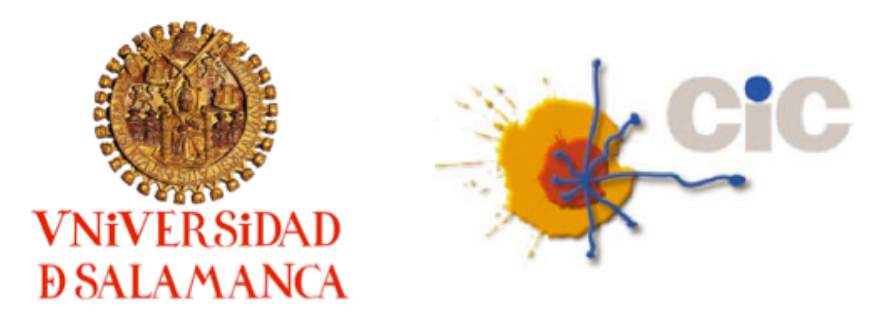

El Dr. XOSÉ RAMÓN GARCíA BUSTELO, Profesor de Investigación del Consejo Superior de Investigaciones Científicas en el Instituto de Biología Molecular y Celular del Cáncer de Salamanca,

\section{CERTIFICA:}

Que el trabajo de tesis titulado "Nuevos mecanismos reguladores de la activación y funciones efectoras de la oncoproteína Vav1 en linfocitos", presentado por Dña. MARÍA BARREIRA GONZÁLEZ para optar al grado de Doctor en Biología por la Universidad de Salamanca, ha sido realizado bajo mi dirección en el Centro de Investigación del Cáncer (CSICUSAL). Considerando que cumple con las condiciones necesarias, autorizo su presentación a fin que pueda ser defendido ante el tribunal correspondiente.

Y para que conste a los efectos oportunos, expido y firmo el presente certificado en Salamanca, a 17 de Junio de 2013.

Fdo. Dr. Xosé Ramón García Bustelo 
Este trabajo de tesis ha sido financiado por:

- Una beca JAE-predoc del Consejo Superior de Investigaciones Científicas (2008-2011).

- Programa de Biomedicina del Ministerio de Educación y Ciencia (SAF2006-01789) (2006-2009).

- 70 Programa Marco de la UE, Tema 1 (Health-2007-2.4.1-6). MetaFight (FP7-HEALTH2007-A-201862) (2008-2010).

- Ayudas a Grupos de Investigación de Excelencia de Castilla y León. Consejería de Educación de la Junta de Castilla y León (2008-2010).

- Role of Vav family proteins in cell signaling and cancer. RO1 (5RO1CA73735). National Cancer Institute (NIH) (2005-2011).

- Programa de Biomedicina del Ministerio de Ciencia e Innovación (SAF2009-07172) (2010-2012).

- Red Temática de Investigación Cooperativa de Cáncer (RD06/0020/001). Proyecto financiado por el Instituto de Salud Carlos III (2007-2012).

- Ayudas para la realización de proyectos de Investigación (Subprograma de Proyectos de Investigación Fundamental No Orientada). Ministerio de Economía y Competitividad (SAF2012-31371) (2013-2015).

- Red Temática de Investigación Cooperativa de Cáncer (RD12/0036/0002). Proyecto financiado por el Instituto de Salud Carlos III (2013-2016). 
"La vida no es fácil, para ninguno de nosotros. Pero... iqué importa! Hay que perseverar $y$, sobre todo, tener confianza en uno mismo. Hay que sentirse dotado para realizar alguna cosa y que esa cosa hay que alcanzarla, cueste lo que cueste."

Marja Skłodowska (Marie Curie) 



\section{ÍNDICE}

$\begin{array}{ll}\text { INTRODUCCIÓN } & 1\end{array}$

1. LA PROTEÍNA Vav1 3

1.1. Estructura de la proteína Vav1 5

1.2. Expresión tisular 6

1.3. Función biológica $\quad 6$

1.4. Regulación de su actividad biológica $\quad 8$

1.4.1. Fosforilación en tirosinas $\quad 8$

1.4.2. Interacciones proteína-proteína $\quad 12$

1.4.3. Localización subcelular $\quad 20$

1.4.4. Otros mecanismos de regulación postraduccional 20

1.4.5. Efectos de algunos medicamentos $\quad 20$

1.4.6. Estados patológicos $\quad 21$

2. LA PROTEÍNA Vav1 EN CÉLULAS HEMATOPOYÉTICAS 23

2.1. Análisis genético de la proteína Vav1 23

2.1.1. Linfocitos $T$

2.1.2. Linfocitos B 31

2.1.3. Plaquetas 32

2.1.4. Neutrófilos 32

2.1.5. Macrófagos 32

2.1.6. Mastocitos 33

2.1.7. Células asesinas naturales (NK) 33

2.1.8. Células dendríticas $\quad 34$

2.2. Vav1 como diana terapéutica $\quad 34$

\begin{tabular}{l|l} 
OBJETIVOS & 37
\end{tabular}

MATERIALES Y MÉTODOS

$\begin{array}{ll}\text { RESULTADOS } & 59\end{array}$

Capítulo 1: Nuevo mecanismo de regulación de Vav1 a través de una interacción entre sus regiones DH-PH y CSH3

1. El dominio $\mathrm{CSH} 3$ participa en un mecanismo de regulación negativo de la proteína Vav1 
2. El CSH3 inhibe la actividad de Vav1 mediante su unión en cis a la región $\mathrm{DH}-\mathrm{PH}$

3. El dominio $\mathrm{CSH} 3$ interacciona con la región $\mathrm{DH}-\mathrm{PH}$

4. La hélice $\alpha 6$ del dominio $\mathrm{DH}$ participa en la estabilidad de la interacción inhibitoria CSH3/Vav1

5. La inhibición de Vav1 es mediada por la acción cooperativa de residuos del $R T$-loop y el extremo C-terminal del CSH3

79

6. Los efectos sinérgicos entre los sitios de fosforilación de Vav1 afectan a la eliminación de la inhibición ejercida por sus regiones $\mathrm{N}$ - y C-terminal

\section{Capítulo 2: Disociación de rutas de señalización por mutaciones en los sitios de fosforilación de la proteína Vav1}

1. Existe un diálogo cruzado entre los sitios de fosforilación de Vav1 que facilita su completa activación

2. Las tirosinas implicadas en la regulación de Vav1 modulan las respuestas celulares asociadas a la activación de ésta en linfocitos

\section{Capítulo 3: Identificación de los elementos de señalización implicados en la regulación de la proteína Vav1 en linfocitos}

1. La proteína Vav1 es activada, principalmente, por Lck y otra quinasa de la familia Src, y, en menor medida, por Zap70

2. La proteína Lat es requerida para la óptima activación de Vav1 y su reclutamiento a la membrana plasmática durante la señalización celular

3. Las proteínas SIp76 y PLC $\gamma 1$ regulan negativamente la activación de Vav1 en ausencia de estímulos

\section{DISCUSIÓN}





\section{LA PROTEÍNA Vav1}

Los factores de intercambio nucleotídico (GEFs) son los principales activadores de las GTPasas Rho/Rac. Unos de los GEFs que más interés despierta debido a su implicación en una gran diversidad de procesos biológicos son los miembros de la familia de proteínas Vav. La función biológica principal de esta familia es actuar como GEFs de las GTPasas Rho/Rac favoreciendo el paso de esas GTPasas de un estado inactivo (unido a GDP) a un estado activo (unido a GTP) durante la transducción de señales (Figura 1) (Crespo et al, 1997; Movilla et al, 1999; Schuebel et al, 1998). Las proteínas Vav promueven la activación de las GTPasas Rac (e.j. Rac1, RhoG) y en menor medida, de las GTPasas Rho (e.j. RhoA) in vitro.

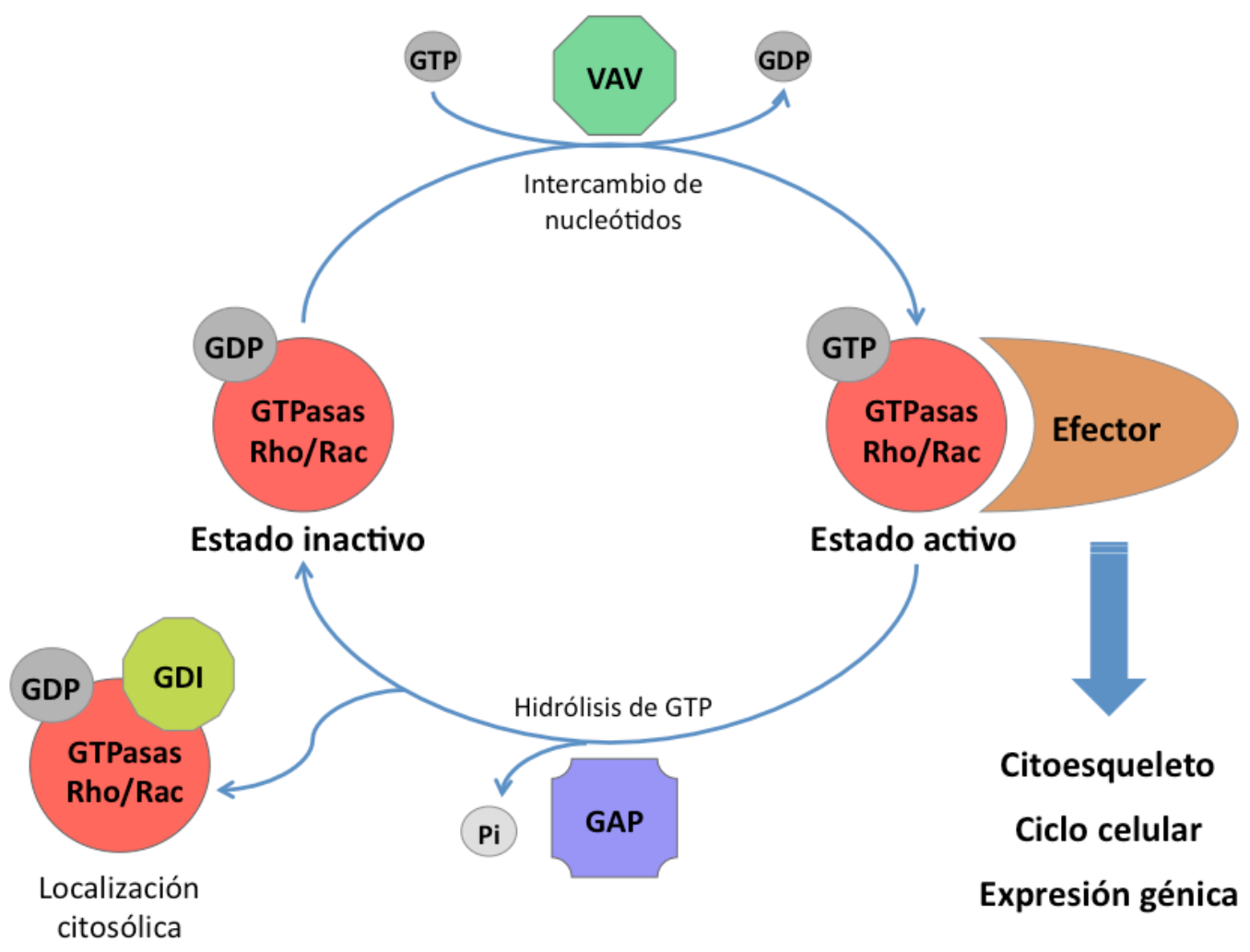

Figura 1. Esquema del ciclo de activación de las GTPasas de la familia Rho/Rac. Las GTPasas Rho/Rac se encuentran unidas a GDP en su estado inactivo y se convierten en funcionales al unirse a GTP. Los GEFs, en este cas las proteínas Vav, se unen a las regiones switch de las GTPasas y realizan el intercambio de GDP por GTP. En su estado activo, unidas a GTP, estas GTPasas son capaces de regular la actividad de sus efectores por unión directa, desencadenando así distintas respuestas celulares. Las proteínas GAP catalizan la hidrólisis de las GTPasas dando lugar a la conformación unida a GDP. En este estado, las proteínas GDI son capaces de unirse a las regiones switch impidiendo la activación de las GTPasas mediada por las proteínas Vav y su reclutamiento a la membrana plasmática. Pi, fosfato inorgánico. 
La proteína Vav1 fue descubierta en el año 1989 debido a la expresión de su versión oncogénica (truncación de los 66 primeros aminoácidos) durante ensayos de formación de focos en células NIH3T3 usando ADN genómico derivado de tumores (Coppola et al, 1991; Katzav et al, 1991; Katzav et al, 1989). Las proteínas Vav2 y Vav3 fueron identificadas posteriormente en humanos y ratones entre los años 1995 y 2000 (Henske et al, 1995; Movilla et al, 1999; Schuebel et al, 1998; Trenkle et al, 2000). La secuenciación genómica de especies de distintas líneas evolutivas ha permitido en los últimos años el descubrimiento de miembros adicionales de esta familia presentes en especies tanto de invertebrados como de vertebrados (Dekel et al, 2000; Wilson et al, 1994).

La presencia de más de un miembro de la familia Vav es una característica exclusiva de vertebrados. Concretamente, en mamíferos existen tres representantes de esta familia, Vav1, Vav2 y Vav3. En varias especies de peces se ha descubierto un nuevo miembro de la familia, Vav4. En el caso de las aves, sólo los homólogos de Vav2 y Vav3 han sido descritos. En anfibios aparecen los ortólogos de los tres miembros conocidos en mamíferos. Por el contrario, las especies de invertebrados y urocordados (e. j., Caenorhabditis elegans, Drosophila melanogaster, Anopheles gambiae, Apis mellifera, Ciona intestinalis) sólo presentan un único miembro de esta familia.

Este grupo de factores de intercambio presenta una serie de características únicas tanto desde el punto de vista funcional como estructural. En primer lugar, la actividad catalítica de estas proteínas es directamente dependiente de la fosforilación en tirosinas. Además, la presencia en tándem de dominios DH, PH y ZF (dominio en dedos de zinc) es una característica estructural única de la familia Vav. También lo es la presencia de un dominio de homología a Src de tipo 2 (SH2) en una proteína con dominio $\mathrm{DH}$, facilitando la función adaptadora de estas proteínas.

La implicación de esta familia de proteínas en diversos procesos biológicos queda constatada por los estudios realizados en ratones knock-out. Estos estudios han revelado que la expresión de las proteínas Vav es fundamental para el perfecto funcionamiento de las rutas apoptóticas, proliferativas y citoesqueléticas necesarias para el desarrollo, la selección y las respuestas celulares de las células linfoides. Además, se ha demostrado a través de estos estudios que esta familia esta implicada en otros procesos fisiológicos tales como el desarrollo del cerebelo (Quevedo et al, 2010), la homeostasis cardiovascular (Sauzeau et al, 2006, Sauzeau et al, 2007), las respuestas dependientes de óxido nítrico en células del músculo liso (Sauzeau et al, ) o los procesos metastáticos a partir de tumores de mama 
(Citterio et al, 2012). Este trabajo de tesis se ha centrado en el estudio de la regulación de la proteína Vav1 en linfocitos.

\subsection{Estructura de la proteína Vav1}

La proteína Vav1, al igual que los demás miembros de mamíferos, presenta una organización de dominios estructurales altamente conservada a lo largo de la evolución. Esta estructura consta de ocho dominios diferentes: un dominio de homología a calponina $(\mathrm{CH})$, una región acídica $(\mathrm{Ac})$, un dominio de homología a $\mathrm{Dbl}(\mathrm{DH})$, un dominio de homología a pleckstrina $(\mathrm{PH})$, un dominio en dedos de zinc (ZF), una región rica en prolinas (PRR), dos dominios de homología a Src de tipo 3 (SH3) y uno de tipo 2 (SH2) (Figura 2).

Los dominios $\mathrm{CH}$ y Ac están implicados en la regulación de la actividad de la proteína Vav1 ya que participa en un mecanismo de inhibición intramolecular. La actividad GEF de Vav1 reside en su dominio $\mathrm{DH}$, que necesita la presencia de los dominios $\mathrm{PH}$ y ZF para llevar a cabo su función. El resto de regiones participan en el establecimiento de interacciones proteína-proteína. Cada dominio estructural presenta un rol distinto pudiendo participar en mecanismos de regulación intramoleculares, interacciones proteína-proteína y/o funciones efectoras (Figura 2) (Bustelo, 2000; Bustelo and Couceiro, 2008).

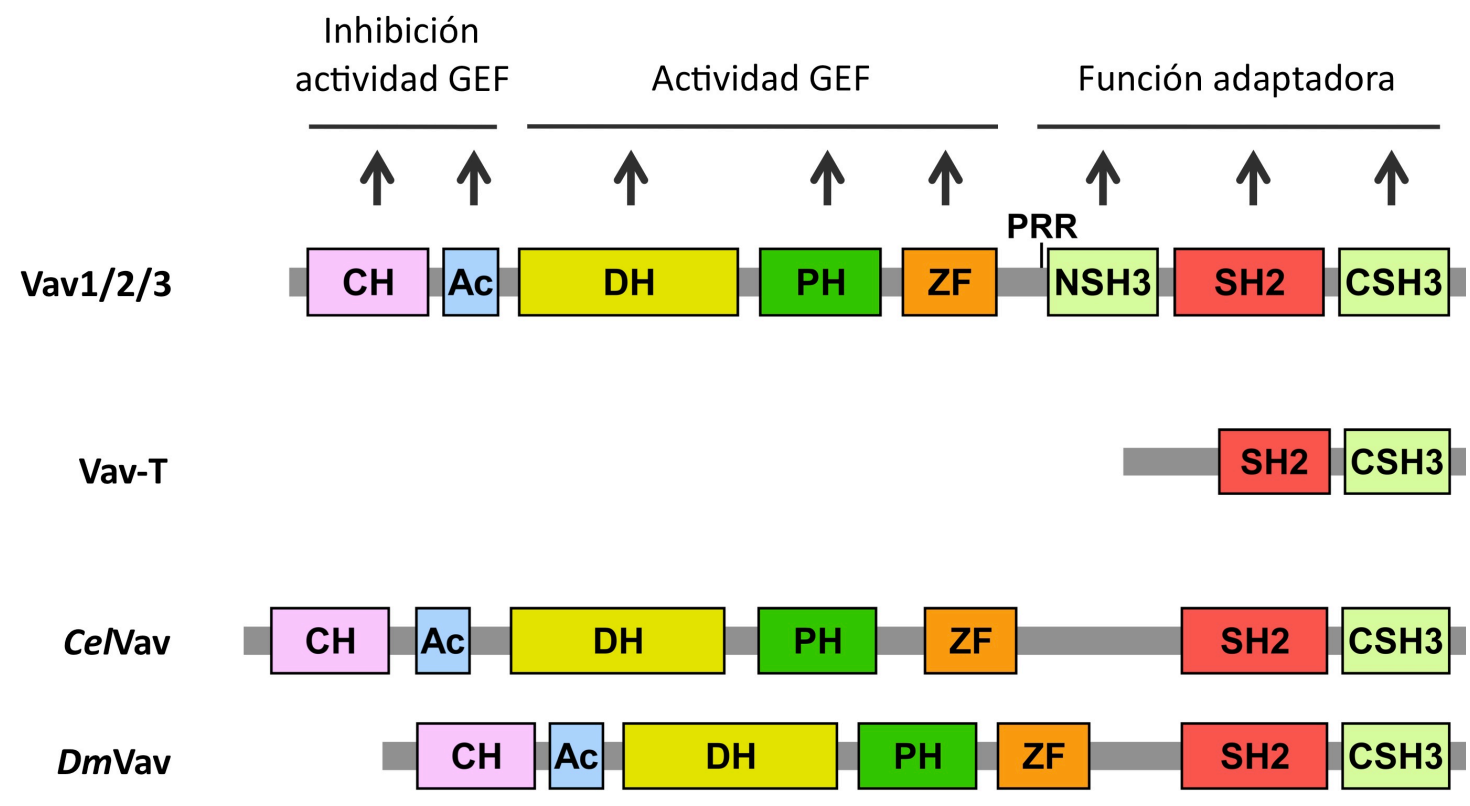

Figura 2. Estructura de dominios de los miembros de la familia Vav y la variante transcripcional Vav-T. En la parte superior se indican las funciones asociadas a cada dominio. 


\subsection{Expresión tisular}

Se ha demostrado, mediante estudios con técnicas de hibridación in situ y Northern-blot, que la expresión de la proteína Vav1 está prácticamente restringida a las células hematopoyéticas tanto en la fase embrionaria como adulta. Este patrón de expresión es común en humanos y ratones (Bustelo et al, 1993; Katzav et al, 1989). Vav2 y Vav3 también se expresan en células hematopoyéticas pero, a diferencia de Vav1, también presentan altos niveles de expresión en tejidos no hematopoyéticos (Bustelo, 2000). Fuera del sistema hematopoyético, Vav1 ha sido detectado en células madre embrionarias (Wulf et al, 1993; Zmuidzinas et al, 1995), en la capa ameloblástica del brote dental de animales neonatos (Bustelo et al, 1993), células trofoblásticas (Higuchi et al, 1995; Zmuidzinas et al, 1995), neuronas cerebelares (Betz et al, 2003), enterocitos cecales (Liu et al, 2009), pulmón (Coppola et al, 1991) y páncreas (Schuebel et al, 1996). Además, aparece en células tumorales de cáncer de pulmón (Lazer et al, 2009), y en líneas celulares derivadas de neuroblastoma (Hornstein et al, 2003; Betz et al, 2003) y melanoma (Bartolome et al, 2006). No se puede excluir la posibilidad de que existan bajos niveles de expresión de Vav1 en otros tejidos, ya que clones de ADNc de Vav1 han sido aislados de ojos, del núcleo caudado, la sustancia negra y otros tipos de tejidos. En mamíferos encontramos también una isoforma de la proteína Vav1, Vav-T, que sólo presenta la región SH2-SH3 y que se expresa en espermatocitos y las espermátidas de ratón (Figura 2) (Okumura et al, 1997).

\subsection{Función biológica}

Como se mencionó en anteriormente, la función principal de la proteína Vav1 es su papel como GEF de las GTPasas Rho/Rac. A diferencia de otros activadores de las proteínas Rho/Rac, en los cuales su actividad catalítica reside exclusivamente en el dominio $\mathrm{DH}$, la catálisis de intercambio de nucleótidos en las GTPasas sustrato requiere del casete DH-PH-ZF ( Chrencik et al, 2008; Rapley et al, 2008). La proteína Vav1 necesita una fosforilación previa en tres residuos de tirosina pertenecientes a la región acídica (la tirosina 174, y en menor medida las tirosinas 142 y 160) por parte de proteínas tirosina quinasa, que se encuentran por encima de la proteína Vav1 en las rutas de señalización, dando lugar a la activación catalítica de las mismas. Por ello, la proteína Vav1 actúa por debajo de receptores de membrana que presentan actividad quinasa intrínseca (EGF, PDGF) o asociada (receptores de antígeno) (Bustelo, 2000; Bustelo and Couceiro, 2008).

De acuerdo con el rol de los GEFs de la familia Rho/Rac, la proteína Vav1 induce respuestas biológicas dependientes de Rho/Rac tales como la polimerización de F-actina, la invasión, la 
motilidad, la adhesión mediada por integrinas, transiciones del ciclo celular, o metástasis. También es capaz de activar rutas de señalización canónicas por debajo de las GTPasas Rho/Rac como la activación de la quinasa p21 (PAK), la quinasa c-Jun N-terminal (JNK), el factor nuclear potenciador de las cadenas ligeras kappa de las células B activadas (NF-КB), la familia de proteínas de la proteína activadora-1 (AP-1), y el factor de respuesta al suero (SRF) (Bustelo, 2000; Bustelo and Couceiro, 2008; Turner et al, 2002).

Al ser una proteína cuya expresión está prácticamente restringida a la línea hematopoyética, Vav1 participa en las rutas de señalización asociadas a receptores hematopoyéticos siendo esta una característica específica de Vav1 dentro de la familia Vav. Los resultados obtenidos en estudios con ratones knock-out para Vav1 indican que esta proteína tiene un papel crucial en las respuestas celulares resultado de la activación de los receptores de células $T(T C R)$ y $B(B C R)$, integrinas y receptores con motivos ITAMs (motivos de activación en inmunoreceptores basados en tirosinas) que regulan el desarrollo y/o funciones efectoras de una amplia variedad de células hematopoyéticas.

A parte de este rol principal, Vav1 funciona también como molécula adaptadora, participando en la formación de complejos heteromoleculares que desencadenan respuestas biológicas independientes de su actividad catalítica (Bustelo, 2001). Esta función adaptadora fue demostrada a partir de la expresión, en linfocitos T, de una versión de Vav1 catalíticamente inactiva, viendo que esta era capaz de inducir igualmente la activación de NF-AT, un factor de transcripción implicado en la regulación de interleuquina-2 (IL-2), y otras citoquinas de células linfoides (Kuhne et al, 2000).

Además de estas funciones, Vav1 también participa en la amplificación de señales y en la diversificación de los eventos producidos por la estimulación de receptores de membrana en las células hematopoyéticas. Vav1 es una proteína fundamental para la generación de segundos mensajeros $\left(\mathrm{Ca}^{2+}\right.$, diacilglicerol, $\left.\mathrm{PIP}_{3}\right)$, siendo estos los encargados de diversificar la señalización celular, promoviendo la estimulación de rutas como la de la proteína disociadora de Ras GDP (RasGRP) / Ras / Erk / Akt (Caloca et al, 2003,Caloca et al, 2008; Costello et al, 1999; Reynolds et al, 2002; Zugaza et al, 2004), las proteínas quinasa C (PKCs) (Caloca et al, 2008; Reynolds et al, 2002), y las proteínas quinasa D (PKDs) (Caloca et al, 2008; Reynolds et al, 2004; Vigorito et al, 2006). Este efecto de Vav1 sobre los mensajeros secundarios se debe a que esta proteína es necesaria para la óptima fosforilación de la fosfatidilinositol-3 quinasa (PI3K) y los miembros de la familia de la fosfolipasa C- $\gamma$ (PLC $\gamma$ ) (Costello et al, 1999; Manetz et al, 2001; Spurrell et al, 2009). Aunque muchos de estos efectos de la señalización está relacionados con la actividad catalítica de Vav1, en otros casos son fruto de las funciones de 
Vav1 independientes de Rac1 en linfocitos T (Saveliev et al, 2009). Algunas de estas funciones de Vav1 parecen ser específicas del tipo celular y de la especie, y no hay que olvidar que estas respuestas también conllevan la interacción de Vav1 con otras moléculas de transducción de señales que son requeridas para el correcto desarrollo de esas respuestas biológicas.

\subsection{Regulación de su actividad biológica}

\subsubsection{Fosforilación en tirosinas}

La actividad catalítica de Vav1 depende principalmente de su estado de fosforilación a través de la regulación de interacciones intramoleculares autoinhibitorias (Figura 3). Este mecanismo de regulación fue demostrado inicialmente mediante experimentos bioquímicos y de biología celular (Crespo et al, 1997; Movilla et al, 1999; Schuebel et al, 1998; Zugaza et al, 2002) y, posteriormente, corroborado a nivel estructural mediante resonancia magnética nuclear (NMR) (Aghazadeh et al, 2000) y, más recientemente, mediante técnicas cristalográficas (Figura 3) (Yu et al, 2010).

Estos análisis indicaron que el estado inactivo no fosfoforilado, de la proteína Vav1 se establece a través de una red compleja de interacciones entre:

- El dominio $\mathrm{CH}$ con los dominios $\mathrm{PH}, \mathrm{DH}$ y dos residuos de tirosinas ( $\mathrm{Y} 142$ y $\mathrm{Y} 160$ ) presentes en la región acídica

- La región acídica con el dominio PH

- La tirosina 174 (Y174) de la región acídica con la región de unión a las GTPasas que se encuentra en el dominio $\mathrm{DH}$.

Todas estas interacciones cooperan entre ellas para inducir una conformación "cerrada" de la proteína Vav1 que no permite la unión de las GTPasas substrato a la región catalítica (Figura 3) (Yu et al, 2010).

La fosforilación de Vav1 en los residuos de la región acídica causa la disrupción de la estructura inhibitoria y la exposición, por tanto, del sitio de unión a las GTPasas (Figura 3). Además de estos cambios, la comparación de las estructuras cristalinas de las regiones de Vav1 CH-Ac-DH-PH-ZF (cataliticamente inactiva; Yu et al, 2010) y Ac-DH-PH-ZF (cataliticamente activa; Chrencik et al, 2008; Rapley et al, 2008) indican que la activación de la proteína induce cambios en la orientación relativa del dominio ZF respecto al resto de 
dominios presentes en el casete central de Vav1, DH-PH-ZF. Esto es debido cambios en la curvatura de la hélice $\alpha 6$ del dominio DH de Vav1 entre estos dos estados (Yu et al, 2010).

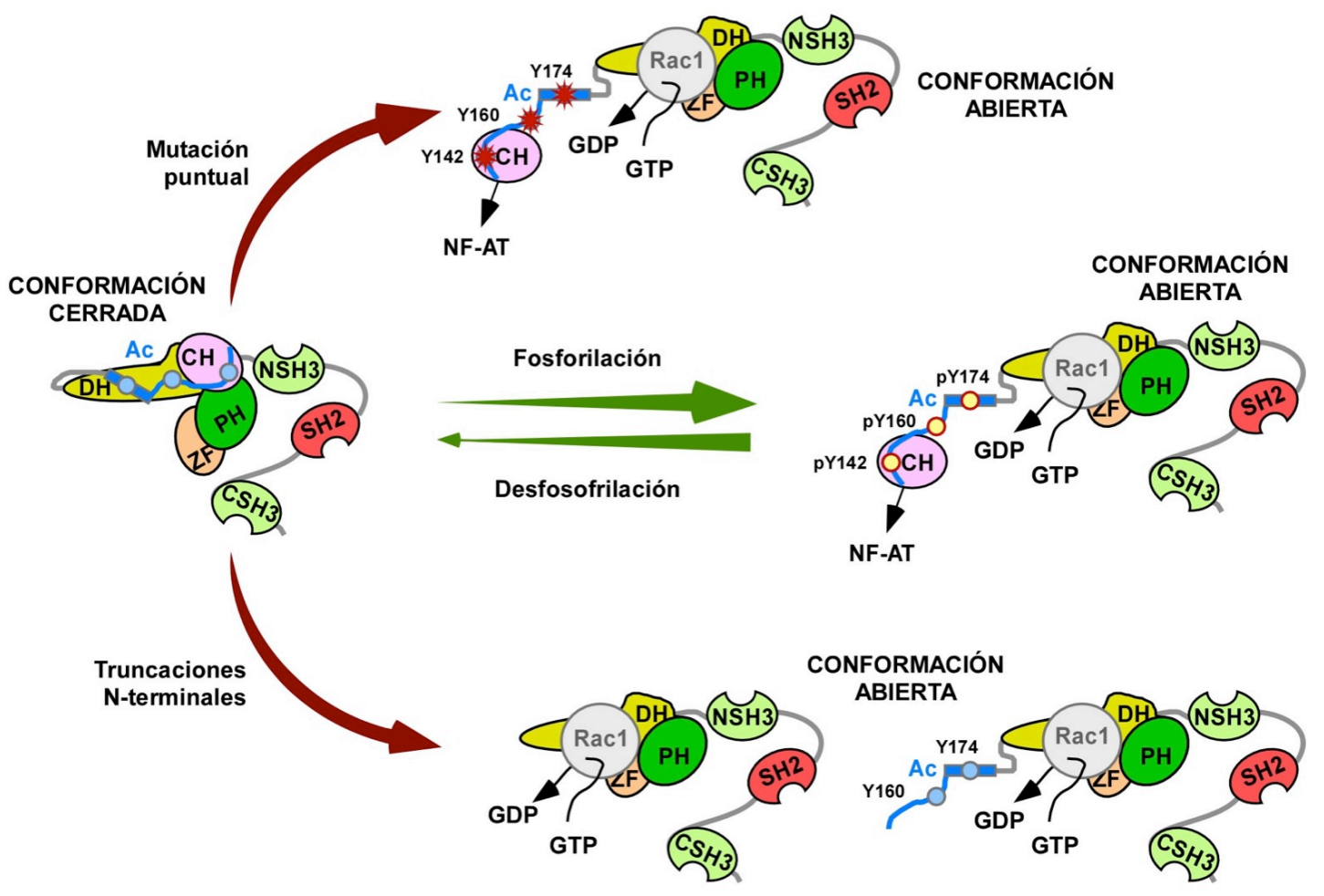

Figura 3. Modelo actual de activación de las proteínas Vav. Representación esquemática de los mecanismos de activación fisiológicos (flechas verdes) y oncogénicos (flechas rojas) de la familia de proteínas Vav. Las localizaciones de la región $\mathrm{CH}-\mathrm{Ac}$ y del casete NSH3-SH2-CSH3 son hipotéticas ya que no existen estructuras 3D disponibles. La hélice $\alpha$ que contiene al sitio de fosforilación $Y^{174}$ está indicada con un rectángulo azul. Puntos en azul claro, residuos de tirosina no fosforilados; puntos amarillos, residuos de tirosina fosforilados (p); asteriscos rojos, mutaciones en los sitios de fosforilación.

Este mecanismo de regulación fue establecido muy tempranamente en la evolución ya que una regulación similar ha sido observada tanto en todas las proteínas Vav de mamíferos (Movilla and Bustelo, 1999; Schuebel et al, 1998) como en miembros de la familia Vav presentes en D. melanogaster (Couceiro et al, 2005) y C. elegans (Norman et al, 2005) (ver Figura 2, pág. 5).

Una vez activada, la proteína Vav1 promueve la activación de las proteínas de la subfamilia Rac (e.j. Rac1, RhoG) y, en menor medida, de las GTPasas Rho in vitro (Crespo et al, 1997; Han et al, 1997) ( ver Figura 2, pág. 5). La información obtenida de estudios in vivo constata la existencia de la activación de la subfamilia de proteínas Rac mediada por Vav1 (Arana et al, 2008; Crespo et al, 1997; Couceiro et al, 2005; Dumont et al, 2009; Gomez et al, 2000; 
Walmsley et al, 2003). Los detalles estructurales de la interfaz de la unión Vav1/Rac1 han sido descritos recientemente (Chrencik et al, 2008). Resulta interesante ver que, a diferencia de otros miembros de la familia Dbl, la actividad catalítica de Vav1 y del resto de la familia Vav requieren la presencia del dominio ZF (Booden et al, 2002; Movilla and Bustelo, 1999; Zugaza et al, 2002). Aunque inicialmente se propuso que el ZF de Vav1 contactaba con la GTPasa (Movilla and Bustelo, 1999; Zugaza et al, 2002), datos estructurales recientes sugieren que su rol en la catálisis es debido a que facilita la estabilización de la estructura catalíticamente competente del dominio DH (Chrencik et al, 2008; Rapley et al, 2008).

Entre los receptores de membrana capaces de desencadenar la fosforilación de Vav1 durante la señalización celular se encuentran el receptor del factor de crecimiento epidérmico (EGF-R), el receptor del factor de crecimiento derivado de plaquetas (PDGF-R), el receptor de células B (BCR) y el receptor de células T(TCR) (Bustelo et al, 1992a; Bustelo et al, 1992b; Margolis et al, 1992). Además, la proteína Vav1 ha sido implicada en las rutas de señalización de más de 35 receptores de membrana (Bustelo, 2000). Cabe destacar que el estado de fosforilación de Vav1 durante la señalización celular es transitorio, sugiriendo que hay proteínas tirosina fosfatasas a cargo de la inhibición de Vav1 al final del ciclo de estimulación celular. Sin embargo, muchas de estas fosfatasas siguen sin ser identificadas a día de hoy.

La cuestión que aún no ha sido esclarecida es el pape que juega la región C-terminal de la proteína Vav1 en el establecimiento de la conformación inactiva de esta proteína en ausencia de estimulación del TCR.

Este mecanismo de regulación se desajusta artificialmente por la generación de mutaciones o truncaciones en determinadas regiones de la molécula. La mutación de la tirosina 174 a fenilalanina (Vav1 ${ }^{\mathrm{Y} 174 \mathrm{~F}}$ ) impide que este residuo sea fosforilado por las quinasas correspondientes, pero también disocia su interacción con otros dominios favoreciendo así la conformación abierta mencionada anteriormente (Figura 3). Esta mutación desencadena, por tanto, la actividad catalítica de Vav1 al permitir el acceso de las GTPasas al dominio DH y, a su vez, la funciones adaptadoras de dicha proteína ya que mantiene la integridad de todos sus dominios. La versión oncogénica de Vav1 (Vav1 $\left.{ }^{1-186}\right)$, que corresponde a una truncación de las regiones $\mathrm{CH}$ y acídica, favorece también la conformación abierta al no presentar los dominios que participan en el mecanismo intramolecular autoinhibitorio que estabiliza la conformación cerrada (Figura 3). 
La unión de la proteína Vav1 a las GTPasas de la familia Rho/Races indispensable para que se produzca el intercambio nucleotídico de GDP por GTP en estas GTPasa, fruto de la actividad catalítica de Vav1 (Crespo et al, 1997; Han et al, 1997). Estudios de microscopía electrónica han descrito los cambios conformacionales que se producen en el paso de la proteína Vav1 a un estado activo y que permiten al dominio DH unirse a GTPasas sustrato,

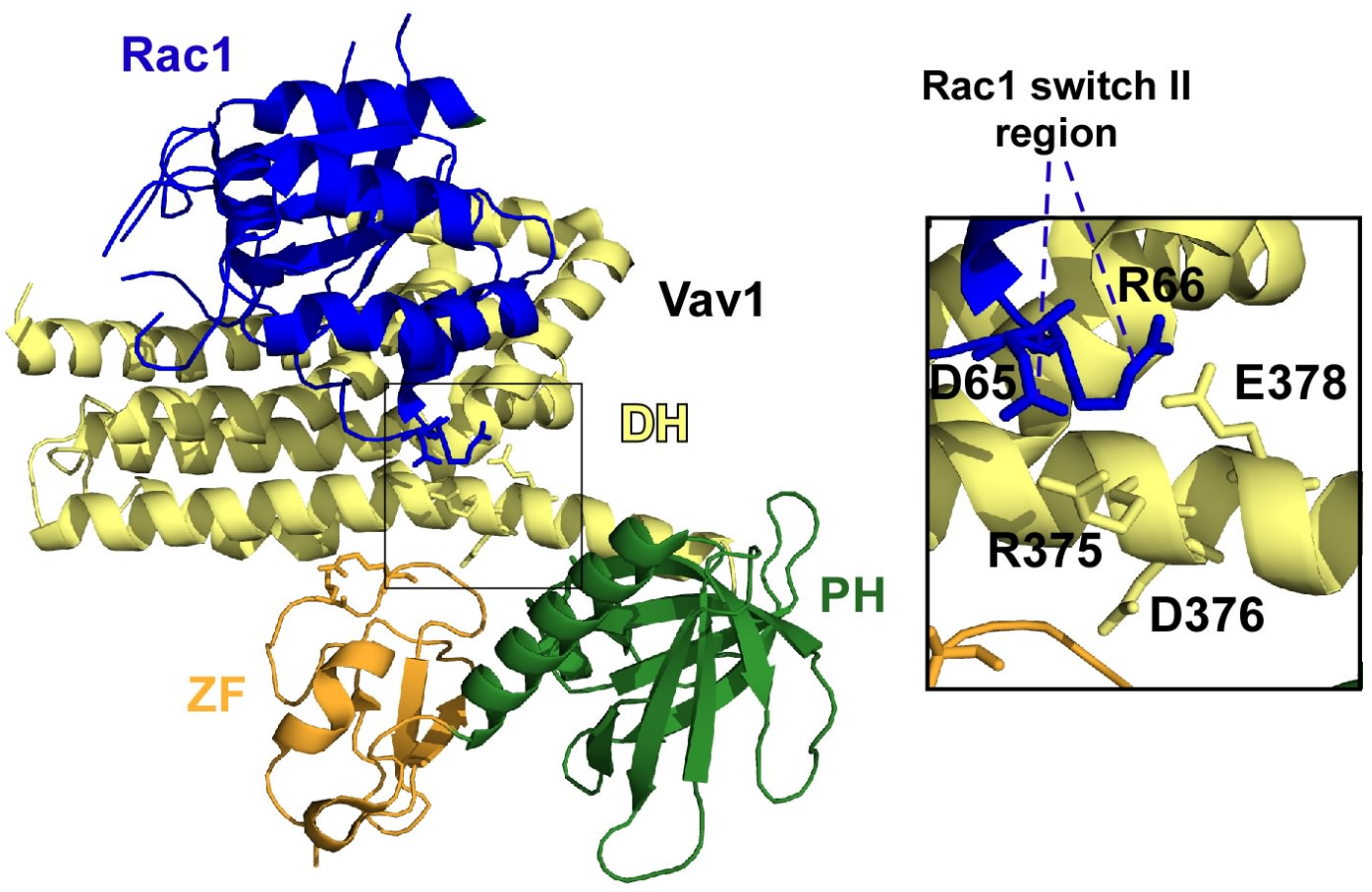

Figura 4. Modelo estructural de la interacción Vav1/Rac1. La estructura de la GTPasa Rac1 esta en color azul. La estructura del casete DH-PH-ZF también se encuentra representada en color amarillo (DH), verde (PH) y naranja (ZF). El rectángulo a la derecha indica los residuos de Rac1 y Vav1 que participan en la interacción.

como Rac1 (Figura 4) (Llorca et al, 2005). Durante este proceso se establecen una serie de interacciones entre la proteína Vav1 y las regiones switch I y switch II de Rac1 (Chrencik et al, 2008). Estudios de mutagénesis han permitido identificar los residuos implicados en dichas interacciones (Chrencik et al, 2008). Por un lado, Vav1 se une a la región switch I a través de sus residuos $\mathrm{E}^{201} \mathrm{y} \mathrm{Q}^{331}$, que establecen interacciones con los residuos $\mathrm{Y}^{32} \mathrm{y} \mathrm{V}^{36}, \mathrm{y} \mathrm{N}^{39}$ de $\operatorname{Rac} 1$, respectivamente (Chrencik et al, 2008). Por otro lado, los residuos $\mathrm{R}^{375}$ y $\mathrm{E}^{378}$ de la hélice $\alpha 6$ del $\mathrm{DH}$ establecen interacciones con los residuos $\mathrm{D}^{65}$ y $\mathrm{R}^{66}$ de la región switch II de Rac1, respectivamente (Chrencik et al, 2008). Además, la proteína Vav1 crea interacciones intramoleculares entre residuos del dominio $\mathrm{DH}\left(\mathrm{D}^{365}, \mathrm{D}^{376}\right)$ y residuos del $\mathrm{PH}\left(\mathrm{K}^{404}\right)$ y el $\mathrm{ZF}$ $\left(\mathrm{L}^{535}, \mathrm{R}^{537}\right)$ encaminadas estabilizar la unión a Rac1 (Chrencik et al, 2008). La unión de Vav1 a las 
regiones switch I y switch // de la GTPasa alteran la conformación de sus dominios de unión a nucleótidos y a $\mathrm{Mg}^{2+}$ (Worthylake et al, 2000). De esta manera, la GTPasa pierde afinidad por el $\mathrm{Mg}^{2+}$ y el GDP, y permanece sin unirse a otras moléculas, estabilizada por su unión a Vav1. Esta conformación de la GTPasa permite, sin embargo, el libre acceso de GTP. Una vez activada la GTPasa, la unión de GTP de forma espontánea (más abundante en la célula que el GDP) modifica sus regiones switch I y switch II, haciendo que esta pierda afinidad por Vav1, disociándose así del factor de intercambio (Worthylake et al, 2000).

\subsubsection{Interacciones proteína-proteína}

Otro mecanismo que regula la actividad de la proteína Vav1 es el establecimiento de uniones con otras proteínas implicadas en la transducción de señales in vivo. Estas incluyen

\section{(Figura 5):}

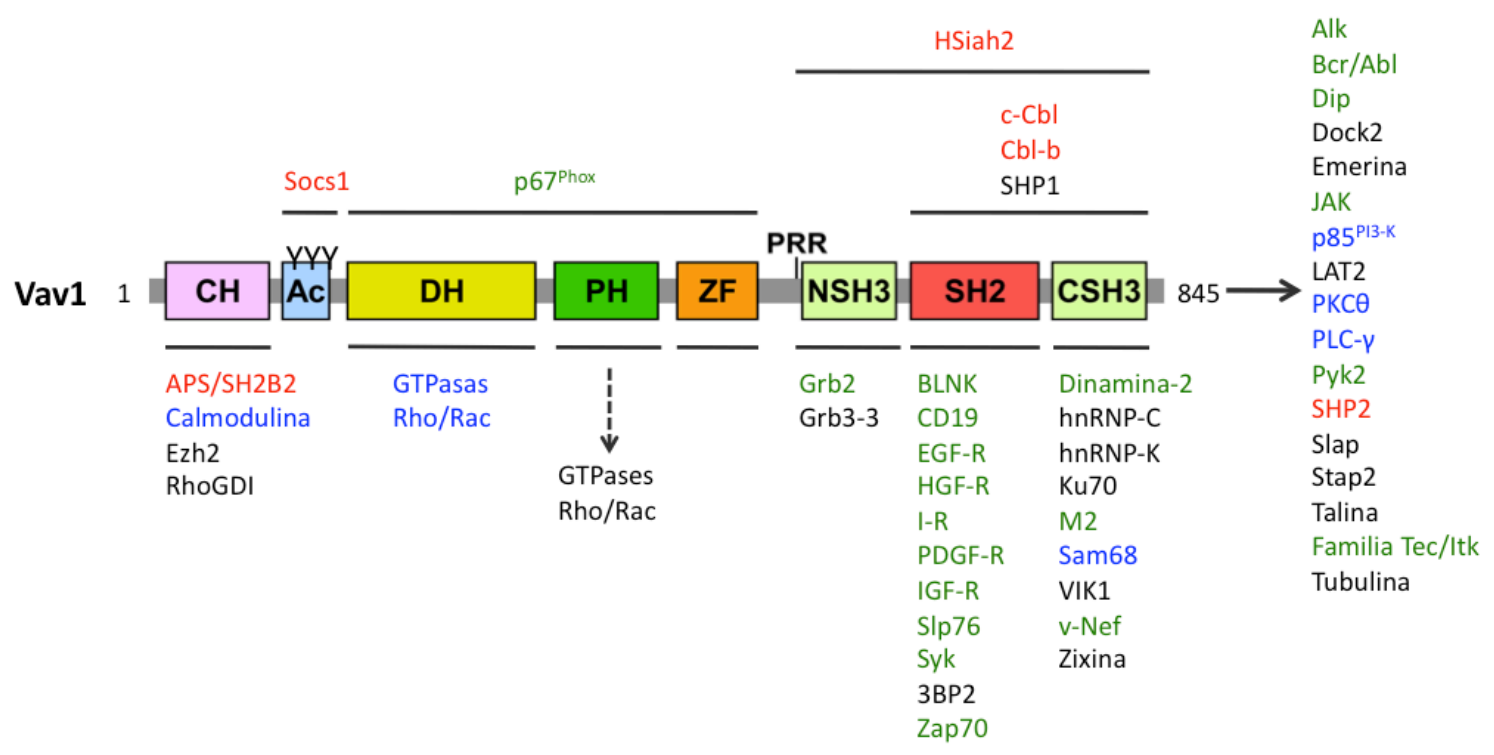

Figura 5. Interacciones de los distintos dominios de la proteína Vav1 con otras proteínas. Las proteínas con roles positivos, negativos y efectores aparecen coloreadas en verde, rojo y azul, respectivamente. Sin embargo, hay que tener en cuenta que algunas de ellas además de tener un rol positivo actúan como efectores (e. j. Slp76, Blnk). La proteínas cuya función en la ruta de Vav1 todavía no ha sido esclarecida, se muestran en negro. Las proteínas cuya interacción con Vav1 ha sido demostrada pero aún se desconoce a través de qué mecanismo aparecen a la derecha. Los dominios estructurales implicados en estas interacciones, pudiendo ser uno o varios, también están indicados. En el caso del dominio $\mathrm{PH}$, este parece contribuir a la unión de las GTPasas Rho/Rac al dominio DH aunque no ha sido demostrado que interaccione directamente con ellas. EGF-R, receptor del factor de crecimiento epidérmico; HGF-R, receptor del factor de crecimiento de hepatocitos; I$\mathrm{R}$, receptor de insulina; PDGF-R, receptor del factor de crecimiento derivado de plaquetas; IGF-R, receptor del factor de crecimiento similar a insulina.

- Receptores transmembrana con actividad tirosina quinasa intrínseca o asociada que pueden desencadenar la translocación de Vav1 a la membrana plasmática, y su 
consiguiente activación por fosforilación en tirosinas. Estos receptores incluyen entre otros, el receptor de células $T(T C R)$ y el de células $B(B C R)$, los receptores de neutrófilos y células NK y tirosina quinasas transmembrana (Bustelo, 2000; Turner and Billadeau, 2002; Tybulewicz, 2005).

- Moléculas adaptadoras y co-receptores que favorecen la translocación de Vav1 a la membrana plasmática, como el conector de células $T$ activadas (Lat), el conector de células B (BInk), Itk, CD28 o CD19 (Bustelo, 2000).

- Moléculas capaces de activar a Vav1 de una forma no dependiente de fosforilación, como p6 $7^{\text {Phox }}$, también conocido como factor citosólico de neutrófilos 2 (Ming et al, 2007).

- Factores que contribuyen positivamente a la función efectora de Vav1, como Slp76 (proteína leucocitaria de $76 \mathrm{kDa}$ que contiene un dominio SH2), la calmodulina, la histona-lisina metiltransferasa Ezh2, la dinamina 2, la fosfatidilinositol-3 quinasa (PI3K) y los miembros de las familias de la fosfolipasa C gamma (PLC $\gamma$ ) y la proteína quinasa C (PKC) (Bustelo, 2000; Gomez et al, 2005; Zhou et al, 2007).

- Proteínas que contrarrestan la actividad biológica de Vav1, como c-Cbl, Cbl-2 y SHP2 (fosfatasa que contiene dominios SH2) (Bustelo, 2000).

\subsubsection{Receptores de membrana con actividad tirosina quinasa}

Se han descrito un gran número de receptores de membrana que, una vez activados in vitro, son capaces de unirse y fosforilar a la proteína Vav1 expresada de forma ectópica (Bustelo, 2000). Entre ellos se encuentran el receptor del factor de crecimiento epidérmico, EGF-R (Bustelo et al, 1992; Margolis et al, 1992), el receptor del factor de crecimiento derivado de plaquetas, PDGF-R (Bustelo et al, 1992), los receptores de linfocitos B y T (Bustelo and Barbacid, 1992; Bustelo et al, 1992; Margolis et al, 1992), los receptores de Fcع (FcعR) (Kiener et al, 1997; Margolis et al, 1992) o el receptor de interleuquina-2, IL-2R (Evans et al, 1993).

Una de las estrategias de unión de Vav1 a dichos receptores se produce por la interacción estándar de su dominio SH2 a receptores autofosforilados (Bustelo et al, 1992; Margolis et al, 1992). Una vez fosforilada, la proteína Vav1 no solo es catalíticamente activa sino que también es capaz de interaccionar con otras proteínas que contienen dominios SH2. La unión de ligandos, y su consiguiente activación, promueven la fosforilación rápida y transitoria de la proteína Vav1 en residuos de tirosina aunque variando el nivel y la cinética de fosforilación según el receptor asociado. A su vez, un mismo receptor es capaz de dar lugar a distintas cinéticas de fosforilación en función del ligando al que se une. Un claro 
ejemplo de esta diversidad de respuesta es el caso del receptor $\operatorname{TCR} \alpha \beta$, que en linfocitos inmaduros puede dar lugar a distintos niveles de fosforilación de Vav1 dependiendo de si se une a péptidos agonistas o antagonistas, resultando, por tanto, en respuestas celulares diversas de las cuales depende la supervivencia de la célula (Smyth et al, 1998). Además, pueden existir también procesos de coestimulación o inhibición a través de proteínas de membrana adyacentes al receptor. Es el caso de los linfocitos T en los que la fosforilación de Vav1 producida por la activación del TCR aumenta en intensidad y duración debido a la activación conjunta del receptor CD28 ( Nunes et al, 1994; Salojin et al, 1999). De una forma similar, en linfocitos $B$, la estimulación conjunta del BCR y el receptor CD19 contribuye a una mayor fosforilación de Vav1 (O'Rourke et al, 1998 ; Sato et al, 1997). Por el contrario, al estimular simultáneamente el receptor CD22, la fosforilación de Vav1 disminuye considerablemente (Sato et al, 1997).

En resumen, existe una modulación muy precisa de los niveles de fosforilación de Vav1 indicando que el nivel de activación de esta proteína es uno de los parámetros que las células utilizan para regular la intensidad y duración de las cascadas de señalización que dan lugar a las diferentes respuestas celulares.

\subsubsection{Proteínas tirosina quinasa citoplasmáticas}

En los casos en los que los receptores no presentan actividad tirosina quinasa intrínseca, la proteína Vav1 es fosforilada y activada tras su unión a quinasas pertenecientes a las familias Src, Syk, Tec o Jak (Bustelo, 2000). La activación de Vav1 por parte de las quinasas de las familias Src y Syk ha sido demostrada mediante ensayos tirosina quinasa in vitro (Crespo et al, 1997; Han et al, 1997; Zugaza et al, 2000). Estas interacciones se producen por asociación directa del dominio $\mathrm{SH} 2$ de Vav1 a las quinasas autofosforiladas (este es el caso de Src y Syk/Zap70) o, alternativamente, a través de un reclutamiento previo de Vav1 a las colas citoplasmáticas fosforiladas de co-receptores transmembrana (como CD28 o CD19) o a moléculas adaptadoras fosforiladas como pueden ser Lat o Blnk.

Además, la proteína Vav1 puede unirse a las quinasas de la familia Syk (compuesta por Syk y Zap70) a través de la interacción de su dominio SH2 con una tirosina fosforilada de la región de interdominios B de estas quinasas (Deckert et al, 1996 ; Katzav et al, 1994). La mutación de estos residuos a fenilalanina elimina la unión de Vav1 a estas quinasas y su consiguiente activación, lo que indica que la interacción física entre estas proteínas es necesaria para que se produzca su fosforilación (Deckert et al, 1996; Wu et al, 1997; Zhao et al, 1999). A parte de mediar en la activación de Vav1 en linfocitos a través de los receptores BCR 
y TCR, estas quinasas también están implicadas en la señalización de otros receptores como FcعR (Hirasawa et al, 1995; Teramoto et al, 1997 ), integrinas (Miranti et al, 1998) y el complejo receptor de células NK (Galandrini et al, 1999).

En algunos estudios se postula que las quinasas de la familia Src (a las que pertenecen Fyn, Lck o Hck entre otras) podrían fosforilar directamente a la proteína Vav1. Se ha demostrado que las quinasa Lck, Fyn y Hck son capaces de producir la fosforilación y la activación catalítica de Vav1 in vitro y en condiciones de sobreexpresión (Crespo et al, 1997; Movilla and Bustelo, 1999; Schuebel et al, 1998). Aún así, los estudios llevados a cabo no aclaran exactamente qué quinasas de la familia Src son capaces de fosforilar directamente a Vav1, en linfocitos, y en qué medida. De la misma manera, no se puede descartar su participación en la fosforilación de Vav1 en condiciones celulares anormales, como en tumores en los que existan mutaciones de elementos situados por encima de Vav1 en la ruta de señalización.

Las quinasas de la familia Tec se asocian a Vav1 tras la estimulación de los receptores de interleuquina-3 (IL-3) y de eritropoyetina en células hematopoyéticas. Estas tirosina quinasas citosólicas participan en la ruta de Vav1 funcionando más como proteínas adaptadoras que como quinasas. Por ejemplo, ha sido descrito que Itk, una quinasa miembro de la familia Tec, promueve la translocación de Vav1 a la membrana plasmática independientemente de su actividad quinasa (Dombroski et al, 2005; Labno et al, 2003). Así mismo, la quinasa Pyk2 está implicada en el anclaje de Vav1 a receptores específicos como las integrinas $\alpha v \beta_{3}$ en neutrófilos (Gao et al, 2009). Sin embargo, estas dos interacciones funcionales están probablemente implicadas en un diálogo cruzado durante la señalización celular, ya que otros estudios han puesto de manifiesto que Vav1 es importante para la estimulación de Itk (Reynolds et al, 2002) y Pyk2 (Gakidis et al, 2004) en linfocitos T y neutrófilos, respectivamente.

Las quinasas de la familia JAK se encargan de mediar la transducción de señales a través de receptores de citoquinas como EpoR o c-Mpl, cuyos ligandos son la eritropoyetina y la trombopoyetina, respectivamente. A diferencia de las quinasas de la familia Syk, estas quinasas están unidas de forma constitutiva a las colas citoplasmáticas de los receptores. La estimulación de los receptores hace que las quinasas JAK se activen por fosforilación cruzada, y, a su vez, activen a Vav1 por fosforilación en tirosinas (Fujii et al, 1995). La asociación entre Vav1 y las proteínas JAK esta mediada a través del dominio SH2 de Vav1 y regiones con residuos de fosfotirosina no descritas de la quinasa (Matsuguchi et al, 1995). 


\subsubsection{Proteínas adaptadoras}

Las proteínas adaptadoras colaboran en la activación de la proteína Vav1 mediante su reclutamiento a las zonas de la membrana donde se produce la activación de los receptores y manteniendo a la proteína Vav1 próxima a las quinasas que la activan. Las interacciones entre la proteína Vav1 y sus adaptadores se realizan a través de dominios SH2 y SH3 de ahí que, en algunas ocasiones, el adaptador deba ser fosforilado en residuos de tirosina específicos para adquirir afinidad por el dominio SH2 de la proteína Vav1.

Lat es una proteína palmitoilada, presente en células T, NK y mastocitos (Zhang et al, 1998b) que se asocia a las balsas lipídicas de la membrana plasmática (Xavier et al, 1998; Zhang et al, 1998b). Esta proteína, una vez activada mediante fosforilación, promueve el reclutamiento a la membrana plasmática de un gran número de proteínas por las que posee afinidad (Zhang et al, 1998a, 1998b). Este reclutamiento se produce a través de la de numerosas fosfotirosinas que posee Lat en su secuencia (Zhang et al, 1998a). La translocación de Vav1 a la membrana depende, por tanto, de la activación de Lat siendo esta translocación indispensable para la correcta fosforilación y activación de Vav1 (Fanto et al, 2000; Zhang et al, 1999). La proteína Vav1 no es capaz de unirse a Lat a través de su dominio SH2, asi que es necesaria la presencia de una proteína que medie esta interacción, Grb2.

La proteína Grb2 se une a la PRR de Vav1 a través de su dominio SH3 C-terminal y a LAT mediante su dominio SH2 (Nishida et al, 2001; Ramos-Morales et al, 1995; Ye et al, 1994; Zhang et al, 1998a). Esta asociación es importante para la subsiguiente interacción de Vav1 no sólo con Lat sino también con el coreceptor CD28 (Dennehy et al, 2007; Kim et al, 1998; Michel et al, 2000). Estas dos moléculas favorecen la translocación de Vav1 a la membrana plasmática y la consiguiente interacción con tirosina quinasas en linfocitos T (Finco et al, 1998; Kim et al, 1998; Zhang et al, 1999).

En linfocitos B, la proteína responsable de la translocación de Vav1 a la membrana es CD19. Esta proteína se une a Vav1 permitiendo su aproximación a las quinasas Syk y Lyn asociadas a CD19 y al BCR, respectivamente (Li et al, 1997; O'Rourke et al, 1998; Weng et al, 1994). La unión entre Vav1 y CD19 se produce a través del dominio SH2 de Vav1 y un residuo de fosfotirosina de CD19 (O'Rourke et al,1998).

Vav1 puede también interaccionar, a través de su dominio $\mathrm{SH}$, con las proteínas adaptadoras citoplasmáticas Slp76 y BInk en células T y B, respectivamente (Fu et al, 1998 ; Onodera et al, 1996; Raab et al, 1997; Tuosto et al, 1996; Wu et al, 1996). Estas proteínas juegan 
un papel funcional doble en la ruta de Vav1 permitiendo su fosforilación durante la transducción de señales y, al mismo tiempo, promueven las funciones efectoras de Vav1, como la activación de los miembros de la familia PLC $\gamma$ (Myung et al, 2001; Raab et al, 1997; Wu et al, 1996).

\subsubsection{Proteínas efectoras}

Al ser una de las funciones de esta proteína la activación de las GTPasas Rho/Rac, Vav1 posee un amplio espectro de efectores que han sido descritos previamente como proteínas diana de estas GTPasas. Es el caso de al gunas quinasas como JNK (Crespo et al, 1996, 1997; Song et al, 1999; Teramoto et al, 1997), PAK (Bubeck Wardenburg et al, 1998; Salojin et al, 1999) y PIP5K (O'Rourke et al, 1998). JNK es una serina/treonina quinasa implicada en la regulación de la transcripción, ya que fosforila a numerosos factores de transcripción tales como c-Jun o ATF2 (Van Aelst, 1997). PAK, por su parte, es una familia de serina/treonina quinasas formada por seis miembros (Jaffer et al, 2002) que ha sido implicada en la fosforilación de factores de transcripción (Van Aelst and D'Souza-Schorey, 1997), respuestas citoesqueléticas (Van Aelst and D'Souza-Schorey, 1997), y la estimulación de la ruta de Ras (Schaeffer et al, 1999). PIP5K es la quinasa responsable de mantener elevados los niveles intracelulares de fosfatidilinositol-4,5-bisfosfato $\left(\mathrm{PI}(4,5) \mathrm{P}_{2}\right)$, lo cual consigue mediante la fosforilación del fosfatidilinositol-4-fosfato (PI(4)P). El PI(4,5) $\mathrm{P}_{2}$ es el sustrato de la PLC, por lo que se cree que la quinasa PIP5K cumple un papel clave en las rutas de señalización mediadas por fosfoinosítidos (Czech, 2000; Toker, 2002).

La transducción de señales mediada por la proteína Vav1 también es necesaria para la activación de factores de transcripción como NF-AT, NF-KB y SRF (Holsinger et al, 1998; Montaner et al, 1998; Wu et al, 1995). El más estudiado es NF-AT, un factor de transcripción específico de linfocitos Timplicado en respuestas típicas de la activación linfocitaria como la transcripción del gen codificante de la interleuquina-2 (IL-2) (Rao et al, 1997). Este factor es especialmente interesante ya que su activación es una de las funciones de Vav1 independiente en gran medida de su actividad catalítica (Holsinger et al, 1998; Kuhne et al, 2000; Lopez-Lago et al, 2000; Wu et al, 1995). Por otro lado, Vav1 también puede activar la transcripción de NF-KB y SRF, factores de transcripción con funciones tanto en células hematopoyéticas como en no hematopoyéticas implicados en la proliferación celular y la respuesta inmune (Johansen et al, 1995; Rao et al, 1997; Treisman, 1994). 


\subsubsection{Otras proteínas asociadas a Vav1}

En los últimos años se ha descrito una larga lista de moléculas de señalización capaces de interaccionar con Vav1, además de las ya mencionadas anteriormente. A la región $\mathrm{CH}$ se unen proteínas tales como la calmodulina (Zhou et al, 2007), miembros de la familia de inhibidores de la disociación de GDP en proteínas Rho (RhoGDI) (Groysman et al, 2000, Groysman et al, 2002) y proteínas adaptadoras con dominios PH y SH2 (APS/SH2B2) (Yabana et al, 2002) (Figura 5). También se unen a esta región Ezh2, una histona-lisina metiltransferasa implicada en la remodelación citoesquelética y el mantenimiento de la represión transcripcional (Hobert et al, 1996) (Figura 5). La región DH-PH-ZF se une a la proteína p6 $67^{\text {Phox }}$, un componente regulador del complejo NADPH que puede activar a Vav1 (Ming et al, 2007) (Figura 5). El SH3 C-terminal se ha demostrado que se une a las ribonucleoproteínas nucleares heterogéneas hnRNP-K (Bustelo et al, 1995; Hobert et al, 1996; Van Seuningen et al, 1995) y hnRNP-C (Bustelo et al, 1995; Romero et al, 1996), a Grb3-3 (Ramos-Morales et al, 1995), hSiah (Germani et al, 1999), Sam68 (Lazer et al, 2007), VIK1 (Houlard et al, 2005), Ku70 (Romero et al, 1996), la dinamina 2 (Gomez et al, 2005) y la zixina (Hobert et al, 1996) (Figura 5). A este dominio también se unen las proteínas virales Nef y M2 como se describió anteriormente (Fackler et al, 1996; Rodrigues et al, 2006) (Figura 5). Algunas proteínas necesitan unirse a más de un dominio de Vav1 siendo su interacción más compleja. Este es el caso de SHP1 (Kon-Kozlowski et al, 1996), Cbl-b (Bustelo et al, 1997) y 3BP2 (Foucault et al, 2005) (Figura 5).

Algunas de estas proteínas son citoplasmáticas (RhoGDI, calmodulina, APS, p67 ${ }^{\text {Phox }}$, dinamina 2, zixina) mientras que otras se mueven entre el núcleo y el citoplasma (Ezh2, hnRNPs, Sam68, VIK1, Ku70). Algunas de ellas también han sido asociadas a la regulación del citoesqueleto (RhoGDI, Ezh2, APS, p67 ${ }^{\text {Phox }}$, hnRNP-K, dinamina 2 y zixina) sugiriendo que estas proteínas puedan cooperar en las funciones de Vav1 dependientes de Rac1 (Beckerle, 1997; DerMardirossian et al, 2005; Gomez et al, 2005; Ming et al, 2007; Nagano et al, 2006; Su et al, 2005; Yabana and Shibuya, 2002).

Se han descrito también interacciones con otras proteínas aunque no han sido definidas estructuralmente. Este es el caso de Slap (Sosinowski et al, 2000), Stap2 (Sekine et al, 2009), Pyk2 (Gismondi et al, 2003; Gao and Blystone, 2009), p85 ${ }^{\text {PlsK }}$ (Bertagnolo et al, 1998, Bertagnolo et al, 2004;), la talina (Fischer et al, 1998; Garcia-Bernal et al, 2009), PKCө (Hehner et al, 2000; Kong et al, 1998; Moller et al, 2001), la tubulina (Huby et al, 1995), Dock2 (Nishihara et al, 2002), la emerina (Wilkinson et al, 2003) y LAT2 (Malhotra et al, 2009). 


\subsubsection{Proteínas inactivadoras de la proteína Vav1}

Al producirse la activación de Vav1 a través de su fosforilación, son las proteínas con actividad tirosina fosfatasa (PTPasa) las que se encargan de su desfosforilación $y$, por tanto, de su inactivación. Las fosfatasas de la familia SHP, compuesta por SHP1 y SHP2, han sido las más estudiadas a este respecto (Tamir et al, 2000). Se ha demostrado que Vav1 coinmunoprecipita con SHP1 en células B estimuladas y además en esta interacción participa el dominio SH3 Cterminal de Vav1 (Kon-Kozlowski et al, 1996; Pani et al, 1996). La unión entre las dos proteínas podría ocurrir también de forma indirecta a través de la interacción de SHP1 con el receptor CD22 (Doody et al, 1995). Este hecho explicaría el efecto negativo de este receptor en la señalización a través del complejo BCR-CD19 (Sato et al, 1997). En las células NK, SHP1 se asocia al receptor de HLA, un receptor con actividad inhibitoria, y defosforila a Vav1, inhibiendo de esta forma los cambios citoesqueléticos necesarios para desencadenar la actividad citotóxica de la célula (Stebbins et al, 2003). En células $T$, se cree que la defosforilación de Vav1 es mediada por SHP2 de una forma controlada por la oxidación reversible de una cisteína específica del sitio activo de esta fosfatasa, siendo este contacto entre las dos proteínas indirecto. SHP2 se une al complejo Lat-Gads-Slp76 con el fin de regular los niveles de fosforilación de Vav1 (Kwon et al, 2005). La activación del TCR da lugar a la generación de especies reactivas de oxígeno (ROS) en la célula T, las cuales van a oxidar la cisteína del sitio activo de SHP2, inactivando la actividad fosfatasa y permitiendo por consiguiente una mayor fosforilación de Vav1 (Kwon et al, 2005). A día de hoy, no se han identificado otras PTPasas que podrían estar encargadas de defosforilar Vav1 en linfocitos.

Se han descrito otros mecanismos de inhibición de la actividad de la proteína Vav1 independientemente de su fosforilación. Es el caso de Cbl-b, una proteína de la familia de inhibidores de la transducción que incluye c-Cbl, $\mathrm{Cbl} 3$, Sli-1 y $\mathrm{Cbl}$ de D. melanogaster. Estas proteínas se encargan de disminuir la señalización intracelular a través de la ubiquitinización de receptores de membrana con actividad tirosina quinasa (Joazeiro et al, 1999; Levkowitz et al, 1998; Ota et al, 1997; Thien et al, 1998). Se ha demostrado que Cbl-b es capaz de unirse a Vav1 en sus dominios SH3-SH2-SH3 (Bustelo et al, 1997). Otros estudios demuestran una inhibición de la señalización a través de Vav1 debida a Cbl-b en células COS1 (Bustelo et al, 1997) y linfocitos Ty B (Krawczyk et al, 2000, Krawczyk et al, 2005). No obstante, el mecanismo molecular a través del cual se produce esta inhibición es desconocido. Esto no ocurre con otro miembro de la familia, c-Cbl, capaz de unirse al dominio SH2 de Vav1 a través de una tirosina fosforilada (Marengere et al, 1997), y promover su ubiquitinización y 
posterior degradación, inhibiendo así la señalización dependiente de Vav1 (Miura-Shimura et al, 2003).

\subsubsection{Localización subcelular}

Una correcta localización subcelular es importante para asegurar completamente las respuestas biológicas inducidas por Vav1. Este paso es importante para facilitar la fosforilación de la proteína pero, además, también para desencadenar las posteriores respuestas biológicas, probablemente favoreciendo una interacción más eficiente de Vav1 con sus sustratos y moléculas efectoras. Este último punto es apoyado por la observación de que la actividad transformante de las versiones de Vav1 oncogénicas y no dependientes de fosforilación es reducida al eliminar la región $\mathrm{SH} 3-\mathrm{SH} 2-\mathrm{SH} 3$, que contiene los dominios implicados en las interacciones proteína-proteína (Schuebel et al, 1998; Zugaza et al, 2002). La actividad oncogénica de estas proteínas se resestablece a niveles normales e, incluso, es incrementada cuando la región $\mathrm{SH} 3-\mathrm{SH} 2-\mathrm{SH} 3$ es reemplazada por una señal de anclaje a la membrana (Zugaza et al, 2002).

\subsubsection{Otros mecanismos de regulación postraduccional}

Existen estudios que han demostrado la existencia de otros mecanismos postraduccionales que también podrían contribuir a la actividad de la proteína Vav1. Se ha descrito que fracciones activas de la proteína Vav1 pueden ser ubiquitinizadas por unión a Cbl (MiuraShimura et al, 2003) o Cbl-b (Sattler et al, 2002). También se ha reseñado que una fracción pequeña, y de localización nuclear, de Vav1 puede ser metilada en residuos de arginina bajo estimulación de las células T con anticuerpos CD28 (Blanchet et al, 2005; Lawson et al, 2007). Experimentos de proteómica también han sugerido que la proteína Vav1 podría ser sometida a acetilación en residuos específicos de lisina (Choudhary et al, 2009). El significado fisiológico de todas estas modificaciones postraduccionales aún no ha sido determinado con exactitud.

\subsubsection{Efectos de algunos medicamentos}

Algunos efectos inmunosupresores de la azatioprina han sido asociados a la disminución de la activación de las proteínas Rac1 mediada por Vav1 (Poppe et al, 2006). Se ha descrito que el tratamiento de los linfocitos T con inhibidores de la indoleamina-2,3-dioxigenasa da lugar a niveles reducidos de la expresión de Vav1 (Li et al, 2009). El efecto de ácidos grasos poliinsaturados en la sinapsis inmune está asociado a una reducción de la fosforilación de proteínas de señalización, incluyendo Vav1 (Geyeregger et al, 2005). La inhibición de la 
hidrolasa S-adenosil-L-homocisteína, un tratamiento potencial contra enfermedades autoinmunes e inflamatorias, promueve el descenso de los niveles de metilación de Vav1 en residuos de arginina (Lawson et al, 2007).

\subsubsection{Estados patológicos}

Se ha descrito que en algunas enfermedades o trastornos existe una desregulación de la proteína Vav1 debida a:

- Hiperfosforilación. Vav1 puede mostrar niveles anormalmente elevados de fosforilación en tumores o líneas celulares debido a la activación constitutiva de quinasas, como pueden ser Bcr/Abl (Bassermann et al, 2002; Harnois et al, 2003) o Alk (Ambrogio et al, 2008). Niveles elevados de fosforilación en tirosinas han sido también observados en ratones Lpr (Mimura et al, 1997), en células T CD4+ (Garcia et al, 2009), y en ratones tightskin (un modelo de fibrosis de piel y autoinmunidad, Saito et al, 2002).

- Hipofosforilación y bajo reclutamiento a la membrana. El reclutamiento a la membrana se ve afectado por el corte proteolítico depediente de caspasa en células T anérgicas (Puga et al, 2008). La hipofosforilación ha sido observada en pacientes con la enfermedad linfoproliferativa ligada al cromosoma X (Aoukaty et al, 2005; Sanzone et al, 2003).

- Niveles de expresión. La expresión de Vav1 puede incrementarse por polimorfismos específicos en su locus (Jagodic et al, 2009), por desmetilación (Fernandez-Zapico et al, 2005) y por mecanismos aún no caracterizados (Hollmann et al, ; Konno et al, 2007; Lazer et al, 2009; Lustig et al, 2009; Prieto-Sanchez et al, 2006).

- Proteínas virales. La fosforilación de Vav1 (y Vav2, pero no Vav3) pueder ser desencadenada en células $B, T$ y sistemas de expresión ectópicos por $M 2$, una proteína, codificada por los gammaherpesvirus, que es crucial para el establecimiento del estado latente de estos virus en células B. Esta fosforilación resulta de la formación de un complejo heteromolecular compuesto por M2, quinasas de la familia Src y Vav1. Además, M2 promueve la translocación de Vav1 a la membrana plasmática (Rodrigues et al, 2006; Pires de Miranda et al, 2008). Estímulos independientes de la translocación de Vav1 a la membrana plasmática son desencadenados por v-Nef, una proteína codificada por el virus de inmunodeficiencia humano-1 (VIH-1) en linfocitos T (Fackler et al, 1999; Rauch et al, 2008) y células dendríticas (Quaranta et al, 2003). v-Nef también inhibe la ubiquitinización de Vav1 mediante la exclusión del complejo c-Cbl/UbcH7 (enzima conjugada con ubiquitina $\mathrm{H} 7$, también conocida como enzima conjugada con ubiquitina E2 L3) de las 
balsas lipídicas (Simmons et al, 2005). Finalmente, proteínas codificadas por la región pX del virus de la leucemia de células T de tipo 1 (HTVL-1) acentúan la fosforilación en tirosinas de Vav1 en linfocitos T (Mahana et al, 1998). Estos tres pasos de regulación parecen ser importantes para el ciclo de infección de estos virus (Fackler et al, 1999; Mahana et al, 1998; Pires de Miranda et al, 2008; Rodrigues et al, 2006; Simmons et al, 2005). Experimentos de proteómica han mostrado que Vav1 también está entre las proteínas que se unen a $\mathrm{K} 1$, una proteína codificada por el herpesvirus del sarcoma de Kaposi (Lee et al, 2005), aunque la activación de Vav1 en este complejo todavía no ha sido demostrada.

Las proteínas de algunos virus pueden promover la inactivación de Vav1. La hipofosforilación de Vav1 (debida a la inactivación de las quinasas Lck y Syk) ha sido observada en células B que expresan la proteína integral de membrana-2 codificada por el virus de Epstein-Barr (Miller et al, 1995). También se ha demostrado que la expresión de la proteína $\mathrm{p} 12^{\mathrm{I}}$ codificada por el HTLV-1 induce reducidos niveles de fosforilación de Vav1 bajo la estimulación del TCR, un efecto que puede ser debido a la asociación directa de la proteína viral con la molécula adaptadora Lat (Fukumoto et al, 2007).

- Patógenos bacterianos. La fosforilación de Vav1 puede ser desencadenada independientemente de la estimulación antigénica en células T por la exotoxina VacA producida por Helicobacter pylori. Dado que la exotoxina bloquea la activación de NF-AT, su acción lleva a la activación de sólo algunas de las respuestas celulares inducidas por Vav1 en linfocitos (Boncristiano et al, 2003). 


\section{LA PROTEÍNA Vav1 EN CÉLULAS HEMATOPOYÉTICAS}

\subsection{Análisis genético de la proteína Vav1}

Como se mencionó anteriormente, la expresión de la proteína Vav1 está restringida, prácticamente, a las células de la línea hematopoyética. Por ello, en los últimos años, se han realizado diversos estudios in vivo con el fin de desentrañar las funciones fisiológicas específicas de Vav1 en estas células . A continuación se detallan los resultados obtenidos a partir de estos estudios para cada tipo celular.

\subsubsection{Linfocitos $T$}

\subsubsection{Vav1 y el desarrollo de linfocitos $T$}

Los ratones knock-out para Vav1 muestran un desarrollo normal y son completamente viables. Aunque la mayor parte de células del sistema hematopoyético presentan un desarrollo normal, existe un importante descenso del número de células Ty la presencia de linfocitos Ty B maduros incapaces de producir respuestas inmunes contra antígenos (Fischer et al, 1995, 1998; Tarakhovsky et al, 1995; Turner et al, 1997; Zhang et al, 1995). La reducción del número de linfocitos T se debe a una señalización deficiente en los receptores pre-TCR y TCR $\alpha \beta$ (Fischer et al, 1998; Turner et al, 1997). Este hecho desencadena, durante la maduración linfocitaria, la producción de timocitos doble negativos inmaduros, produciéndose unas selecciones positiva y negativa deficientes que resultan en la reducción del número de linfocitos T citotóxicos y ayudantes maduros (Kong et al, 1998; Turner et al, 1997) (Figura 6). Por otro lado, el desarrollo de linfocitos T con receptores TCR $\gamma \delta$ no se ve afectado por la ausencia de Vav1, aunque sí la activación dependiente de estos receptores en linfocitos maduros (Swat et al, 2003). Por tanto, los linfocitos $T \gamma \delta$ maduros de ratones knock-out para Vav1 presentan una reducción de la proliferación celular y de la secreción de citoquinas (Swat et al, 2003).

Estos defectos en el desarrollo linfocitario no se observan, sin embargo, en ratones deficientes para Vav2 o Vav3, aunque los ratones dobles knock-out para Vav1 y Vav3 muestran un mayor bloqueo en el proceso de maduración linfocitaria que los ratones deficientes solamente en Vav1 (Doody et al, 2001; Fujikawa et al, 2003; Tedford et al, 2001) (Figura 6). Por tanto, Vav1 posee funciones parcialmente redundantes con otros miembros de la familia durante el desarrollo de los timocitos, ostentando Vav1 en papel más relevante pudiendo Vav3 compensar, en parte, los defectos provocados por su ausencia en el desarrollo de linfocitos T, siendo al contrario en linfocitos B (Figura 6). 


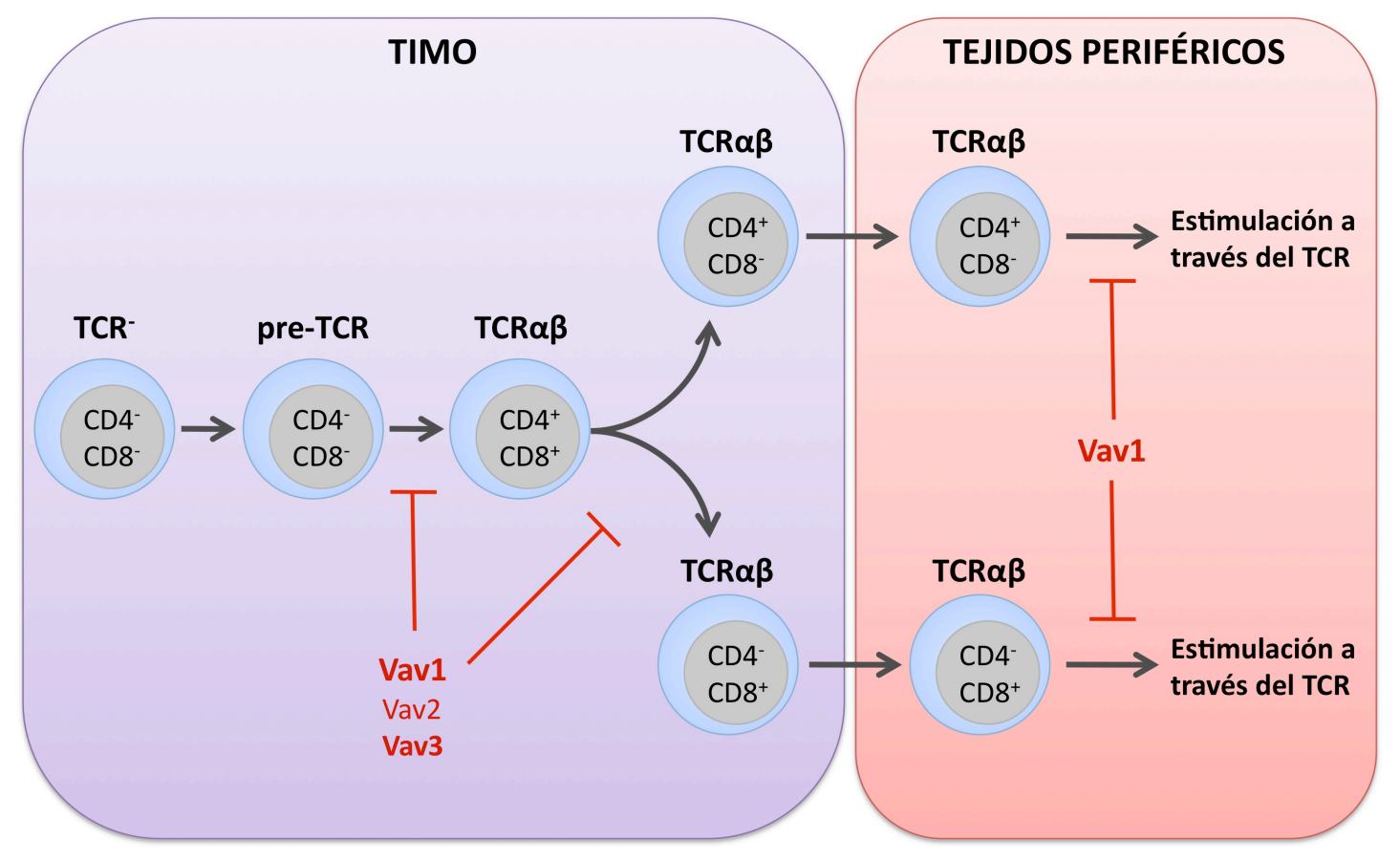

Figura 6. Representación esquemática de la maduración de los linfocitos T. Las etapas de la maduración que se ven comprometidas por la falta de los miembros de la familia Vav se indican en rojo según su relevancia.

En células T maduras, se ha demostrado que la ausencia de Vav1 afecta a la sinapsis inmune (Fischer et al, 1998; Holsinger et al, 1998), la polimerización de F-actina (Fischer et al, 1998; Holsinger et al, 1998; Kong et al, 1998) y la agregación de balsas lipídicas (Villalba et al, 2001) durante la estimulación del TCR (Figura 6). La conjugación LFA y MHC dependiente con las células presentadoras de antígeno también se ve afectada (Ardouin et al, 2003; Krawczyk et al, 2002) así como la proliferación de células T ligada a la estimulación del TCR (Charvet et al, 2006; Costello et al, 1999; Fischer et al, 1998; ; Tarakhovsky et al, 1995; Zhang et al, 1995). La producción de citoquinas (Costello et al, 1999; Fischer et al, 1998; Penninger et al, 1999; Tarakhovsky et al, 1995; Zhang et al, 1995) y la expresión de marcadores específico de estimulación (e. J., CD69) (Fischer et al, 1998; Zhang et al, 1995) también se ven reducidas. Las respuestas citotóxicas (Penninger et al, 1999), de células B dependientes de células T (Gulbranson-Judge et al, 1999) y asociadas a células T con TCR $\gamma \delta$ (Swat et al, 2003) se ven comprometidas. Además, existe un reclutamiento deficiente de células T estimuladas en TCR y CD28 a tejidos periféricos (David et al, 2009).

Estos resultados indicaron que las células T deficientes en Vav1 no eran capaces de inducir una correcta activación de PI3K y PLC 1 (Costello et al, 1999), conllevando la generación de 
flujos de $\mathrm{Ca}^{2+}$ deficientes bajo estimulación del TCR (Costello et al, 1999; Fischer et al, 1998; Kong et al, 1998) y una baja activación de las rutas dependientes de Ras/Erk, PI3K/Akt y PKC/PKD (Costello et al, 1999) (Figura 7). La baja activación de Erk es debida a la eliminación de una ruta dependiente de Vav1 que estimula a Ras a través de RasGRP, un GEF específico de Ras que es activado por el DAG (Caloca et al, 2003, 2008; Reynolds et al, 2004; Zugaza et al, 2004) (Figura 7). Las células deficientes en Vav1 no son capaces de desencadenar la activación óptima de los factores de transcripción NF-AT (Fischer et al, 1998; Holsinger et al, 1998), NF-kB (Costello et al, 1999) y Foxo1 (Charvet et al, 2006) (Figura 7).

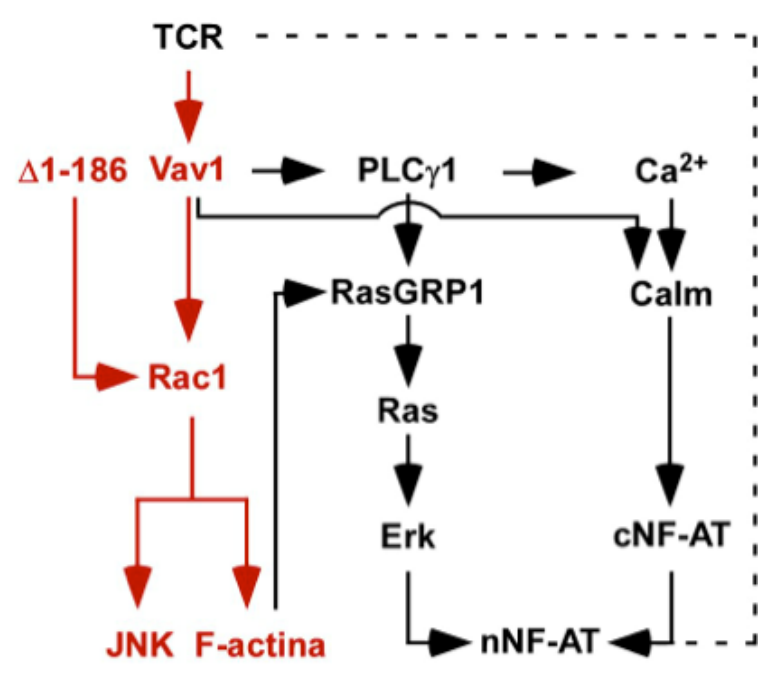

Figura 7. Ruta de Vav1 en linfocitos T. Las rutas directas, por debajo de Vav1 y Rac1, están representadas en rojo así como las respuestas biológicas que requieren de una señalización adicional aparecen en negro. Calm, calmodulina; cNF-AT, NF-AT en el citoplasma; nNF-AT, NFAT en el núcleo.
En todos estos casos, los defectos observados parecen ser parciales, sugiriendo que puede existir redundancia funcional entre Vav1 y Vav3. Mientras que las deficiencias individuales de Vav2 y Vav3 no inducen defectos significativos en el desarrollo y la activación de linfocitos T, la ausencia al mismo tiempo de Vav1 y Vav3 acentúa los defectos en el desarrollo y funciones efectoras de linfocitos $T$ anteriormente descritas en los ratones knock-out de Vav1 (Fujikawa et al, 2003). Estos defectos son mucho más graves en el triple knock-out para Vav1, Vav2 y Vav3 (Fujikawa et al, 2003). Estos resultados están de acuerdo con

la siguiente jerarquía de señalización Vav1 $>>$ Vav3 $>>$ Vav2 bajo los receptores pre-TCR y TCR (ver Figura 6, pág. 24). Un fenotipo aún más agravado de la deficiencia de este gen se observó al combinarlo con el de Rasgrf2, un locus que codifica para un GEF de Ras y Rac1 que también participa en las respuestas dependientes de la señalización del TCR (Ruiz et al, 2007).

A parte de los marcados defectos en el desarrollo y la proliferación encontrados en los ratones deficientes en Vav1, recientemente se ha descrito que la deficiencia de Vav1 promueve el desarrollo de linfomas de células T en ratones envejecidos. Esta tumorigénesis 
es acrecentada en ratones deficientes en Vav1 y RasGRP2 (Ruiz et al, 2009). Las razones para este aumento de los procesos tumorales en estas dos cepas de ratones son aún desconocidas.

Recientemente, se han generado dos cepas de ratones knock-in para Vav1 en las que Vav1 endógeno ha sido remplazado por versiones de est proteína con una mutación en el dominio $\mathrm{PH}$ o una región $\mathrm{DH}$ catalíticamente inactiva. La primera proteína mutante indujo un fenotipo hipomórfico en comparación con el observado en los ratones knock-out para Vav1. Curiosamente, los defectos inducidos por esta versión mutante afectan principalmente a las células T CD4 ${ }^{+}$por razones aún desconocidas (Prisco et al, 2005). Este resultado indica que el dominio PH de Vav1 tiene un papel limitado y específico del linaje de la célula T en la regulación de la actividad de Vav1. El análisis del fenotipo de los ratones que expresan la versión catalíticamente inactiva de Vav1 fue de gran interés, ya que permitió la discriminación entre las funciones dependientes de la actividad catalítica o de la función adaptadora de Vav1. Este estudio reveló que muchas de las funciones de Vav1 en el desarrollo y activación de células T era dependiente de su actividad catalítica. La única excepción fue la activación de rutas dependientes de PLC $\gamma$ como la inducción de flujos de $\mathrm{Ca}^{2+}$ y la activación de las rutas de Erky PKD (Saveliev et al, 2009).

\subsubsection{Vav1 en la activación linfocitaria}

La señal que desencadena la cascada de señalización en las células T es el reconocimiento por parte del receptor de células T (TCR) de un péptido unido a una proteína del complejo mayor de histocompatibilidad (MHC) presente en una célula presentadora de antígeno (APC). Además de la estimulación del TCR, es necesaria, al mismo tiempo, una coestimulación de otros receptores como CD2 o CD28. La ausencia de estas señales coestimulatorias desencadena, en cada caso, respuestas anérgicas o apoptóticas (Michel et al, 2002).

La estimulación del TCR da lugar a la fosforilación de tirosinas de los motivos ITAM, presentes en las subunidades del TCR, por parte de las quinasas de la familia Src, Fyn y Lck (Figura 8). Para que esto ocurra, estas quinasas deben ser previamente defosforiladas por la tirosina fosfatasa CD45 en unos residuos de tirosina que se encuentran en la región Cterminal de estas quinasas (Salmond et al, 2008). Para la completa activación de estas quinasas también es necesaria la fosforilación de una tirosina activadora presente en la región del dominio de actividad quinasa correspondiente al loop de activación (A-loop) (Salmond et al, 2008). El establecimiento de interacciones con otras proteínas a través de sus dominios SH3 y SH2 y la fosforilación de la tirosina activadora favorecen el 
desencadenamiento de su actividad enzimática así como la unión a los sustratos (Figura 8) (Salmond et al, 2008).

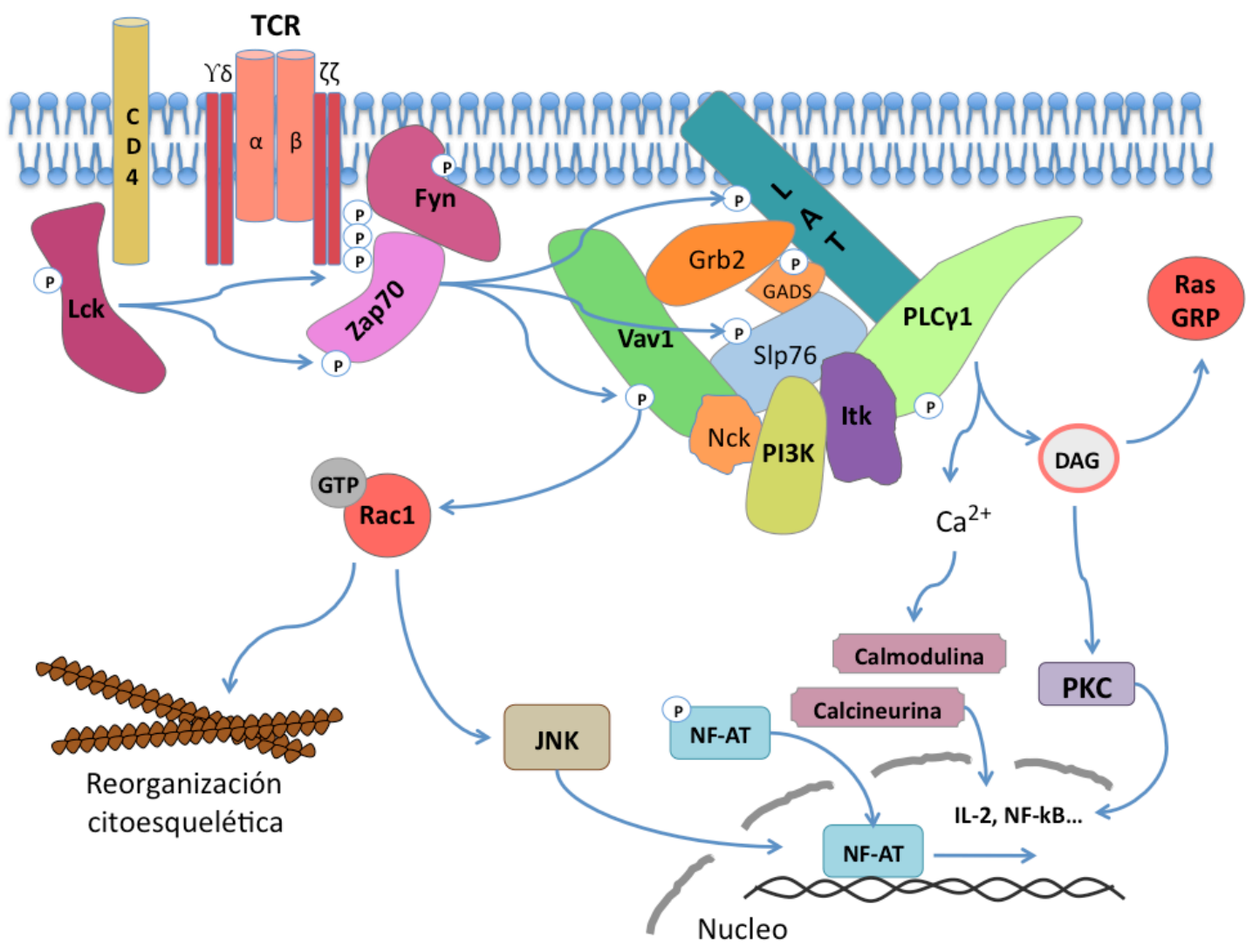

Figura 8. Ruta de señalización de Vav1 bajo el receptor de células T (TCR). Las flechas indican la inducción de la activación de unas proteínas a otras dentro de la cascada de señalización generada por la estimulación del TCR. Los círculos con una P dentro indican aquellas proteínas que son fosforilables. La flechas que llegan al núcleo indican la activación de la transcripción génica.

La proteína Lck activada es capaz de fosforilar a CD3 y a las cadenas $\zeta$ de los motivos ITAM que resultan en el reclutamiento de la quinasa Zap70 a la membrana (Figura 8) (van Oers et al, 1994, van Oers et al, 1995). Es entonces cuando la proteína Lck fosforila y activa a Zap70, que a su vez fosforila a la proteína transmembrana Lat, encargada del reclutamiento a la membrana plasmática de un gran número de proteínas implicadas en esta cascada de señalización (Figura 8) (Zhang et al, 1999). La proteína Fyn participará entonces en la activación de algunas de estas proteínas. Una vez ocurrido este proceso, Lck y Fyn vuelven a su estado inactivo inicial a través de la defosforilación de la tirosina del A-loop por parte de CD45 aunque no se descarta que haya otras fosfatasas implicadas en este proceso de inactivación (Figura 8) (Hermiston et al, 2003). 
En el proceso de reclutamiento a la membrana iniciado por la proteína Lat activada, las proteínas Grb2, Gads y PLC 1 interaccionan directamente con la proteína Lat (Figura 8). A su vez, Grb2 se une al GEF de Ras, Sos, reclutándolo a la membrana, y permitiendo, a su vez, el desencadenamiento de la activación de Ras. Por otro lado, Gads es capaz de unirse a la proteína Slp76, uniéndose esta última también a PLC 1 (Figura 8). Estas proteínas conforman un complejo heteromolecular que permite la activación por fosforilación de Slp76 por Zap70, siendo este proceso indispensable para reclutar a la proteína Vav1, la fosfatidilinositol-3 quinasa (PI3K), la quinasa Itk de la familia Tec y la proteína adaptadora Nck, que se unirán a Slp76 a través de los residuos de esta previamente fosforilados (Figura 8) (Koretzky et al, 2006). La quinasa Itk junto con Lck y Zap70 son las encargadas de activar a PLC $\gamma 1$. Una vez activada, PLC $\gamma 1$ cataliza la hidrólisis del fosfatidilinositol-4,5-bisfosfato (PI(4,5)P2 o PP2) en dos productos, fosfatildilinositol-1,4,5-trifosfato (PIP3) y diacilglicerol (DAG) (Figura 8). La producción de PIP3 lleva a la apertura de canales de calcio $\left(\mathrm{Ca}^{2+}\right)$ en la membrana del retículo endoplasmático, mientras que el DAG induce la activación de la proteína quinasa C (PKC) seguida de la activación de la ruta de señalización de Ras (Figura 8). El aumento del $\mathrm{Ca}^{2+}$ citosólico y la activación de PKC desencadenarán a su vez la transcripción de múltiples factores de transcripción tales como NF-AT, IL-2 o NF-KB (Figura 8) (Katzav, 2004).

La activación de Vav1 se produce una vez que la proteína ha sido reclutada a la membrana a través de su interacción con Slp76. Hasta ahora la fosforilación de Vav1 ha sido asociada a la actividad de la quinasa Zap70, aunque no se puede descartar que existan otras quinasas que pudiesen participar también en la activación de Vav1 en linfocitos T (Costello et al, 1999; Michel et al, 1998; Salojin et al, 1999, Salojin et al, 2000). La activación de Vav1 en linfocitos T es necesaria para el correcto desarrollo de una serie de procesos importantes para la función linfocitaria.

Los dos efectos celulares más estudiados de la proteína Vav1 en linfocitos son la estimulación de la transcripción del gen il-2 y la activación del factor de transcripción NF-AT (Figuras 8) (Billadeau et al, 2000; Costello et al, 1999; Fischer et al, 1995, 1998; Turner et al, 1997; Wu et al, 1995). La activación de NF-AT en células T es un proceso complejo que requiere la concurrencia de diversos eventos. Uno de ellos es el aumento de los niveles de calcio intracelular que permiten la activación de la calcineurina, una proteína fosfatasa encargada de defosforilar a NF-AT permitiendo así su traslocación al núcleo (Figura 8). Una vez en el núcleo, es necesaria la transducción de señales procedentes de las rutas de señalización de Ras y Rac1 para que NF-AT promueva la transcripción de sus genes diana 
(Figura 8) (Serfling et al, 2000; Zhu et al, 2000). Vav1 contribuye a generar el aumento de los niveles de calcio intracelular y producir la activación de NF-AT en los linfocitos T (Figura 8). La activación, por sí sola, de las GTPasas Rho/Rac no es suficiente para estimular la activación de NF-AT o generar flujos de $\mathrm{Ca}^{2+}$, por lo tanto, la actividad de intercambio de Vav1 no es suficiente para la activación de NF-AT y la producción de calcio intracelular en linfocitos T (Figura 8). Además, las versiones oncogénicas de Vav1, que no presentan el dominio $\mathrm{CH}(\Delta 1$ 66) o el dominio $\mathrm{CH}$ más la región acídica ( $\Delta 1-189)$, no son capaces de inducir ninguna de estas dos respuestas a pesar de ser capaces de desencadenar una activación exacerbada de otras proteínas corriente abajo de Rac, como JNK (López-Lago et al, 2000; Wu et al, 1995). Estos mutantes de Vav1, sin embargo, son capaces de activar a NF-AT en presencia de ionomicina (un ionóforo que aumenta la concentración de calcio citosólico) o mutantes activos de la calcineurina (Billadeau et al, 2000), por lo tanto, el dominio CH posee alguna función efectora en la generación de flujos de calcio que favorecen la activación de NF-AT. Ya que PLC $\gamma$ es la principal proteína implicada en el aumento de los niveles de calcio intracelulares, es posible que el dominio $\mathrm{CH}$ de Vav1 actúe como adaptador, permitiendo la unión de alguna proteína o complejo multiproteico responsable de la activación de PLC $\gamma$ y, por tanto, de la generación de flujos de $\mathrm{Ca}^{2+}$ (Figura 8).

\subsubsection{Vav1 y el citoesqueleto}

Dado su papel como factor de intercambio nucleotídico de las GTPasas Rho/Rac, es lógico asumir que la proteína Vav1 transduce las señales del TCR al citoesqueleto de actina. Se ha demostrado que, en ausencia de Vav1, los linfocitos presentan una polimerización de actina bastante reducida (Fischer et al, 1998; Holsinger et al, 1998).

En un primer momento, la proteína Vav1 es fundamental para las reorganizaciones citoesqueléticas que tienen lugar, tras la estimulación del TCR, para la formación de la sinapsis inmune. En células T deficientes en Vav1, no se producen uniones entre el TCR y el citoesqueleto de actina y, por tanto, no se produce la correcta agregación del receptor con la consiguiente disminución en la señalización linfocitaria (Fischer et al, 1998; Holsinger et al, 1998). Vav1 es clave para la agregación de las balsas lipídicas en la membrana plasmática durante la sinapsis inmune, teniendo un papel integrador en la conexión entre los cambios citoesqueléticos y la polarización de las balsas lipídicas inducida por el receptor de células T.

Durante la sinapsis inmune se produce una acumulación de receptores TCR en el centro de la interfaz entre la célula Ty la célula APC. Rodeando a la acumulación de receptores se genera un anillo de integrinas linfocitarias asociadas a la función del antígeno-1 (LFA-1) 
(Monks et al, 1998). Este movimiento de proteínas requiere reordenamientos en el citoesqueleto. La célula T se polariza moviéndose el centro organizador de microtúbulos (MTOC) que queda mirando hacia la célula APC (Kupfer et al, 1989). La proteína Vav1, bajo las señales recibidas del TCR, inducirá la reorganización del citoesqueleto, la activación de LFA1 y la polarización de MTOC, pero esta proteína no es estrictamente necesaria para la agrupación de proteínas en la membrana o para los cambios morfológicos producidos por la formación de los conjugados (Ardouin et al, 2003).

La señalización a través de las GTPasas Rho/Rac es clave para la formación de la sinapsis (Arrieumerlou et al, 2000; Valitutti et al, 1995; Villalba et al, 2001). La activación de Rac1 mediada por Vav1 en linfocitos permite la agregación de las balsas lipídicas, favoreciendo así la formación de la sinapsis inmune (Villalba et al, 2001). Entre los efectores que llevan a cabo esta misión está la proteína PAK y la quinasa PIP5K que activa a las proteínas vinculina y talina (dos proteínas responsables de las uniones entre el citoesqueleto y la membrana) (Critchley, 2000). Además, Rac1 interviene en la polimerización del citoesqueleto de actina a través de la activación de WAVE, una proteína adaptadora capaz de activar a Arp2/3 (una proteína con actividad polimerizadora de filamentos de actina) (Eden et al, 2002).

No se puede descartar que Vav1 regule las respuestas citoesqueléticas a través de otras GTPasas distintas de Rac1. RhoG, por ejemplo, una vez activada por la versión oncogénica de Vav1, es capaz de promover la polimerización de actina aunque no se ha esclarecido a través de qué moléculas efectoras (Vigorito et al, 2003). Aunque la activación de Cdc42 mediada por la proteína Vav1 aún no ha sido completamente establecida, esta GTPasa funciona como un activador de la proteína WASP, mediador clave en la polimerización de actina, mediante el control de la actividad de Arp2/3 (Thrasher, 2002). Esta hipótesis es apoyada por dos hechos, que los linfocitos de ratones carentes de WASP presentan respuestas citoesqueléticas similares a aquellos procedentes de ratones deficientes en Vav1 (Snapper et al, 1998), y que, en estos últimos, no se observa activación de Cdc42 (Krawczyk et al, 2000).

Aunque Vav1 es un GEF de la familia Rho/Rac, esto no significa que su actividad enzimática sea la única manera a través de la cual contribuye a respuestas celulares que precisan de la remodelación del citoesqueleto de actina. Existen evidencias que sugieren que otros dominios de esta proteína podrían contribuir a la regulación del citoesqueleto indirectamente, mediante la generación de flujos de $\mathrm{Ca}^{2+}$ o la activación de factores de transcripción (ver apartado anterior). Como se comentó anteriormente, se ha descrito la interacción directa de Vav1 con otras proteínas relacionadas con el citoesqueleto de actina, 
como talina y vinculina (Fischer et al, 1998) o zixina (Hobert et al, 1996). Estas uniones sugieren una posible función adaptadora de la proteína Vav1 que, a través de sus dominios $\mathrm{SH} 2$ y SH3, podría estar sirviendo de conexión entre la cascada de señalización y distintos elementos citoesqueléticos. En el futuro, sería interesante estudiar este punto más a fondo para confirmar esta hipótesis.

\subsubsection{Linfocitos $B$}

En los ratones deficientes en Vav1, se observó también la existencia de defectos del desarrollo en la línea linfoide caracterizados por la ausencia de células B-1a. Además, los defectos observados en células B de ratones knock-out para Vav1 no tienen que ver con el número de células $B$, sino con la capacidad de estas para responder a estímulos específicos a través de sus receptores BCR y CD19 (Fischer et al, 1998; O'Rourke et al, 1998; Tarakhovsky et al, 1995; Turner et al, 1997; Zhang et al, 1995). Algunas de las respuestas deficientes de estas células B in vivo se deben a la falta de secreción de interleuquina-4 (IL-4) por parte de las células T ayudantes (Gulbranson-Judge et al, 1999). La reducida proliferación observada en estas células in vivo se explica con este hecho. A pesar de que la expresión de Vav1 no es necesaria para generar los linfocitos B convencionales, sí lo es para producir los linfocitos B1 a, una subpoblación especializada de linfocitos $B$ que se localiza en el peritoneo, ya que para su generación, a partir de células madre embrionarias, y su perpetuación en el adulto son necesarias estimulaciones periódicas a través del BCR (Fischer et al, 1998; Tarakhovsky et al, 1995; Zhang et al, 1995).

Recientemente, se ha descrito la redundancia funcional de las proteínas Vav existente en linfocitos B. Los ratones deficientes para Vav1 y Vav2, al contrario que los deficientes sólo en Vav1, presentan una gran reducción en el número de linfocitos B maduros (Tedford et al, 2001). Además, estos linfocitos $B$ no son capaces de proliferar en respuesta a la estimulación del BCR y no movilizan el calcio intracelular tras su activación a través del BCR (Tedford et al, 2001) o lipopolisacáridos (Hebeis et al, 2005). Esto indica que Vav2 es capaz de compensar parcialmente la ausencia de Vav1 durante la maduración de los linfocitos B y la generación de respuestas celulares en linfocitos B maduros. Los ratones carentes de los tres miembros de la familia Vav presentan un número aún menor de linfocitos B maduros (Fujikawa et al, 2003). Además, los pocos linfocitos $B$ maduros que presentan tienen una vida media corta, debido a que no son capaces de promover la activación de NF-אB (Vigorito et al, 2005). 


\subsubsection{Plaquetas}

La deficiencia en el gen Vav1 no produce defectos graves en plaquetas. Sin embargo, la deficiencia combinada de los genes Vav1 y Vav3 inducen defectos en la agregación plaquetaria y la diseminación de la glicoproteína VI recombinante del receptor de colágeno (GPVI) y de integrinas (Pearce et al, 2004, Pearce et al, 2007). Estas moléculas también producen la reducción de los niveles de activación de PLC $\gamma 2$ en las plaquetas deficientes en Vav1 y Vav3 (Pearce et al, 2004, 2007). En esta respuesta, Vav2 es prescindible ya que las plaquetas deficientes en los tres miembros de la familia Vav presentan los mismos defectos que las células deficientes en Vav1 y Vav3 (Pearce et al, 2004). Vav1 y Vav3,además, también trabajan por debajo del segundo receptor de plaquetas, CLEC-2 (Suzuki-Inoue et al, 2007).

\subsubsection{Neutrófilos}

Los neutrófilos deficientes en Vav1 presentan defectos en migración bajo condiciones de flujo así como una extravasación deficiente de la vasculatura inflamada (Phillipson et al, 2009). En cooperación con Vav3, Vav1 es importante para la adhesión, diseminación y fagocitosis dependientes de la integrina $\alpha_{M} / \beta_{2}$ pero no para la quimiotaxis. Estudios de señalización han demostrado que estas dos proteínas de la familia Vav son requeridas para la activación de proteínas quinasa, ya que los neutrófilos deficientes en ambas proteínas presentan niveles reducidos de fosforilación total en tirosinas y una disminución en los niveles de fosforilación de Pyk2, paxilina y Akt (Gadikis et al, 2004). Vav1, en combinación con Vav3, también participa en el óptimo ensamblaje de las respuestas hemorrágicas y de edema mediadas por IgG/FcyR en pulmón y piel (Utomo et al, 2008).

Finalmente, los neutrófilos deficientes para los tres miembros de la familia Vav presentan deficiencias en la liberación de ROS bajo diferentes estímulos (Graham et al, 2007; Miletic et al, 2007), en el tránsito intersticial deficiente a través de los lugares de infección bacteriana (Graham et al, 2009), y en respuestas deficientes a organismos nosocomiales (Graham et al, 2007).

\subsubsection{Macrófagos}

Vav1, cooperativamente con Vav3, es importante para la fagocitosis mediada por el complemento en macrófagos. Estas proteínas, sin embargo, no son requeridas para la fagocitosis inducida por FcyR. La deficiencia solo del gen Vav1 o Vav3 no induce ningún defecto en fagocitosis, indicando que ambas proteínas son requeridas para la activación de 
este proceso. En cambio, Vav2 es totalmente dispensable, ya que los fenotipos de los macrófagos $\operatorname{Vav1}^{-1}$, $\operatorname{Vav2}^{-{ }^{--}}$, Vav3 ${ }^{-/-}$y $\operatorname{Vav1}^{-1-} \operatorname{Vav}^{3^{-/}}$son idénticos. La fagocitosis anormal ha sido asociada a la ausencia de reclutamiento del complejo Arp2/3 y de la F-actina a la copa fagocítica (Hall et al, 2006).

Los macrófagos deficientes para las tres proteínas Vav no inducen niveles apropiados de ROS bajo estimulación con lipopolisacáridos (LPS) o proteoglicanos (PGN). Bajo estas condiciones, se ha observado que los macrófagos derivados de médula ósea no activan de forma apropiada a MAPK, Akt y Erk. También se ha observado una producción reducida de TNF $\alpha$ e interleuquina-10 (IL-10). Si embrago, la activación de JNK y NFKB y la producción de interleuquina-6 (IL-6) también ocurren de forma normal en los neutrófilos deficientes en la familia Vav (Miletic et al, 2007).

En cultivo, los macrófagos deficientes en Vav1 muestran un área de adhesión más pequeña, bajos niveles de microtúbulos y una reducida rapidez de migración (Wells et al, 2005). Cuando se combina con la eliminación de Vav2 y Vav3, la deficiencia de la familia Vav induce macrófagos morfológicamente muy alargados con frentes delanteros muy pequeños, una mayor persistencia migratoria en movimientos aleatorios y defectos severos en las respuestas de adhesión y diseminación mediadas por integrinas. Además, estos macrófagos presentan respuestas efectoras deficientes en señalización, como la activación de la ruta de Erk (Bhavsar et al, 2009).

\subsubsection{Mastocitos}

El desarrollo de mastocitos no se ve afectado por la ausencia de Vav1. Aunque estas células muestran una reducción en la desgranulación y la producción de citoquinas bajo estimulación en ausencia de Vav1. Por el contrario, la producción de IL-10 está hiperactivada en los mastocitos deficientes en Vav1. Como en el caso de los linfocitos T, este defecto ha sido asociado a la activación deficiente de PI3K y PLC $\gamma 2$. Debido a estos defectos, estas células no pueden desencadenar los flujos de $\mathrm{Ca}^{2+}$ adecuados tras su estimulación. La activación de JNK, pero no de Erk1 o Erk2, es también defectuosa en estas células. Todos estos defectos tienen una gran importancia fisiológica ya que las células deficientes en Vav1 no pueden responder de manera apropiada a los estímulos anafilácticos sistémicos (Manetz et al, 2001).

\subsubsection{Células asesinas naturales (NK)}

La proteína Vav1 no es importante para el desarrollo de las células NK (Chan et al, 2001 ;Colucci et al, 2001). Sin embargo, sí es importante para las funciones dependientes de 
células NK como las respuestas citotóxicas naturales (Chan et al, 2001) y antitumorales (Colucci et al, 2001). La respuesta defectuosa de las células NK deficientes en Vav1 esta ligada a defectos en la activación de la ruta de Erk y a la granulación deficiente (Colucci et al, 2001). Sin embargo, a diferencia de otras células hematopoyéticas, no se han observado ninguna disfunción en los flujos de $\mathrm{Ca}^{2+}$ intracelular (Colucci et al, 2001). La proteína Vav1 también es requerida para las respuestas citotóxicas inducidas por las células NK a través del receptor DAP10. Esta implicación es específica de Vav1, ya que Vav2 y Vav3 no presentan ningún rol en esta respuesta biológica (Cella et al, 2004). En su lugar, Vav1, en cooperación con Vav2 y Vav3, es requerido para la muerte celular inducida por las células NK a través de los receptores DAP10, DAP12 y FcyR (Cella et al, 2004). A este nivel de la señalización, también ha sido demostrado que la deficiencia simultánea de las tres proteínas Vav bloquea la estimulación normal de Erk por los receptores de las células NK mencionados anteriormente (Cella et al, 2004).

\subsubsection{Células dendríticas}

La proteína Vav1 es importante en la adhesión mediada por integrinas y en la dinámica normal de los podosomas en estas células. Los defectos en la adhesión se han asociado a la activación impropia de FAK (quinasa de adhesión focal), PLC 2 2, Erk1 y Erk2 por las integrinas durante la adhesión dirigida por fibronectina (Spurrell et al, 2009).

La deficiencia en las tres proteínas Vav afecta de forma severa a la señalización de DAP12 y Fc $\gamma \mathrm{R}$, dos receptores que contienen dominios ITAM presentes en células dendríticas, dando lugar a una presentación deficiente del antígeno. Este defecto ha sido ligado a la producción baja de ROS por NOX2 (NADPH oxidasa 2) y por una segunda, aunque no caracterizada, ruta independiente de la de ROS/NOX2 (Graham et al, 2007). Que estos defectos sean debidos a Vav1 o a la acción cooperativa de diferentes combinaciones de las proteínas de la familia Vav todavía no ha sido esclarecido.

\subsection{Vav1 como diana terapéutica}

Dado el importante papel que representan las proteínas Vav, y en concreto Vav1, en respuestas relacionadas con el sistema inmune, se puede especular que su inactivación podría ser una vía farmacéutica para el tratamiento de enfermedades directa o indirectamente relacionadas con el sistema inmune. En este contexto, la disponibilidad de modelos animales de la familia Vav ha revelado algunos de los puntos a favor y en contra de estas estrategias. Por un lado, se ha descrito que la inactivación de las proteínas Vav podría 
ser eficiente para combatir la encefalomielitis autoinmune (Korn et al, 2003), la artritis reumatoide (Cremasco et al, 2008), las reacciones inflamatorias exacerbadas (Phillipson et al, 2009; Utomo et al, 2008), y el rechazo en transplantes (Wang et al, 2007; Weckbecker et al, 2007). Por el contrario, también se ha visto que la inactivación de estas proteínas puede desencadenar inmunodeficiencia, enfermedades cardiovasculares (Sauzeau et al, 2006, Sauzeau et al; Sauzeau et al, 2007), y disfunciones a nivel de cerebelo (Quevedo et al, 2010). Sin embargo, dado que los animales knock-out presentan las mutaciones a nivel de la línea germinal, sería interesante usar en un futuro animales inducibles knock-in para eliminar la expresión de Vav1 en el periodo adulto, pudiendo así mimetizar el escenario clínico de forma más aproximada. 

OBJETIVOS 

1. Caracterización de nuevos mecanismos reguladores de la función de Vav1 en linfocitos.

2. Identificación de los principales sitios de fosforilación presentes en Vav1.

3. Determinación de la cinética de fosforilación de los aminoácidos identificados usando una colección de nuevos anticuerpos fosofoespecíficos contra Vav1.

4. Estudio de los roles reguladores y/o efectores de los sitios de fosforilación de Vav1 identificados en nuestro análisis.

5. Análisis de los elementos de la señalización celular que regulan la activación de Vav1 en linfocitos. 




\section{PLÁSMIDOS}

El vector de expresión del dominio SH3 C-terminal de Vav1 fusionado con GST (pGEX-SH3) fue cedido por el Dr. P. Simas (Instituto de Medicina Molecular, Facultade de Medicina da Universidade de Lisboa, Portugal). El plásmido pMEX fue un obsequio del Dr. M. Barbacid (Centro Nacional de Investigaciones Oncológicas-CSIC, Madrid). El plásmido reportero pNFAT-Luc fue un regalo del Dr. G. R. Crabtree (Howard Hughes Medical Institute, Stanford University, U.S.A.). El plásmido pRL-SV40 se obtuvo de Promega y los plásmidos pFR-Luc y pFA2-cJun de Stratagene. Los vectores vacíos pEGFP-C2 y pEGFP-C3 se compraron a Clontech, los plásmidos pcDNA3 y pEF1 a Invitrogen, el plásmido pGEX-4T3, que codifica para la proteína de fusión GST, a Pharmacia.

Los vectores de expresión para las formas silvestre (Vav1 ${ }^{\text {WT }}$ ) y oncogénica (Vav1 $\left.{ }^{1-186}\right)$ de Vav1 subclonadas en los plásmidos pcDNA3, pEF1, pMEX y pEGFP, la forma truncada de Vav1 $1^{\triangle 835-845}$ en el plásmido pcDNA3, así como las construcciones Vav1 ${ }^{\mathrm{DH}-\mathrm{PH}-\mathrm{ZF}}$, Vav1 ${ }^{\mathrm{DH}+\mathrm{N}-\mathrm{PH}}$, $\operatorname{Vav}^{\mathrm{PH}}$ y Vav1 ${ }^{\mathrm{ZF}}$ subclonadas en el vector pEGFP-C2, fueron generados previamente en nuestro laboratorio. Los mutantes puntuales Vav1 ${ }^{\mathrm{Y} 142 \mathrm{~F}}$, Vav1 ${ }^{\mathrm{Y} 160 \mathrm{~F}}, \operatorname{Vav}^{\mathrm{Y} 174 \mathrm{~F}}, \operatorname{Vav}^{\mathrm{Y5} 11 \mathrm{~F}}, \operatorname{Vav}^{\mathrm{Y} 544 \mathrm{~F}}$ y Vav1 ${ }^{\mathrm{P} 833 \mathrm{~L}}$, y los mutantes combinados Vav1 ${ }^{\mathrm{Y} 142 \mathrm{~F}+\mathrm{Y} 174 \mathrm{~F}}$, Vav1 ${ }^{\mathrm{Y} 160 \mathrm{~F}+\mathrm{Y} 174 \mathrm{~F}}$, Vav1 ${ }^{\mathrm{Y3XF}}$ (triple mutante de las tirosinas 142,160 y 174 a fenilalanina) y Vav1 ${ }^{\mathrm{Y} 3 \times F+\Delta 835-845}$ en los plásmidos pcDNA3 y pEF1 fueron obtenidos anteriormente en nuestro laboratorio mediante mutagénesis dirigida.

Los vectores de expresión de las proteínas de fusión EGFP-Vav1 ${ }^{\Delta 835-845}$ (pMB6) y EGFP$\operatorname{Vav} 1^{\mathrm{Y} 3 \times \mathrm{F}+\Delta 835-845}$ (pMB46) fueron obtenidos del siguiente modo: la forma truncada Vav1 ${ }^{\triangle 835-845}$ se amplificó por PCR con el oligo directo 5'- CCA GGA CAA GAA AAG GAA TG -3' (amplificando justo antes del sitio de restricción para BamHI que presenta la secuencia de Vav1 antes del dominio SH3 N-terminal) y el reverso 5'- AGC TAG GAT CCA ATA TTC AGT TAG AAG GGA ACC AGC C -3' (la secuencia de restricción de BamHI, utilizada para el clonaje, aparece subrayada) utilizando como molde el plásmido pKES29, que consiste en la secuencia de la forma truncada en el vector pcDNA3. A continuación se subclonó el fragmento resultante de la PCR en los vectores que codifican para Vav1 ${ }^{\text {WT }}$ (pSRM3) o Vav1 ${ }^{\text {Y3XF }}$ (pKES14), después de la digestión enzimática con BamHI.

Para generar el vector de expresión de la forma truncada Vav2 ${ }^{\triangle 860-868}$ fusionada con EGFP (pMB127), se introdujo por mutagénesis dirigida un codón de terminación en el lugar del codón correspondiente al aminoácido 860 de Vav2, utilizando el kit de Quickchange (Stratagene). Con este fin, se usó de molde el plásmido pAA7, vector de expresión de la forma silvestre de Vav2 etiquetada con EGFP en su región N-terminal, y para introducir la 
mutación se utilizaron los siguientes oligos: directo 5'- CGG TTG GTT TCC TTC GAC GTA GGT GGA AGA GGA AGG CGT CCA G -3', y reverso 5'- CTG GAC GCC TTC CTC TTC CAC CTA CGT CGA AGG AAA CCA ACC G-3' (codón de terminación subrayado).

El vector de expresión de la forma truncada Vav3 ${ }^{\Delta 841-847}$ fusionada con EGFP (pMB121) fue generado mediante amplificación por PCR usando el oligo directo 5'- ATA CTC GAG GCC ACC ATG GAG CCG TGG AAG CAG TGC GCTC -3' y el reverso 5'- CCG GGC GAA TTC TTA TGT GGA TGG AAA CCA GCC CAC CC -3' (las secuencias para Xhol y EcoRI se encuentran subrayadas) utilizando como molde el plásmido pC.HA-Vav3, que contiene la secuencia de la forma silvestre de Vav3 etiquetada con el epítopo HA (Addgene). A continuación, el fragmento resultante de la reacción de PCR fue introducido en el vector pEGFP-C3 linearizado por digestión enzimatica con Xhol y EcoRI. Un procedimiento similar se empleó para obtener los vectores de expresión de las proteínas de fusión EGFP-DmVav ${ }^{W T}$ e EGFP-DmVav ${ }^{\Delta 781-793}$. Se utilizaron los siguientes oligos para la amplificación por PCR a partir del plásmido pID18, que contiene la secuencia silvestre de DmVav, etiquetada con el epítopo Myc, subclonada en el vector pSecTag (cortesía de la Dra. S. Katzav, Department of Development Biology and Cancer Research, Faculty of Medicine, The Hebrew University of Jerusalem, Israel) : el directo 5'- ATA CTC GAG GCC ACC ATG GCC AGC AGC AGT AGC AGC AAC -3' (el sitio de restricción Xhol aparece subrayado), en ambos casos, y los reversos 5'- CCG GGC GAA TTC TCA AAG CTC TTC GCT GGC CAA TIT CTG -3' (el sitio de restricción EcoRI aparece subrayado) y 5'- CCG GGC GAA TTC TCA CTT GGG AAA GTA GCC CAC CGT ATC -3' (el sitio de restricción EcoRI aparece subrayado), respectivamente. El producto de PCR se introdujo en el plásmido pEGFP-C3 linearizado con Xhol y EcoRI como en el caso anterior.

Para generar el plásmido que codifica para la proteína de fusión EGFP-Vav1 ${ }^{\mathrm{DH}}$ (pMB49) se introdujo un condón de terminación en el ADNc de Vav1 presente en el vector que codifica para la proteína EGFP-Vav1 ${ }^{\mathrm{DH}+\mathrm{NPH}}$ (pNM109) usando los oligos 5'- CTA GTG AAA CAC ACA CAG TAG GCT ACA GAG AAG GAG AAC-3' y 5'-GTT CTC CTT CTC TGT AGC CTA CTG TGT GTG TIT CAC TAG-3' (codón de terminación subrayado).

El vector de expresión de la proteína de fusión EGFP-Vav1 ${ }^{\text {Alpha6 }}$ (pMB48) se generó por amplificación por PCR usando los oligos directo 5'- GGC GAA TTC CAG GAG CTA GTG AAA CAC ACA CAG GAT GC -3' y reverso 5'- AGC TAG GAT CCA ATA TTC AGT TCA GAG ACT GGT CCA GGT TC -3' (las secuencias de EcoRl y BamHI se indican subrayadas). Se usó como molde el plásmido pNM103, que consiste en la secuencia del casete DH-PH-ZF de Vav1 en el vector pEGFP-C2. El fragmento obtenido se introdujo en el vector pEGFP-C2 linearizado con EcoRI y BamHI. 
Los vectores de expresión que codifican para el resto de mutantes puntuales y combinados de la proteína Vav1 (Anexo I) se generaron utilizando el kit de mutagénesis dirigida QuikChange (Agilent Technologies). Los oligos utilizados para realizar la mutagénesis se recogen en el Anexo II. Tanto los plásmidos generados por mutagénesis como aquellos obtenidos por técnicas de clonaje fueron secuenciados para descartar la presencia de mutaciones no deseadas.

\section{CULTIVOS CELULARES}

Todas las líneas celulares de Jurkat fueron cultivadas en medio RPMI-1640 suplementado con $10 \%$ de suero fetal bovino (FBS), $1 \%$ de glutamina, $10 \mu \mathrm{g} / \mathrm{mL}$ penicilina y $100 \mu \mathrm{g} / \mathrm{mL}$ estreptomicina. Se utilizaron como células Jurkat silvestres a la línea celular Jukat Tet-on (obtenida de ATCC). Las líneas celulares correspondientes a las células Jurkat deficientes en alguna proteína se recogen en la Tabla 1.

\begin{tabular}{|c|c|c|}
\hline $\begin{array}{l}\text { Línea celular } \\
\text { Jurkat }\end{array}$ & $\begin{array}{c}\text { Proteína } \\
\text { deficiente }\end{array}$ & Origen \\
\hline Jurkat Tet-on & - & ATCC \\
\hline J.31.13 & TCR & $\begin{array}{c}\text { Dr. B. Alarcón (Centro de Biología Molecular Severo } \\
\text { Ochoa-CSIC, Madrid) }\end{array}$ \\
\hline ANJ3 & Lat & $\begin{array}{c}\text { Dr. L.E. Samelson (Department of Cellular and } \\
\text { Molecular Biology, Centre of Cancer Research, NCl, } \\
\text { Bethesda, U.S.A.) }\end{array}$ \\
\hline P116 & Zap70 & $\begin{array}{c}\text { Dr. B. Alarcón (Centro de Biología Molecular Severo } \\
\text { Ochoa-CSIC, Madrid) }\end{array}$ \\
\hline J.Cam1.6 & Lck & ATCC \\
\hline J45.01 & CD45 & ATCC \\
\hline J14 & Slp76 & $\begin{array}{l}\text { Dr. A. Weiss (Department of Medicine, Microbiology } \\
\text { and Immunology, University of San Francisco, U.S.A) }\end{array}$ \\
\hline J.gamma1 & PLC $\gamma 1$ & ATCC \\
\hline
\end{tabular}

Tabla 1. Líneas célulares de Jurkat utilizadas en este trabajo de tesis. Esta tabla recoge el nombre de la línea celular, si no expresan alguna proteína y el origen de la misma.

La línea celular DT40 fue cultivada en medio RPMI-1640 suplementado con un $10 \%$ de FBS, $1 \%$ suero de pollo, 0,1 mM $\beta$-mercaptoetanol (Sigma), $1 \%$ glutamina, $10 \mu \mathrm{g} / \mathrm{mL}$ penicilina y $100 \mu \mathrm{g} / \mathrm{mL}$ estreptomicina.

Las líneas celulares COS-1 y NIH3T3 fueron cultivadas en medio DMEM suplementado con $10 \%$ de FBS, $1 \%$ de glutamina, $10 \mu \mathrm{g} / \mathrm{mL}$ penicilina y $100 \mu \mathrm{g} / \mathrm{mL}$ estreptomicina. Todas las 
líneas celulares fueron mantenidas a $37^{\circ} \mathrm{C}$ en una atmósfera con un contenido del $5 \%$ de $\mathrm{CO}_{2}$.

\section{ESTIMULACIÓN CELULAR Y TRATAMIENTOS CON INHIBIDORES}

En los experimentos en los que se deseaba activar la ruta de señalización del receptor de células T (TCR) en las células Jurkat, se utilizó el anticuerpo monoclonal anti-CD3 (clon UCHT1, Merck-Millipore) a una concentración de $10 \mu \mathrm{g} / \mathrm{mL}$ en medio RPMI-1640 sin suero (salvo en periodos de incubación superiores a 1 hora que se usó medio completo) durante los periodos de tiempo indicados en un baño o estufa a $37^{\circ} \mathrm{C}$.

Para estimular el receptor de células B (BCR) en los ensayos de actividad luciferasa, las células DT40 fueron incubadas con el anticuerpo anti-lgM (Southern Biotech) a una concentración de $5 \mu \mathrm{g} / \mathrm{mL}$ en medio completo en una estufa a $37^{\circ} \mathrm{C}$.

Para el tratamiento de las células Jurkat con el inhibidor de la familia de quinasas Src, PP2 (Merk Millipore), las células a tratar se pusieron en medio sin suero y se añadió el inhibidor PP2 a una concentración de $100 \mu \mathrm{M}$ durante 1 hora a $37^{\circ} \mathrm{C}$. Para inhibir la actividad de PLC $\gamma 1$, las células Jurkat fueron incubadas con el inhibidor U73122 (Merk Millipore) a una concentración de $10 \mu \mathrm{M}$ durante 30 minutos a $37^{\circ} \mathrm{C}$. Para inhibir la actividad de la quinasa PKC, las células Jurkat se trataron con el inhibidor GF109203X (Sigma) a una concentración de $5 \mu \mathrm{M}$ durante 30 minutos a $37^{\circ} \mathrm{C}$. En los experimentos en que fue necesario, la estimulación con anti-CD3 se realizó después del tratamiento con los inhibidores manteniendo los mismos en el medio.

\section{TRANSFECCIONES TRANSITORIAS}

\subsection{Tranfección por electroporación}

Este procedimiento se utilizó para transfectar las células Jurkat y DT40 para los ensayos de actividad luciferasa. En primer lugar, se recogieron por punto 20 millones de células en el caso de las Jurkat y 10 millones en el caso de las DT40. Las células se lavaron dos veces con medio RPMI-1640 sin suero, centrifugando a $1400 \mathrm{rpm}$ a temperatura ambiente. Se resuspendieron en el volumen adecuado de medio sin suero para obtener una densidad celular de 100.000 células / $\mu \mathrm{L}$ (Jurkat) o 50.000 células / $\mu \mathrm{L}$ (DT40). Para realizar la 
electroporación se usaron cubetas Gene Pulser de 0,4 cm de Bio-Rad. En cada cubeta se introdujeron $200 \mu \mathrm{L}$ del cultivo así como la cantidad correspondiente de los plásmidos que se deseaban transfectar, mezclando todo suavemente con la pipeta. La electroporación se realizó en un sistema Gene Pulser II de Bio-Rad a $950 \mu \mathrm{F}$ y 250 V durante 30-40 ms. Posteriormente, el contenido de cada cubeta se trasladó a un frasco de cultivo de $25 \mathrm{~cm}^{2}$ con $10 \mathrm{~mL}$ de medio completo. La células transfectadas se cultivaron durante 36-48 horas en condiciones estándar de cultivo para posteriormente proceder a realizar los ensayos de actividad luciferasa.

\subsection{Método del DEAE-dextrano}

Este procedimiento fue inicialmente descrito por Ridley y Hall en 1992. Este método se ha utilizado para la transfección de células en experimentos de pull-down, inmunoprecipitación y detección de proteínas a través de Western-blot. El día previo a la transfección, cada placa confluente de células COS1 (aproximadamente $4 \times 10^{6}$ células) fue dividida en proporción 1:3 en placas de $10 \mathrm{~cm}$ de diámetro. Al día siguiente se procedió a la tranfección utilizando una mezcla de $4 \mathrm{~mL}$ de DMEM ( sin L-glutamina ni suero pero con antibióticos), 0,16 mL de una solución DEAE-dextrano/cloroquina (PBS con $10 \mathrm{mg} / \mathrm{mL}$ de DEAE-dextrano (Sigma) y 2,5 $\mathrm{mM}$ de cloroquina (Sigma), y 8 ug del plásmido a transfectar. Las células fueron lavadas dos veces con medio sin suero y se incubaron con la mezcla anterior en condiciones estándar de cultivo durante 3-4 horas. Transcurrido este tiempo, el medio fue retirado y las células se trataron con $5 \mathrm{~mL}$ de una solución DMSO (Sigma) al 10\% en PBS durante 2 minutos a temperatura ambiente. Tras aspirar la solución de DMSO, las células se incubaron en medio completo durante un periodo de 36-48 horas.

\subsection{Método de la precipitación de fosfato cálcico}

Este procedimiento se empleó para los ensayos de formación de focos en células NIH3T3. Con este fin, 1,5 × $10^{5}$ células NIH3T3 fueron sembradas en placas de $10 \mathrm{~cm}$ de diámetro y transfectadas al día siguiente. Para la transfección se mezclaron $20 \mu \mathrm{g}$ de ADN de timo de ternera de alto peso molecular (Sigma) con $1 \mu \mathrm{g}$ del plásmido a transfectar en un volumen final de $0,5 \mathrm{~mL}$ de $\mathrm{H}_{2} \mathrm{O}$ MiliQ estéril (por placa). A esta mezcla se añadieron $0,5 \mathrm{~mL}$ de $0,5 \mathrm{M}$ $\mathrm{CaCl}_{2}$. La solución anterior se añadió gota a gota sobre $1 \mathrm{~mL}$ de tampón HNP (50 mM HEPES [pH 7,1], $280 \mathrm{mM} \mathrm{NaCl}, 1,4 \mathrm{mM}$ tampón fosfato [pH 7,1]), burbujeando aire através de una bomba de vacío. La mezcla se incubó durante unos 15 min hasta la formación de un precipitado blanco. Cada punto se hizo por duplicado en un mismo experimento. Los tubos se agitaron suavemente para resuspender el precipitado y la solución de $2 \mathrm{~mL}$ se añadió acto seguido a las células. Tras 20-22 horas en condiciones estándar de cultivo, el medio fue 
aspirado y las células lavadas dos veces con medio completo. Posteriormente, las células se mantuvieron en medio completo, cambiando el medio cada tres días durante un total de 14 días, transcurridos los cuales se tiñeron con Giemsa para revelar la presencia de focos de células transformadas. Para ello, tras aspirar el medio de cultivo y lavar con PBS, las células fueron fijadas con formaldehído al 4\% (Sigma) durante 10 minutos. Las células se lavaron con agua destilada dos veces y se tiñeron con una dilución 1:10 de Giemsa (Sigma) durante 20-30 min a temperatura ambiente, transcurridos los cuales el colorante fue aspirado y las placas lavadas varias veces con agua destilada. Por último las placas se dejaron secar en ángulo boca abajo a temperatura ambiente.

\subsection{Liposomas}

Para los experimentos de inmunofluorescencia, las células COS1 fueron transfectadas usando Lipofectamine 2000 (Invitrogen) de acuerdo con las recomendaciones del fabricante.

\subsection{Sistema Neon Tranfector (Invitrogen)}

Con el fin de obtener una eficiencia de transfección mayor que en el caso de la electroporación tradicional, para los experimentos de inmunofluorescencia con células Jurkat, se utilizó este sistema de electroporación en capilar. A este fin, se realizó una optimización previa para determinar el programa del sistema que resultaba más adecuado para transfectar células Jurkat concluyendo que el programa no 5 (1,7 mV, $20 \mathrm{~ms})$ era el más idóneo. Las transfecciones se llevaron a cabo siguiendo las indicaciones del fabricante.

\section{ENSAYOS DE ACTIVIDAD LUCIFERASA}

La expresión de proteínas en las células Jurkat y DT40 fue obtenida mediante transfección por electroporación siguiendo el procedimiento detallado previamente en el apartado de Transfecciones Transitorias. Todas las tranfecciones se realizaron por triplicado. Se usaron los siguientes plásmidos según el tipo de ensayo.

\subsection{Ensayos de activación de NF-AT (Nuclear Factor of Activated T-cells)}

En este caso se cotransfectaron por punto $10 \mu \mathrm{g}$ del plásmido pNFAT-Luc (vector reportero de la luciferasa), $5 \mathrm{ng}$ del plásmido pRL-SV40 (vector reportero de la renila luciferasa) y $20 \mu \mathrm{g}$ del vector de expresión de la proteína de interés (en algunos casos se varió la cantidad del plásmido de interés para obtener una expresión homogénea de las proteínas). Como control 
negativo se sustituyó el vector de expresión de la proteína de interés por el vector vacío correspondiente.

\subsection{Ensayos de activación de JNK}

Para medir la activación de JNK se usó un sistema de transactivación. En estos ensayos se cotransfectaron por punto $10 \mu \mathrm{g}$ del plásmido pFR-Luc (plásmido reportero que contiene 5 sitios de unión en tandem para el dominio de unión a ADN de Gal4 y una TATA box localizándose el gen de la luciferasa por debajo de esta región promotora), 5 ug del plásmido pFA2-Luc (plásmido que codifica para una proteína transactivadora de fusión compuesta por el dominio de activación de c-Jun y el dominio de unión al ADN de Gal4) y $20 \mu \mathrm{g}$ del vector de expresión de la proteína de interés (en algunos casos se varió la cantidad del plásmido de interés para obtener una expresión homogénea de las proteínas). El vector vacío correspondiente se usó como control negativo.

En ambos casos, después de 48 horas de incubación en condiciones estándar de cultivo, las células fueron centrifugadas a $1.400 \mathrm{rpm}$ durante 5 minutos a temperatura ambiente y resuspendidas en $2 \mathrm{~mL}$ de medio RPMI-1640 completo. El volumen de cultivo fue dividido en dos disponiendo cada mililitro en un pocillo de una placa de 12 pocillos. La mitad de las células fueron estimuladas con $10 \mu \mathrm{g} / \mathrm{mL}$ de anti-CD3 (Clon UCTH1, Merck Millipore), en caso de las Jurkat, o con $5 \mu \mathrm{g} / \mathrm{mL}$ de anti-IgM (Southern-Biotech), en el caso de las DT40. La otra mitad del cultivo se dejó sin estimular. La incubación con el anticuerpo se prolongó durante 7 horas manteniendo las células en las condiciones estándar de cultivo. Pasado este tiempo, se recogieron células de cada punto para su posterior lisado en tampón de muestra de Laemmli. Estas muestras se usaron, posteriormente, para analizar los niveles de expresión de proteínas por Western-blot.

El resto de células fueron recogidas y centrifugadas a $14.000 \mathrm{rpm}$ durante 2 minutos a temperatura ambiente. El sedimento de células fue resuspendido en una dilución del tampón de lisis Ilamado Passive Lysis Buffer 5X presente en el kit Dual Luciferase Reporter Assay System (Promega) de acuerdo con las instrucciones facilitadas por el fabricante. Posteriormente, los lisados se congelaron a $-80^{\circ} \mathrm{C}$ durante 10 minutos para después ser centrifugados a $14.000 \mathrm{rpm}$ durante $10 \mathrm{~min}$ a $4{ }^{\circ} \mathrm{C}$ para facilitar el lisado y la eliminación de restos celulares. Alícuotas de $10 \mu \mathrm{L}$ del sobrenadante fueron utilizadas para realizar la medida de la actividad luciferasa y renilla usando los reactivos del kit mencionado previamente. Para realizar las mediciones se utilizó un luminometro Lumat LB 9507 (Berthold Technologies). En los ensayos de activación de NF-AT, los valores de la actividad 
luciferasa obtenidos para las diferentes muestras fueron normalizados en relación a la actividad renila obtenida en cada muestra. Los resultados se expresan como el incremento relativo a la activación de NF-AT o JNK-1 que presentan las células no estimuladas transfectadas con el vector vacío. Los resultados presentados son las medias y las desviaciones estándar de tres transfecciones independientes.

\section{ELECTROFORESIS EN GELES DE POLIACRILAMIDA Y WESTERN-BLOT}

Los extractos proteicos se hirvieron en tampón de muestra de Laemmli durante 5-10 minutos y, a continuación, se resolvieron en geles de poliacrilamida al 8\% (para la separación de proteínas Vav1), al 10\% (para la separación de las formas truncadas o los dominios aislados de la proteína Vav1) y al 12\% (para la separación de la proteína Rac1) utilizando un tampón de carrera compuesto de $0,25 \mathrm{M}$ de Tris, $2 \mathrm{M}$ de glicina y $0,5 \%$ de SDS.

A continuación, las proteínas fueron transferidas a una membrana de nitrocelulosa siguiendo dos procedimientos distintos según fuese un gel de tamaño grande o pequeño. En el caso de los geles grandes esta transferencia se hizo siguiendo el protocolo tradicional de transferencia húmeda, utilizando un equipo Maxi Trans-Blot Cell (Bio-Rad), un tampón de transferencia ( $25 \mathrm{mM}$ Tris, $192 \mathrm{mM}$ glicina y $20 \%$ metanol) y una membrana de nitrocelulosa de GE Healthcare. La transferencia se realizó a un amperaje fijo de $400 \mathrm{~mA}$ durante 90-100 minutos. En el caso de los geles pequeños, la transferencia a una membrana de nitrocelulosa se realizó utilizando el sistema iBlot Dry Blotting (Invitrogen) que permite realizar la transferrencia seca en 6 minutos. El correcto funcionamiento de la transferencia fue comprobado en ambos casos mediante la tinción con rojo Ponceau que tiñe las proteínas de forma inespecífica (esta tinción se utilizó también para analizar los niveles de expresión de las proteínas de fusión GST-SH3 en los experimentos de Pull-Down). Dicha tinción se eliminó mediante varios lavados con una solución de TBS-T ( $25 \mathrm{mM}$ Tris-HCl [pH 8,0] y 0,1\% de Tween20 (Sigma).

Las membranas fueron posteriormente bloqueadas en una disolución al $5 \%$ de albumina sérica bovina (BSA; Sigma) en TBS-T durante 1 hora a temperatura ambiente. La hibridación con los anticuerpos primarios se llevó a cabo indistintamente durante 2 horas a temperatura ambiente o toda la noche a $4{ }^{\circ} \mathrm{C}$. Los anticuerpos primarios fueron diluidos en una solución de la misma composición que la de bloqueo. Las diluciones utilizadas se indican en la Tabla 2. Seguidamente, las membranas fueron lavadas tres veces con una solución de TBS-T 
durando 10 minutos cada lavado. A continuación, las membranas fueron incubadas con el anticuerpo secundario de la especificidad adecuada conjugados con peroxidasa de rábano (GE Healthcare) diluidos 1:5.000 en una solución de leche desnatada (Nestlé) al 5\% en TBS-T durante 45 minutos a temperatura ambiente. Después de esta incubación las membranas se volvieron a lavar tres veces con TBS-T durando 10 minutos cada lavado. Todas las incubaciones y lavados se realizaron en agitación. La detección de las proteínas se llevó a cabo por quimioluminiscencia utilizando el reactivo ECL (Thermo). Cuando fue necesario remover los anticuerpos primarios de las membranas para repetir el proceso, éstas fueron incubadas con $10 \mathrm{~mL}$ de una disolución de Re-Blot Plus Strong 10X (Millipore) durante 15 minutos a temperatura ambiente en agitación. Posteriormente fueron lavadas con TBS-T tres veces durante 5 minutos, bloqueadas durante 45 minutos e incubadas con otro anticuerpo primario repitiendo el procedimiento anterior.

\begin{tabular}{llll}
\multicolumn{1}{c}{ Anticuerpo } & \multicolumn{1}{c}{ Compañía } & \multicolumn{1}{c}{ Western-Blot } & \multicolumn{1}{c}{ Inmunoprecipitación } \\
Anti-Vav1 (\#301-2) & Invitrogen & $1: 10.000$ & $1: 5.000$ \\
\hline Anti- $\alpha$-Tubulin & Santa Cruz & $1: 2.000$ & - \\
\hline Anti-GFP & Covance & $1: 5.000$ & - \\
\hline Anti-GST & Sigma & $1: 2.000$ & - \\
\hline Anti-hnRNPK & Merck Millipore & $1: 1.000$ & - \\
\hline Anti-pTyr & Santa Cruz & $1: 1.000$ & - \\
(fosfotirosina) & & & - \\
\hline Anti-pY142-Vav1 & Invitrogen & $1: 1.000$ & - \\
\hline Anti-pY160-Vav1 & Invitrogen & $1: 500$ & - \\
\hline Anti-pY174-Vav1 & Invitrogen & $1: 2.000$ & - \\
\hline Anti-pY541-Vav1 & Invitrogen & $1: 1.000$ & - \\
\hline Anti-pY544-Vav1 & Invitrogen & $1: 1.000$ & - \\
\hline Anti-pY836-Vav1 & Invitrogen & $1: 1.000$ & - \\
\hline Anti-Lat & Abcam & $1: 1.000$ & - \\
\hline Anti-Zap70 & Upstate Biotecnology & $1: 1.000$ & - \\
\hline Anti-Lck & Santa Cruz & $1: 1.000$ & - \\
\hline Anti-Rac1 & BD Biosciences & $1: 2.000$ & $1: 2.000$ \\
\hline Anti-PLC 1 & Cell Signaling & $1: 1.000$ & $1: 2.000$ \\
\hline Anti-Slp76 & Cell Signaling & $1: 1.000$ & \\
\hline
\end{tabular}

Tabla 2. Anticuerpos utilizados en los ensayos de Western-Blot e inmunoprecipitación, casa comercial en la que fueron adquiridos y dilución utilizada en los experimentos. Los anticuerpos contra el dominio DH de Vav1 fueron generados en conejos inmunizados con proteínas de fusión a GST producidas en Escherichia coli. Los anticuerpos fosfoespecíficos contra los distintos residuos de Vav1 fueron encargados a la casa comercial Invitrogen, siendo generados en conejos inmunizados con péptidos específicos.

\section{INMUNOFLUORESCENCIA INDIRECTA}

Para los experimentos con células Jurkat, aproximadamente $1 \times 10^{6}$ células fueron transfectadas por punto utilizando el Neon Transfector System (Invitrogen) y una cantidad de 
plásmido de $30 \mu \mathrm{g}$ por punto. A las 36 horas, las células fueron incubadas durante 20 minutos con cubreobjetos redondos de $12 \mathrm{~mm}$ de diámetro con poli-D-lisina incorporada (BD BioCoat) usando 3 cubreobjetos por pocillo en placas de 6 pocillos.

En el caso de los experimentos con células COS1, éstas se cultivaron en placas de 6 pocillos hasta llegar a una confluencia del $40-50 \%$ y fueron tranfectadas con los vectores de expresión correspondientes usando Lipofectamine 2000 (Invitrogen), un método de transfección basado en liposomas, según las indicaciones del fabricante. La cantidad de plásmido tranfectada fue, en todos los casos, de $1 \mu \mathrm{g}$ por pocillo. A las 24 horas, las células fueron tripsinizadas y tranferidas a otra placa de 6 pocillos conteniendo cada pocillo 3 cubreobjetos de $12 \mathrm{~mm}$ de diámetro (Menzel-Glaser) previamente incubados con una solución de $1 \mu \mathrm{g} / \mathrm{mL}$ de poli-L-lisina (Sigma) durante 10 minutos a temperatura ambiente. A cada pocillo se añadieron $2 \mathrm{~mL}$ de medio DMEM completo y se dejaron incubar las células con los cubreobjetos de 12-24 horas en las condiciones estándar de cultivo.

Con ambas líneas celulares se usaron vectores de expresión que contenían proteínas etiquetadas con EGFP. A partir de aquí el protocolo es común para ambas líneas celulares. Las células fueron lavadas con PBS y se fijaron en formaldehído al 4\% en PBS durante 15 minutos. A continuación, las células fueron lavadas dos veces con PBS para, posteriormente, permeabilizarlas mediante incubación con una solución compuesta de 0,5\% Triton X-100 en PBS durante 10 minutos. Transcurrido ese tiempo, las células fueron lavadas tres veces con TBS-T para luego incubarlas con una solución de bloqueo ( $2 \%$ albúmina sérica bovina, 0,1\% acida sódica y $0,1 \%$ Triton X-100 en una solución tamponada con 25 mM Tris [pH 7,4]) durante 10 minutos.

Para teñir el citoesqueleto de actina, las células se incubaron durante 20 min con faloidina conjugada con rodamina (Invitrogen) a una dilución 1:200 en solución de bloqueo. Posteriormente, las células se lavaron tres veces con TBS-T durante 5 minutos. En el caso de las células Jurkat, se añadió en el último lavado $1 \mu \mathrm{g}$ de DAPI (Invitrogen) por pocillo para teñir los núcleos, incubándolo 5 min para después realizar dos lavados más con TBS-T. Finalmente, las preparaciones fueron montadas sobre portaobjetos utilizando Mowiol (Millipore) para sellar y como agente retardante. Las células fueron analizadas mediante microscopía confocal, utilizando un microscopio de barrido por láser Leica TCS SP5 con un objetivo de magnificación 63x. Para visualizar la proteínas con GFP se utilizó un láser de Argón a una longitud de onda de excitación de $488 \mathrm{~nm}$, para la rodamina se usó un láser de $\mathrm{He} / \mathrm{Ne}$ a una longitud de onda de excitación de $563 \mathrm{~nm}$, y para el DAPI un diodo a una longitud de onda de $405 \mathrm{~nm}$. 


\section{PURIFICACIÓN DE PROTEÍNAS DE FUSIÓN CON GST}

Un cultivo de bacterias $\mathrm{DH} 5 \alpha$ transformadas con el vector de expresión correspondiente (pGEX-PAK1 $1_{\text {CRIB, }}$ pGEX-SH3 y sus derivados) fue crecido en $100 \mathrm{~mL}$ de medio Luria-Bertani (LB) conteniendo $100 \mu \mathrm{g} / \mathrm{mL}$ de ampicilina durante toda la noche en agitación a $37{ }^{\circ} \mathrm{C}$. A la mañana siguiente, el cultivo fue diluido hasta alcanzar una densidad óptica a $600 \mathrm{~nm}$ de 0,8. En ese momento, se indujo la expresión de las proteínas de fusión mediante la adición al medio de cultivo de IPTG (GE-Healthcare) a una concentración final de 1,5 mM. Transcurrida una hora a $30^{\circ} \mathrm{C}$ en agitación, las células fueron recogidas mediante centrifugación a 3.000 rpm a $4{ }^{\circ} \mathrm{C}$, resuspendidas en $40 \mathrm{~mL}$ de PBS frío con una mezcla de inhibidores de proteasas (Complete, Roche) y sometidas a sonicación (6 pulsos de 15 segundos con 30 segundos de parada entre pulsos). A continuación, se añadió Tritón X-100 a una concentración final del 1\%, incubándose la mezcla en hielo durante 30 minutos. Los restos de membranas y núcleos procedentes de la rotura de las células fueron eliminados por centrifugación a $10.000 \mathrm{rpm}$ a $4^{\circ} \mathrm{C}$, y el sobrenadante fue incubado con $800 \mu \mathrm{L}$ de una suspensión de una matriz de sefarosa conjugada con glutatión (GE-Healthcare) al 50\% en PBS durante 2-4 horas a 4 C en rotación. Transcurrido ese tiempo se realizaron 3 lavados de las proteínas unidas a la matriz de sefarosa con PBS frío para luego conservarlas en una solución de glicerol al 50\% en PBS a -80 ${ }^{\circ} \mathrm{C}$. En todos los casos, la concentración de proteína fue calculada mediante el análisis de una muestra de la misma por electroforesis en un gel de poliacrilamida al 10\%, utilizando como estándares cantidades crecientes de albúmina sérica bovina (fracción V, Sigma). Los geles se tiñeron con una solución de azul de Coomassie (0,5\% Coomassie, 10\% ácido acético, 50\% metanol) y se lavaron con una solución de desteñido ( $10 \%$ ácido acético, 50\% metanol) para visualizar las proteínas. Todos los reactivos utilizados para la tinción y la destinción fueron comprados en Sigma.

\section{EXPERIMENTOS DE PULL-DOWN}

\section{Pull-down con GST-SH3 y sus derivados}

Células COS1 fueron transfectadas con los vectores de expresión indicados en cada figura utilizando DEAE-dextrano. Transcurridas 36-48 horas de la transfección, las células fueron lavadas con PBS frío y lisadas con el tampón descrito en el apartado anterior. Las células se incubaron con el tampón de lisis durante 10 minutos en hielo y, a continuación, se centrifugaron a $14.000 \mathrm{rpm}$ durante 10 minutos a $4{ }^{\circ} \mathrm{C}$. Una alícuota del sobrenadante se utilizó para analizar la expresión de las proteínas en los lisados totales. El resto del 
sobrenadante se incubó con $15 \mu \mathrm{g}$ de la proteína GST-SH3 correspondiente y con $30 \mu \mathrm{L}$ de una suspensión de matriz de glutatión-sefarosa al 50\% en PBS durante 5 horas a $4{ }^{\circ} \mathrm{C}$ en rotación. La matriz fue sedimentada por centrifugación a $14.000 \mathrm{rpm}$ a $4{ }^{\circ} \mathrm{C}$, lavada tres veces con tampón de lisis y resuspendida en tampón de muestra de Laemmli. Después de hervir las muestras, las proteínas fueron analizadas mediante electroforesis en un gel grande de poliacrilamida al $8 \%$, seguida de Western-blot. Para la inmunodetección de las distintas formas de la proteína Vav1 se utilizaron un anticuerpo policlonal anti-Vav1 (generado anteriormente en nuestro laboratorio, dilución 1:10.000) o un anticuerpo monoclonal antiGFP (Covance, dilución 1:5.000) según correspondiese, seguido de un anticuerpo secundario anti-lgG de conejo (para el anti-Vav1) o de ratón (para el anti-GFP) conjugado HRP (GEHealthcare) en dilución 1:5.000. El protocolo completo del Western-blot se especifica en el apartado correspondiente (pág. 50).

\section{MICROSCOPÍA ELECTRÓNICA}

Los experimentos de microscopía electrónica fueron realizados por el laboratorio del Dr. O. Llorca (Centro Investigaciones Biológicas-CSIC, Madrid).

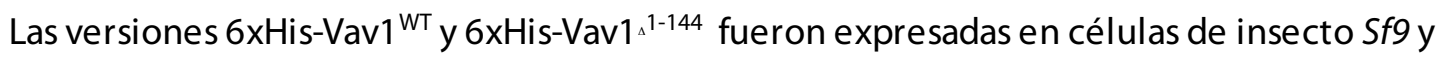
purificadas por cromatografía de afinidad de ión metálico inmovilizado. Las proteínas purificadas fueron posteriormente sometidas a cromatografía de exclusión por tamaño usando una columna Superdex 200 PC3.2/30 (GE Healthcare) equilibrada previamente con $50 \mathrm{mM}$ Tris- $\mathrm{HCl}$ (pH 7.5), $100 \mathrm{mM} \mathrm{NaCl}, 1 \mathrm{mM} \mathrm{MgCl}, 1 \mathrm{mM}$ de ditiotreitol y $10 \%$ de glycerol. Las fracciones obtenidas fueron analizadas mediante electroforesis en un gel de poliacrilamida y posteriormente teñido con nitrato de plata. Una alícuota de la fracción correspondiente al pico fue absorbida en rejillas con carbón adherido e, inmediatamente después de la elución, teñidas usando un $2 \%$ de formato de uranilo (Sigma).

Todas las observaciones fueron realizadas en un microscopio electrónico de transmisión JEOL 1230 operando a 100 kV. Las imágenes de microscopía electrónica fueron capturadas usando un protocolo de dosis baja y un detector CMOS TVIPS $4 \mathrm{k}$ x 4k bajo el control del software EM-TOOLS (TVIPS). La magnificación final de los micrográficos CMOS fue de 68 222x, que fueron posteriormente reducidas a una resolución final de $4.56 \AA$ por pixel. La función de transferencia del contraste de fases (CTF) de cada imagen fue estimada usando CTFFIND3 (Mindell and Grigorieff, 2003) y corregida usando BSOFT (Heymann and Belnap, 2007). 4970 
imágenes de moléculas individuales fueron seleccionadas a partir de los micrográficos de electrones y procesadas usando EMAN (Ludtke et al., 1999). Los promedios fueron obtenidos usando XMIPP. La resolución de las estructuras obtenidas fue estimada en $32.5 \AA$ usando la correlación de Fourier Shell (FSC) y un coeficiente de correlación de 0.5.

\section{ANÁLISIS Y MODELAJE ESTRUCTURAL}

La visualización de las estructuras proteicas fue realizada usando el software MacPyMol (versión 1.5, Delano Scientific LLC). Los archivos PDB de las regiones de Vav1 CH-Ac-DH-PH-ZF (3KY9), DH-PH-ZF (2VRW) y CSH3 (2DMI y 2KBT) fueron obtenidas del RCSB Protein Data Bank. La estructura del dominio CSH3 fue modelada bioinformáticamente a partir del archivo PDB 2DMI usando el software Phyre2 (www.sbg.bio.ic.ac.uk/phyre2).

Las secuencias de las proteínas de la familia Vav de diferentes especies fueron obtenidas con la aplicación BLAST (http://blast.ncbi.nlm.nih.gov), alineadas usando CLUSTALW (http://www.ebi.ac.uk/Tools/msa/clustalw2/), y los niveles de conservación evaluados mediante métodos bayesianos implementados en el servidor ConSurf (http://consurf.tau.ac.il/).

\section{IDENTIFICACIÓN DE SITIOS DE FOSFORILACIÓN}

La proteína Vav1 fue inmunoprecipitada a partir de células COS-1 y Jurkat, sin estimular y estimuladas con EGF y anti-CD3, respectivamente. Los inmunoprecipitados fueron separados electroforéticamente y teñidos con imidazol/zinc. Las bandas correspondientes a la proteína Vav1 fueron cortadas, tripsinizadas y analizadas usando un aparato de MALDI-TOFF (Ultrafex, Bruker). Los sitios de fosforilación detectados en tres determinaciones independientes fueron usados para una caracterización más detallada. Además de los sitios de fosforilación descritos en este trabajo también se detectó el aminoácido $Y^{745}$ fosforilado pero únicamente en el caso de las células COS-1 estimuladas con EGF. También se detectaron residuos de serina y treonina que no fueron caracterizados en detalle. Para confirmar la fosforilación de estos residuos usando técnicas independientes, se analizó su estado de fosforilación en inmunoprecipitados de la proteína Vav1 obtenidos de células Jurkat mediante Western-blot usando anticuerpos fosfoespecíficos para dichos residuos (Invitrogen). Después de este paso, se eliminó el anticuerpo fosfoespecífico usando Re-Blot Plus Strong 10X (Millipore), y las membranas se incubaron de nuevo con el anticuerpo contra la proteína total Vav1. 


\section{EXPERIMENTOS DE INMUNOPRECIPITACIÓN}

En el caso de los experimentos en los que se usaron células Jurkat para inmunoprecipitar la proteína Vav1 endógena, se procedió a recoger $5 \times 10^{6}$ células por punto. Estas células fueron lavadas dos veces con medio RPMI-1640 sin suero ni L-glutamina ni antibióticos centrifugándolas a $1.400 \mathrm{rpm}$ durante 5 minutos a temperatura ambiente. Las células se resuspendieron en $1 \mathrm{~mL}$ de medio de lavado por punto y se procedió a realizar las estimulaciones periódicas correspondientes (el tiempo de estimulación se indica en cada experimento) con $10 \mu \mathrm{g}$ del anticuerpo monoclonal anti-CD3 (clon UCTH1, Merk Millipore) por punto incubando las muestras en un baño a $37^{\circ} \mathrm{C}$. Para lisar rápidamente las células, una vez finalizado el periodo de estimulación se añadieron $250 \mu \mathrm{L}$ de tampón de lisis RIPA 5 veces más concentrado (50 mM Tris- $\mathrm{HCl}, 750 \mathrm{mM} \mathrm{NaCl}, 5 \%$ Triton X-100, $5 \mathrm{mM} \mathrm{Na}_{3} \mathrm{VO}_{4}, 5 \mathrm{mM}$ $\mathrm{NaF}$ ) conteniendo una mezcla de inhibidores de proteasas (Complete, Roche) por cada mililitro de células. Después de agitar las células en un vortex, los tubos se introdujeron inmediatamente en hielo durante 5 minutos. Para eliminar los restos celulares, los lisados fueron centrifugados a $14.000 \mathrm{rpm}$ durante 10 minutos a $4^{\circ} \mathrm{C}$.

En el caso de las células COS-1 transfectadas con los vectores de expresión de las formas silvestres y mutantes de la proteína Vav1, se procedió a lavar las placas de células una vez con PBS frío para, posteriormente, lisarlas sobre hielo con $500 \mu \mathrm{L}$ de tampón de lisis RIPA (10 mM Tris- $\mathrm{HCl}, 150 \mathrm{mM} \mathrm{NaCl}, 1 \%$ Triton X-100, $1 \mathrm{mM} \mathrm{Na}_{3} \mathrm{VO}_{4}, 1 \mathrm{mM} \mathrm{NaF}$ ) conteniendo una mezcla de inhibidores de proteasas (Complete, Roche). Los lisados fueron recogidos y puestos en hielo durante $10 \mathrm{~min}$ para luego ser centrifugados a $14.000 \mathrm{rpm}$ durante 10 minutos a $4{ }^{\circ} \mathrm{C}$. A partir de aquí el procedimiento fue similar para ambas líneas celulares.

Después de la centrifugación, los sobrenadantes fueron transferidos a tubos nuevos y una alícuota de cada lisado fue recogida añadiéndole tampón de muestra de Laemmli para el posterior análisis de la expresión de proteínas por Western-blot. A cada sobrenadante se le añadieron $2 \mu \mathrm{L}$ del anticuerpo policlonal de conejo anti-Vav1 (generado anteriormente en nuestro laboratorio) y se incubaron en rotación durante 2 horas a $4{ }^{\circ} \mathrm{C}$. En los experimentos de inmunoprecipitación de las proteínas PLC 1 y Slp76, se añadieron $5 \mu \mathrm{L}$ del anticuerpo anti-PLC $\gamma 1$ o anti-Slp76 (Cell Signaling) por cada mililitro de lisado. Transcurrido ese tiempo se añadieron $45 \mu \mathrm{L}$ de una suspensión de una matriz Gammabind G-sefarosa (GE Healthcare) al 50\% en PBS por tubo. Tras 45 minutos de incubación a $4{ }^{\circ} \mathrm{C}$ en rotación, la matriz fue sedimentada por centrifugación a $14.000 \mathrm{rpm}$ durante 1 minuto a $4{ }^{\circ} \mathrm{C}$ y lavada tres veces con el tampón de lisis RIPA. Cada matriz fue resuspendida en $30 \mu \mathrm{L}$ de tampón de muestra de 
Laemmli y, posteriormente hervida durante 5-10 minutos. Tanto los inmunoprecipitados como los lisados totales se sometieron a una electroforesis en un gel grande de poliacrilamida al 8\%, seguida de Western-blot. Para detectar la fosforilación de Vav1 en estos experimentos, se utilizaron anticuerpos policlonales de conejo, fosfoespecíficos para distintos residuos de Vav1 (generados por Invitrogen a petición de nuestro laboratorio) a la dilución adecuada en cada caso, así como el anticuerpo monoclonal de ratón antifosfotirosina (PY99Santa Cruz, 1:1.000) para analizar la fosforilación general de Vav1 en tirosinas. La cantidad total de proteína Vav1 inmunoprecipitada fue detectada usando el mismo anticuerpo policlonal anti-Vav1 usado para la inmunoprecipitación (dilución 1:10.000). Para detectar los anticuerpos primarios, se usó proteína A conjugada con la peroxidada de rábano (GE Healthcare, 1:5.000) salvo en el caso del anticuerpo primario antifosfotirosina que se utilizó el anticuerpo secundario anti-lgG de ratón conjudado también con la peroxidada de rábano (GE Healthcare, 1:5.000).

\section{PROGRAMAS INFORMÁTICOS}

El procesamiento de las imágenes obtenidas mediante microscopía confocal se llevó acabo con el software LAS AF versión 2.6.0.7266 (Leica). El montaje y la composición final de las figuras se realizó con el programa Canvas 9, versión 9.0.4 (ACD Systems). 


En este trabajo se han abordado diversos aspectos de la regulación de la proteína Vav1 en el contexto de las rutas de señalización asociadas a linfocitos. En primer lugar, se ha descubierto que la correcta autoinhibición de las proteínas Vav requiere la interacción coordinada de las regiones $\mathrm{CH}-\mathrm{Ac}$ y $\mathrm{CSH} 3$ con el núcleo central catalítico (Figura 45A).

La estructura autoinhibida restringe las señales dependientes e independientes de la actividad catalítica de estas proteínas, como se evidencia de la estimulación simultánea de las respuestas asociadas a JNK y NF-AT bajo la liberación de la inhibición mediada por el CSH3 usando técnicas de mutagénesis. En esta estructura, los dominios $\mathrm{CH}-\mathrm{Ac}$ parecen principalmente implicados en la oclusión del sitio catalítico $y$, en menor medida, en la estabilización de la interacción intramolecular CSH3/Vav1 (Figura 45B,C). Por el contrario, la interacción mediada por el CSH3 no bloquea la actividad catalítica y parece funcionar como un cierre adicional que favorece la estabilidad de la interacción $\mathrm{CH}-\mathrm{Ac} /$ núcleo catalítico. Además, este mecanismo de regulación a está conservado en esta familia de proteínas, al menos hasta $D$. melanogaster. De acuerdo con estas ideas, este trabajo ha demostrado que las proteínas con truncaciones de la región $\mathrm{N}$-terminal son constitutivamente activas, a pesar de que mantienen la interacción intramolecular CSH3/Vav1 (Figura 45B). Además, se ha visto que la eliminación de la inhibición mediada por el CSH3 lleva a la activación constitutiva de las proteínas Vav incluso bajo condiciones que no favorecen la liberación dependiente de fosforilación de la región $\mathrm{CH}-\mathrm{Ac}$ del núcleo catalítico (e.j., células Jurkat deficientes en el TCR) (Figura 45B,C).

Las dos contribuciones inhibitorias son eliminadas por el efecto sinérgico de la fosforilación de varios residuos de tirosina (Figura 45F), permitiendo de este modo correlacionar la fosforilación de estas proteínas con la adquisición de su completa funcionalidad en el desarrollo de respuestas celulares durante la transducción de señales.

En consecuencia, este modelo de activación podría generar diferentes estados conformacionales que controlasen la correcta estimulación espacio-temporal de estas proteínas. Además, el requerimiento de múltiples sitios de fosforilación para la activación de estas proteínas ofrece un mecanismo de garantía para evitar la activación errónea derivada de la fosforilación estocástica de las proteínas Vav en un solo sitio de fosforilación. El ruido generado por este tipo de fosforilación existe en células $T$, tal como se evidencia por la fosforilación detectada en Vav1 bajo condiciones basales (e. j., ver Capítulo 1, Figura 25, pág. 85). La participación de múltiples sitios de fosforilación en el proceso de activación podría contribuir potencialmente a una regulación precisa de la intensidad y/o diversidad de la 


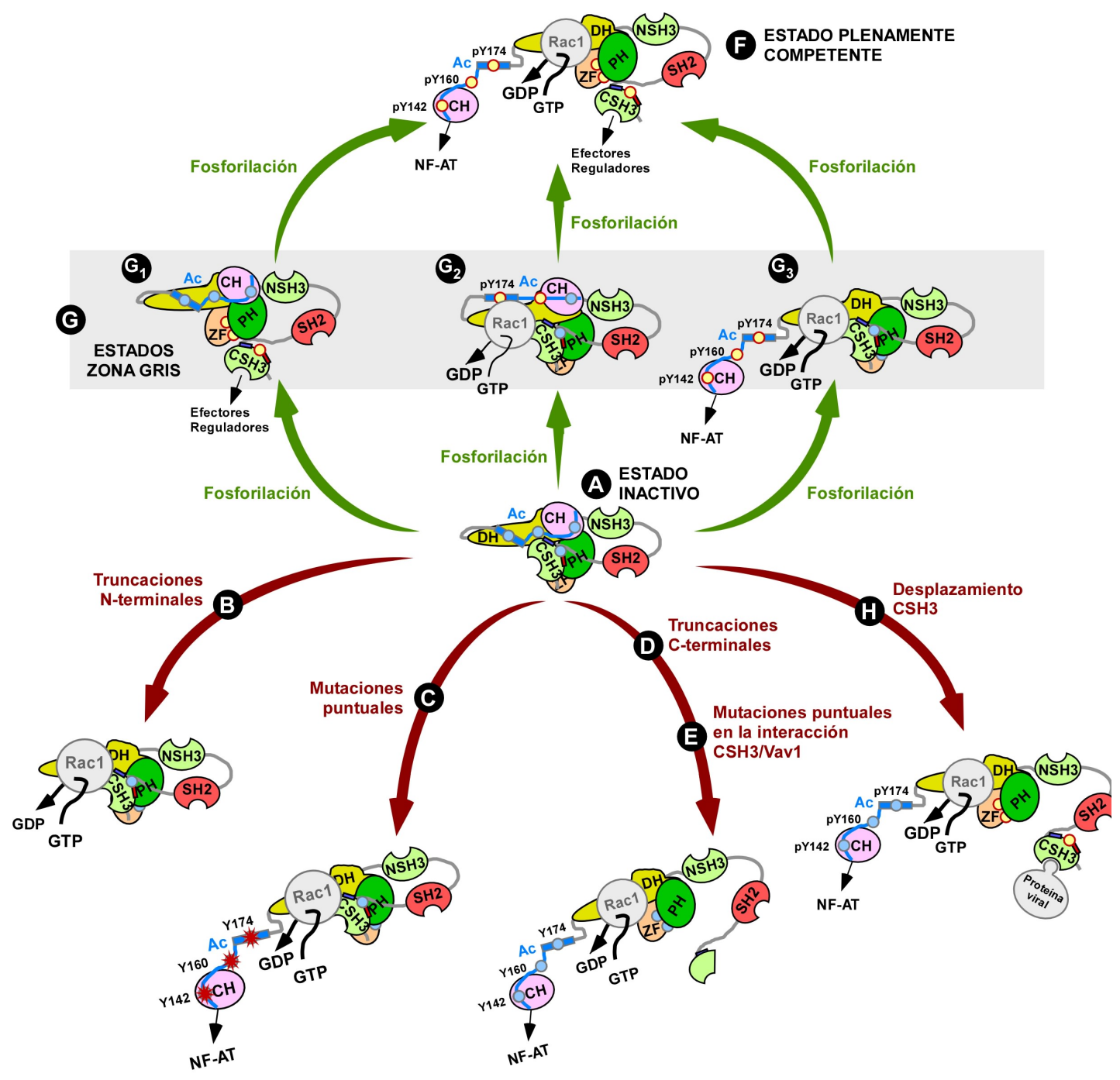

Figura 45. Nuevo modelo propuesto para la regulación de la familia de proteínas Vav. En este esquema se muestran los mecanismos fisiológicos (flechas verdes) e inducidos (flechas rojas) que llevan a su activación. Rectángulo azul claro, hélice $\alpha$ que contiene los sitios de fosforilación de la región Ac, $Y^{142}, Y^{160}$ y $Y^{174}$; rectángulos en rojo y azul oscuro, motivos de interacción no canónica con el CSH3 de la familia Vav; puntos azul claro, residuos de tirosina no fosforilados; puntos amarillos, residuos de tirosina fosforilados (p); asteriscos rojos, mutaciones en los sitios de fosforilación de la región Ac. Los movimientos de las regiones $\mathrm{CH}-\mathrm{Ac}$ y NSH3-SH2$\mathrm{CSH} 3$ representados durante los procesos de activación son hipotéticos. Pueden existir otros "estados de zona gris" a parte de los representados $\left(\mathrm{G}_{1}-\mathrm{G}_{3}\right)$ si se tienen en cuenta las posibles permutaciones de los residuos fosforilados y/o proteínas de unión. Para simplificar, no se han incluido la interacción de las proteínas Vav con otras moléculas de señalización. El viejo modelo de regulación se puede encontrar en la Figura 3.

señalización dependiendo de la fuerza, duración, o tipo de estímulos extracelulares recibidos por las células. En el mismo contexto, el hecho de que la mutación del sitio de unión canónica a PRR del CSH3 (CSH3 ${ }^{\mathrm{P} 833 \mathrm{~L}}$ ) aumente la interacción CSH3/Vav1 (ver Capítulo 1, 
Figura 13D, pág. 67) sugiere que la asociación entre las proteínas Vav fosforiladas y proteínas con PRR podría impedir el retorno al estado autoinhibido y, en consecuencia, prolongar la señalización de las proteínas Vav bajo condiciones de estimulación o localizaciones subcelulares específicas (Figura 45F). Esto podría explicar la gran diversidad funcional y estructural encontrada en las proteínas que se unen canónicamente a los dominios $\mathrm{SH} 3$ de la familia Vav (Bustelo, 2000; 2012). La dependencia de la interacción mediada por el CSH3 para mantener el estado autoinhibido tiene también un lado negativo, ya que puede llevar una activación errónea a través de mecanismos que desplazan al SH3. En este contexto, merece la pena recalcar que el dominio CSH3 de Vav1 es una diana de señalización común para Nef y M2, dos proteínas ricas en prolinas que están codificadas por los virus HIV y gammaherpesvirus, respectivamente (Fackler et al, 1999; Rodrigues et al, 2006). Dicho mecanismo podría de hecho explicar el caso de Nef, ya que resultados previos han mostrado que podría estimular a las proteínas Vav de manera independiente a la fosforilación (Fackler et al, 1999). Estas observaciones apoyan además la hipótesis de que este mecanismo de regulación a través del CSH3 podría determinar la especificidad de respuesta de las proteínas Vav en función del tipo celular ya que las proteínas Vav1, Vav2 y Vav3 no sólo presentan distintos patrones de expresión tisular sino también de interacción con otras proteínas a través de sus dominios CSH3.

Procesos de autoinhibición mediados por dominios $\mathrm{SH} 3$ han sido descritos en otros GEFs de Rho, incluyendo intersectina (Ahmad and Lim, 2010; Kintscher et al, 2010), kalirin (Schiller et al, 2006), y los miembros de las familias ArhGEF4 (también conocido como Asef) (Mitin et al, 2007; Murayama et al, 2007) y ArhGEF5 (Yohe et al, 2008). El mecanismo descrito aquí presenta algunas similitudes, pero también diferencias significativas, con la autoinhibición mediada por SH3 en las proteínas de las familias ArhGEF4 y ArhGEF5. La autoinhibición de ArhGEF4 es mediada por interacciones no canónicas de su SH3 N-terminal con residuos localizados en la región DH-PH, incluyendo la hélice $\alpha 6$ de su dominio DH (Mitin et al, 2007; Murayama et al, 2007). En este caso, sin embargo, el SH3 bloquea directamente el sitio de unión de las GTPasas en vez de estabilizar un segundo motivo inhibidor como en nuestro caso (Mitin et al, 2007; Murayama et al, 2007). El proceso de activación es también diferente, ya que recae exclusivamente sobre la liberación del SH3 a través de la interacción de otras proteínas con el motivo adyacente (Mitin et al, 2007). La familia de proteínas ArhGEF5 tienen, al igual que las proteínas Vav, un sistema de autoinhibición doble consistente en un motivo inhibitorio basado en tirosinas y una región CSH3 (Yohe et al, 2008). Sin embargo, la inhibición mediada por el CSH3 está basado en el reconocimiento de PRR localizadas fuera 
del casete DH-PH (Yohe et al, 2008). El mecanismo por el cual esta interacción se elimina durante la transducción de señales todavía es desconocido. Estos resultados indican que las subfamilias de GEFs de Rho regulados por SH3 utilizan mecanismos idiosincráticos para transitar entre sus estados autoinhibidos y activos.

A estado inactivo
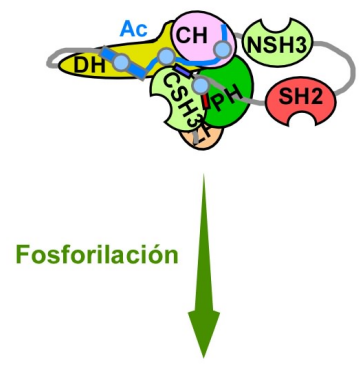

B Estados PARCIALMENTE ACtivos
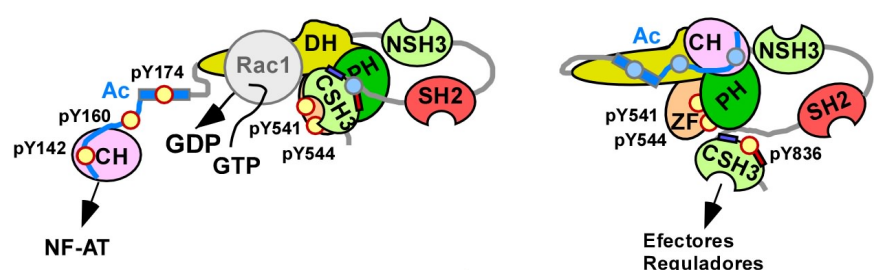

Fosforilación

C estado activo

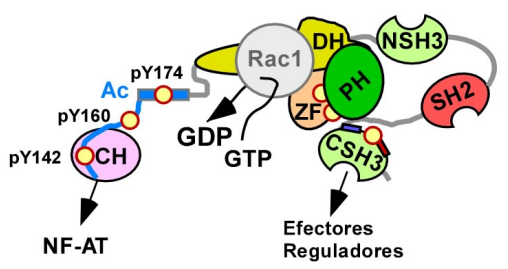

Figura 46. Esquema representativo de la cascada secuencial de fosforilación que lleva a la completa activación de Vav1 en linfocitos. En este esquema se muestran los distintos estados conformacionales derivados de la fosforilación (flechas verdes) de los residuos de las regiones Ac, ZF y SH3 durante la cascada de señalización. El significado de las formas y colores representados se describen en la Figura 45. Los movimientos de las regiones $\mathrm{CH}-\mathrm{Ac}$ y NSH3-SH2-CSH3 representados durante los procesos de activación son hipotéticos.

En cuanto al proceso por el cual se eliminan las interacciones inhibitorias, lo más lógico era pensar que fuese por fosforilación en tirosinas. Hasta ahora sólo se conocían tres tirosinas $\left(Y^{142}, Y^{160}, Y^{174}\right)$ implicadas en la activación de Vav1. Este estudio ha permitido descubrir que otras tirosinas localizadas en las regiones $\mathrm{ZF}\left(\mathrm{Y}^{541}, \mathrm{Y}^{544}\right)$ y $\mathrm{CSH} 3\left(\mathrm{Y}^{836}\right)$ también participan en la 
regulación de Vav1. También se ha observado que la fosforilación de unos residuos favorece la de otros sugiriendo la existencia de una cascada secuencial de fosforilación de la proteína Vav1 durante la transducción de señales, que termina en la completa activación de la proteína Vav1 y en el desarrollo su actividad biológica (Figura 46). Según este modelo, estos aminoácidos serían necesarios para la apertura de la estructura auntoinhibida (Figura 46A). La fosforilación de las regiones Ac y CSH3 no sólo contribuiría a la eliminación de las interacciones inhibitorias que permiten el desencadenamiento de la actividad GEF de Vav1, sino también al establecimiento de interacciones proteicas que permiten la puesta en marcha de las funciones adaptadoras de Vav1 que posibilitan el desarrollo de las respuestas celulares específicas de linfocitos (Figura 46B). Gracias a los resultados obtenidos en este trabajo, se puede especular sobre la existencia de conformaciones intermedias que serían reguladas por la acción de los aminoácidos identificados y que permitirían una regulación específica de las distintas funciones de Vav1 en linfocitos.

Para que la proteína Vav1 adquiera el estado completamente activo, es necesario, por tanto, la fosforilación de todos los residuos mencionados anteriormente ya que la fosforilación simultánea de estos residuos tiene un efecto sinérgico sobre la activación de la proteína Vav1 (Figura 46C). Por tanto, este estado de fosforilación va a facilitar la adquisición de la conformación estructural completamente activa y adecuada para el desarrollo de las actividades biológicas de Vav1, tanto dependientes como independientes de su actividad catalítica, en el contexto linfocitario (Figura 46C). Esta fosforilación secuencial podría verse favorecida además por la interacción de las regiones $\mathrm{N}$ - y C-terminales con otras proteínas que facilitarían también la apertura de la molécula para su completa activación.

Nuestro trabajo también ha permitido establecer el papel de los elementos de la ruta de señalización de linfocitos en el proceso de activación de la proteína Vav1. Según modelos anteriores, la activación de la proteína Vav1 por fosforilación de tirosinas parecía estar mediada únicamente por la acción de Zap70 (Figura 47) (Michel et al 1998; Salojin et al, $1999 ; 2000)$. Según esto, la estimulación de este receptor provoca la activación de la quinasa de la familia Src Lck que, a su vez, activa por fosforilación a Zap70 siendo ésta la responsable principal de la activación de Vav1 (Figura 47). Los experimentos con células Jurkat deficientes han permitido establecer un nuevo modelo de activación de la proteína Vav1 en linfocitos (Figura 47). Según el nuevo modelo, la estimulación del TCR provoca la activación de las quinasas de la familia Src, entre las que se encuentra Lck (Figura 47). Una vez activadas, Lck y otra Src quinasa son capaces de activar directamente a Vav1 por fosforilación en 
tirosinas. Además, aunque en menor medida, Lck activa indirectamente a Vav1 a través de Zap70 (Figura 47).

La otra Src quinasa implicada en la activación de Vav1 aún no ha sido identificada (Figura 47). Durante la cascada de señalización en células $T$, las quinasas encargadas principalmente de la activación de muchas de las moléculas de señalización reclutadas a la membrana plasmática son las quinasas de la familia Src, Lck y Fyn. Existen evidencias previas de la asociación física de la proteína Vav1 con Fyn (Michel et al 1998) y de la capacidad de esta quinasa para fosforilar a Vav1 (Huang et al, 2000; Raab et al, 1997). Además, se ha demostrado que la proteína M2 del gammaherpesvirus se sirve del complejo formado por Fyn y Vav1 para prolongar el estado de latencia de este virus en linfocitos (Pires de Miranda et al, 2008). Según estas observaciones, es más que probable que la quinasa Src desconocida sea Fyn, aunque sería necesario un estudio más detallado para confirmar la implicación de esta quinasa en la fosforilación de Vav1.

Por tanto, las proteínas responsables de la activación de Vav1 en linfocitos T son principalmente las quinasas de la familia Src, Lck y Fyn y, en menor medida, Zap70. Además, según este trabajo, la presencia de la proteína transmembrana Lat es requerida para la óptima activación de Vav1 y su reclutamiento a la membrana plasmática.

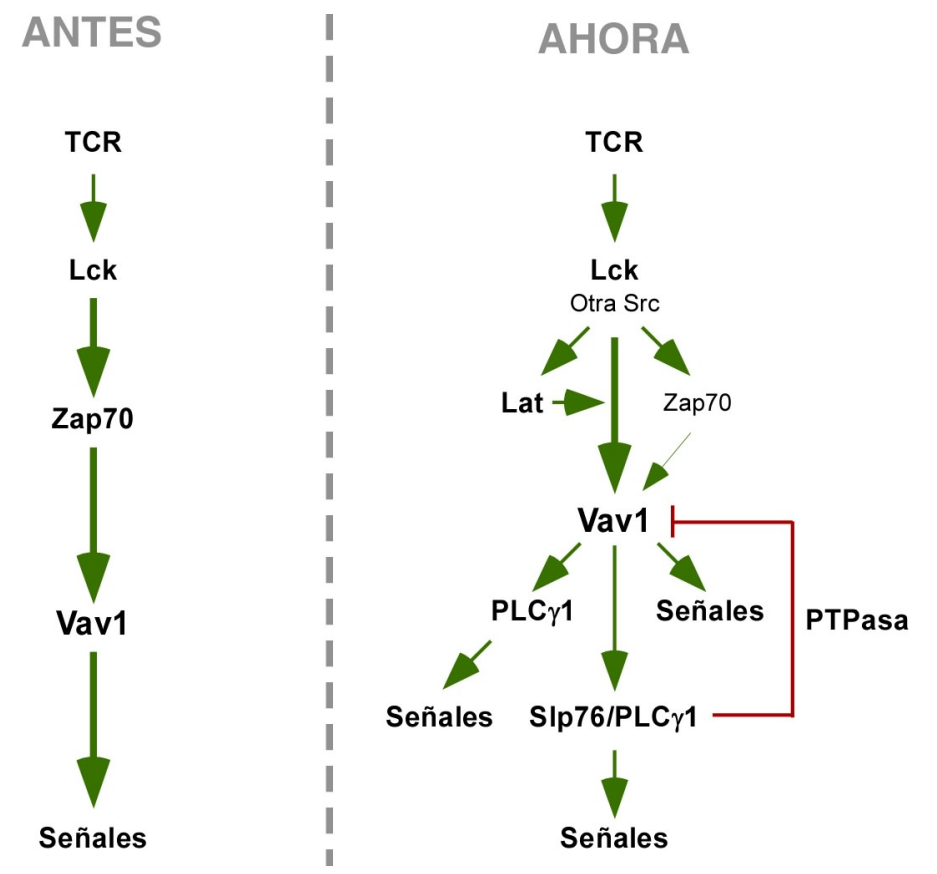

Figura 47. Esquema comparativo de los modelos de activación de la proteína Vav1 anterior y posterior a este estudio. A la izquierda, se encuentra el modelo más aceptado hasta ahora (antes) y, a la derecha, el modelo propuesto a partir de los resultados obtenidos en este trabajo de tesis. Las flechas verdes indican el sentido de la cascada de señalización de la ruta del TCR reflejando las proteínas que contribuyen a la activación de otras. Su grosor también indica la magnitud de esa contribución. La línea roja indica el efecto negativo de una proteína tirosina fosfatasa sobre la activación de Vav1 en linfocitos. 
Un hallazgo inesperado de este trabajo ha sido la existencia de un mecanismo de retroalimentación negativa en el ciclo de activación/inactivación de Vav1 mediado por las proteínas Slp76 y PLC $\gamma$ (Figura 47). Según los resultados obtenidos, esta regulación no está relacionada con la actividad canónica de estas proteínas por lo que probablemente esté ligada a sus funciones adaptadoras. La hipótesis que se maneja en este momento es la existencia de una proteína tirosina fosfatasa (PTPasa) que devolvería a la proteína Vav1 a su estado inactivo no fosforilado una vez terminada la estimulación, manteniéndola en dicho estado hasta la llegada de un nuevo estímulo que inicie otra vez la cascada de señalización (Figura 47). Esta PTPasa necesitaría la presencia de las proteínas SIp76 y PLC $\gamma$ para desarrollar su actividad inhibidora sobre Vav1. Probablemente, estas proteínas estarán relacionadas con la activación de esta PTPasa y/o facilitarán la localización subcelular de Vav1 adecuada para que sea sometida a la acción de dicha PTPasa.

Las PTPasas son las enzimas encargadas de eliminar los grupos fosfato de los residuos de tirosina fosforilados en determinadas proteínas (Mustelin et al, 2005). Estas enzimas son componentes reguladores clave en las rutas de señalización celular y de control del ciclo celular ya que permiten mantener los niveles adecuados de fosforilación en las proteínas implicadas en dichos procesos celulares (Mustelin et al, 2005). De los al rededor de 107 genes que codifican para PTPasas existentes en el genoma humano, las células T expresan al menos 45 PTPasas diferentes (Mustelin et al, 2005). La mayor parte de estas enzimas se localizan próximas a la membrana plasmática o en el citoplasma (Mustelin et al, 2005). Teniendo en cuenta estos datos, las siguientes PTPasas fueron escogidas como posibles candidatas: Shp1, Shp2, LYP, PTP-MEG1 y PTP1B. Se ha demostrado que las tres primeras candidatas se unen a la proteína Vav1 (Kon-Kozlowski et al, 1996; Kwon et al, 2005; Pani et al, 1996; Wu et al, 2006). Utilizando lentivirus con shRNAs contra estas PTPasas, se generaron líneas de Jurkat knockdown y se comprobó que la ausencia de dichas fosfatasas no afectaba al estado de fosforilación de la proteína Vav1 endógena en ausencia de estímulo (datos no mostrados). Curiosamente, en la línea knock-down de LYP se observó un aumento de los niveles de fosforilación de Vav1 bajo estimulación, pudiendo estar esta PTPasa implicada en la regulación del estado de fosforilación de Vav1 una vez iniciada la cascada de señalización y no en condiciones basales. Aunque la ausencia de estas PTPasas no afecta a la fosforilación basal de Vav1, no se puede descartar que tengan funciones redundantes siendo capaces de contrarrestar los efectos producidos por la carencia de una de ellas. Otra explicación posible es que sea otra PTPasa aún no identificada la que esté cumpliendo esta función reguladora del estado de fosforilación basal de la proteína Vav1 en linfocitos T. 
En resumen, este trabajo de tesis ha permitido detallar en profundidad los diferentes pasos de regulación que sigue la proteína Vav1 en su proceso de activación, los mecanismos que regulan dicho proceso durante la cascada de señalización y las proteínas que garantizan que se lleve a cabo de forma correcta. Este mayor conocimiento sobre la regulación de las funciones de la proteína Vav1 podría ser de utilidad en un futuro para el desarrollo de estrategias terapéuticas en enfermedades relacionadas con el sistema inmune así como en procesos tumorales.

El estudio realizado supone un gran avance en el conocimiento de la regulación de las funciones de la proteína Vav1 en linfocitos. Estudios cristalográficos adicionales sobre la estructura autoinhibida de la proteína completa serían de gran utilidad para confirmar estos resultados. Además, sería interesante realizar estudios en modelos de ratón que permitiesen analizar en profundidad los efectos de la regulación la proteína Vav1 en la fisiología y desarrollo del sistema inmunológico. 

1. La estructura autoinhibida de la proteína Vav1 se establece gracias a la interacción coordinada de las regiones $\mathbf{N}$ - y C-terminales con el núcleo central catalítico de esta proteína. Esta inhibición impide el desarrollo de las respuestas celulares asociadas a la proteína Vav1 en linfocitos.

2. El dominio CSH3 inhibe la actividad de esta proteína mediante su unión en cis a la región DH-PH. La inhibición de Vav1 es mediada por la acción cooperativa de residuos del $R T$-loop y el extremo C-terminal del CSH3.

3. La activación fisiológica de la proteína Vav1 se produce a través de efectos sinérgicos de la fosforilación de tirosinas localizadas en las regiones Ac, ZF y CSH3.

4. Las mutaciones en estos sitios de fosforilación afectan diferencialmente a la activación de Rac1/JNK y NF-AT, sugiriendo la existencia de distintos estados conformacionales de la proteína Vav1 que regulen específicamente las respuestas celulares asociadas a ésta.

5. La activación de la proteína Vav1 es principalmente mediada por la acción cooperativa de las quinasas de la familia Src $y$, en menor medida, por la quinasa Zap70. La presencia de la proteína Lat es esencial para la óptima activación de la proteína Vav1 y para el reclutamiento de esta a la membrana plasmática.

6. Existe un mecanismo de regulación negativa de la activación de la proteína Vav1 en el que está implicada un PTPasa aún no identificada. Para el desarrollo de este mecanismo es necesaria la presencia de las proteínas SIp76 y PLC $\gamma 1$. 

BIBLIOGRAFÍA 

Aghazadeh, B., Lowry, W. E., Huang, X. Y. and Rosen, M. K. (2000). Structural basis for relief of autoinhibition of the Dbl homology domain of proto-oncogene Vav by tyrosine phosphorylation. Cell 102(5): 625-33.

Ahmad, K. F. and Lim, W. A. (2010). The minimal autoinhibited unit of the guanine nucleotide exchange factor intersectin. PLoS One 5(6): e11291.

Ambrogio, C., Voena, C., Manazza, A. D., Martinengo, C., Costa, C., Kirchhausen, T., Hirsch, E., Inghirami, G. and Chiarle, R. (2008). The anaplastic lymphoma kinase controls cell shape and growth of anaplastic large cell lymphoma through Cdc42 activation. Cancer Res 68(21): 8899-907.

Aoukaty, A. and Tan, R. (2005). Role for glycogen synthase kinase-3 in NK cell cytotoxicity and X-linked lymphoproliferative disease. J Immunol 174(8):4551-8.

Arana, E., Vehlow, A., Harwood, N. E., Vigorito, E., Henderson, R., Turner, M., Tybulewicz, V. L. and Batista, F. D. (2008). Activation of the small GTPase Rac2 via the B cell receptor regulates $\mathrm{B}$ cell adhesion and immunological-synapse formation. Immunity $\mathbf{2 8 ( 1 ) :}$ 88-99.

Ardouin, L., Bracke, M., Mathiot, A., Pagakis, S. N., Norton, T., Hogg, N. and Tybulewicz, V. L. (2003). Vav1 transduces TCR signals required for LFA-1 function and cell polarization at the immunological synapse. Eur J Immunol 33(3): 790-7.

Arrieumerlou, C., Randriamampita, C., Bismuth, G. and Trautmann, A. (2000). Rac is involved in early TCR signaling. J Immunol 165(6): 3182-9.

Bartolome, R. A., Molina-Ortiz, I., Samaniego, R., Sanchez-Mateos, P., Bustelo, X. R. and Teixido, J. (2006). Activation of Vav/Rho GTPase signaling by CXCL12 controls membranetype matrix metalloproteinase-dependent melanoma cell invasion. Cancer Res 66(1): 248-58.

Bassermann, F., Jahn, T., Miething, C., Seipel, P., Bai, R. Y., Coutinho, S., Tybulewicz, V. L., Peschel, C. and Duyster, J. (2002). Association of Bcr-Abl with the proto-oncogene Vav is implicated in activation of the Rac-1 pathway. J Biol Chem 277(14): 12437-45.

Beckerle, M. C. (1997). Zyxin: zinc fingers at sites of cell adhesion. Bioessays 19(11): 949-57. 
Bertagnolo, V., Brugnoli, F., Marchisio, M., Celeghini, C., Carini, C. and Capitani, S. (2004). Association of PI 3-K with tyrosine phosphorylated Vav is essential for its activity in neutrophil-like maturation of myeloid cells. Cell Signal 16(4):423-33.

Bertagnolo, V., Marchisio, M., Volinia, S., Caramelli, E. and Capitani, S. (1998). Nuclear association of tyrosine-phosphorylated Vav to phospholipase C-gamma1 and phosphoinositide 3-kinase during granulocytic differentiation of HL-60 cells. FEBS Lett 441 (3): 480-4.

Betz, R., Sandhoff, K., Fischer, K. D. and van Echten-Deckert, G. (2003). Detection and identification of Vav1 protein in primary cultured murine cerebellar neurons and in neuroblastoma cells (SH-SY5Y and Neuro-2a). Neurosci Lett 339(1):37-40.

Bhavsar, P. J., Vigorito, E., Turner, M. and Ridley, A. J. (2009). Vav GEFs regulate macrophage morphology and adhesion-induced Rac and Rho activation. Exp Cell Res 315(19): 3345-58.

Billadeau, D. D., Mackie, S. M., Schoon, R. A. and Leibson, P. J. (2000). Specific subdomains of Vav differentially affect T cell and NK cell activation. J Immuno/ 164(8): 3971 81.

Blanchet, F., Cardona, A., Letimier, F. A., Hershfield, M. S. and Acuto, O. (2005). CD28 costimulatory signal induces protein arginine methylation in T cells. J Exp Med 202(3):371-7.

Boncristiano, M., Paccani, S. R., Barone, S., Ulivieri, C., Patrussi, L., Ilver, D., Amedei, A., D'Elios, M. M., Telford, J. L. and Baldari, C. T. (2003). The Helicobacter pylori vacuolating toxin inhibits T cell activation by two independent mechanisms. J Exp Med 198(12): 1887-97.

Booden, M. A., Campbell, S. L. and Der, C. J. (2002). Critical but distinct roles for the pleckstrin homology and cysteine-rich domains as positive modulators of Vav2 signaling and transformation. Mol Cell Biol 22(8):2487-97.

Bubeck Wardenburg, J., Pappu, R., Bu, J. Y., Mayer, B., Chernoff, J., Straus, D. and Chan, A. C. (1998). Regulation of PAK activation and the T cell cytoskeleton by the linker protein SLP-76. Immunity 9(5): 607-16.

Bustelo, X. R. (2000). Regulatory and signaling properties of the Vav family. Mol Cell Biol 20(5): 1461-77.

Bustelo, X. R. (2001). Vav proteins, adaptors and cell signaling. Oncogene 20(44): 6372-81. 
Bustelo, X. R. (2012). Vav family. Encyclopedia of Signaling Molecules. (ed. Choy, S.) 1963-1976 (Springer, New York).

Bustelo, X. R. and Barbacid, M. (1992). Tyrosine phosphorylation of the vav proto-oncogene product in activated B cells. Science 256(5060): 1196-9.

Bustelo, X. R. and Couceiro, J. R. (2008). Vav3. UCSD Nature Mol. Pages (doi: 10.1038/mp.a002362.002301)

Bustelo, X. R., Crespo, P., Lopez-Barahona, M., Gutkind, J. S. and Barbacid, M. (1997). Cbl-b, a member of the Sli-1/c-Cbl protein family, inhibits Vav-mediated c-Jun N-terminal kinase activation. Oncogene 15(21): 2511-20.

Bustelo, X. R., Ledbetter, J. A. and Barbacid, M. (1992). Product of vav proto-oncogene defines a new class of tyrosine protein kinase substrates. Nature 356(6364):68-71.

Bustelo, X. R., Rubin, S. D., Suen, K. L., Carrasco, D. and Barbacid, M. (1993). Developmental expression of the vav protooncogene. Cell Growth Differ 4(4): 297-308.

Bustelo, X. R., Suen, K. L., Michael, W. M., Dreyfuss, G. and Barbacid, M. (1995). Association of the vav proto-oncogene product with poly(rC)-specific RNA-binding proteins. Mol Cell Biol 15(3): 1324-32.

Caloca, M. J., Zugaza, J. L. and Bustelo, X. R. (2008). Mechanistic analysis of the amplification and diversification events induced by Vav proteins in B-lymphocytes. J Biol Chem 283(52): 36454-64.

Caloca, M. J., Zugaza, J. L., Matallanas, D., Crespo, P. and Bustelo, X. R. (2003). Vav mediates Ras stimulation by direct activation of the GDP/GTP exchange factor Ras GRP1. $E M B O J$ 22(13):3326-36.

Cella, M., Fujikawa, K., Tassi, I., Kim, S., Latinis, K., Nishi, S., Yokoyama, W., Colonna, M. and Swat, W. (2004). Differential requirements for Vav proteins in DAP10- and ITAMmediated NK cell cytotoxicity. J Exp Med 200(6): 817-23.

Chan, G., Hanke, T. and Fischer, K. D. (2001). Vav-1 regulates NK T cell development and NK cell cytotoxicity. Eur J Immunol 31(8):2403-10. 
Charvet, C., Canonigo, A. J., Becart, S., Maurer, U., Miletic, A. V., Swat, W., Deckert, M. and Altman, A. (2006). Vav1 promotes T cell cycle progression by linking TCR/CD28 costimulation to FOXO1 and p27kip1 expression. J Immunol 177(8):5024-31.

Choudhary, C., Kumar, C., Gnad, F., Nielsen, M. L., Rehman, M., Walther, T. C., Olsen, J. V. and Mann, M. (2009). Lysine acetylation targets protein complexes and co-regulates major cellular functions. Science 325(5942): 834-40.

Chrencik, J. E., Brooun, A., Zhang, H., Mathews, II, Hura, G. L., Foster, S. A., Perry, J. J., Streiff, M., Ramage, P., Widmer, H., Bokoch, G. M., Tainer, J. A., Weckbecker, G. and Kuhn, P. (2008). Structural basis of guanine nucleotide exchange mediated by the T-cell essential Vav1.J Mol Biol 380(5): 828-43.

Citterio, C., Menacho-Marquez, M., Garcia-Escudero, R., Larive, R. M., Barreiro, O., Sanchez-Madrid, F., Paramio, J. M. and Bustelo, X. R. (2012). The rho exchange factors vav2 and vav3 control a lung metastasis-specific transcriptional program in breast cancer cells. Sci Signal 5(244): ra71.

Colucci, F., Rosmaraki, E., Bregenholt, S., Samson, S. I., Di Bartolo, V., Turner, M., Vanes, L., Tybulewicz, V. and Di Santo, J. P. (2001). Functional dichotomy in natural killer cell signaling: Vav1-dependent and-independent mechanisms. J Exp Med 193(12): 1413-24.

Coppola, J., Bryant, S., Koda, T., Conway, D. and Barbacid, M. (1991). Mechanism of activation of the vav protooncogene. Cell Growth Differ 2(2): 95-105.

Costello, P. S., Walters, A. E., Mee, P. J., Turner, M., Reynolds, L. F., Prisco, A., Sarner, N., Zamoyska, R. and Tybulewicz, V. L. (1999). The Rho-family GTP exchange factor Vav is a critical transducer of T cell receptor signals to the calcium, ERK, and NF-kappaB pathways. Proc Natl Acad Sci U S A 96(6): 3035-40.

Couceiro, J. R., Martin-Bermudo, M. D. and Bustelo, X. R. (2005). Phylogenetic conservation of the regulatory and functional properties of the Vav oncoprotein family. Exp Cell Res 308(2): 364-80.

Cremasco, V., Graham, D. B., Novack, D. V., Swat, W. and Faccio, R. (2008). Vav/Phospholipase Cgamma2-mediated control of a neutrophil-dependent murine model of rheumatoid arthritis. Arthritis Rheum 58(9):2712-22. 
Crespo, P., Bustelo, X. R., Aaronson, D. S., Coso, O. A., Lopez-Barahona, M., Barbacid, M. and Gutkind, J. S. (1996). Rac-1 dependent stimulation of the JNK/SAPK signaling pathway by Vav. Oncogene 13(3): 455-60.

Crespo, P., Schuebel, K. E., Ostrom, A. A., Gutkind, J. S. and Bustelo, X. R. (1997). Phosphotyrosine-dependent activation of Rac-1 GDP/GTP exchange by the vav protooncogene product. Nature 385(6612): 169-72.

Critchley, D. R. (2000). Focal adhesions - the cytoskeletal connection. Curr Opin Cell Biol 12(1): 133-9.

Czech, M. P. (2000). PIP2 and PIP3: complex roles at the cell surface. Cell 100(6): 603-6.

David, R., Ma, L., Ivetic, A., Takesono, A., Ridley, A. J., Chai, J. G., Tybulewicz, V. L. and Marelli-Berg, F. M. (2009). T-cell receptor- and CD28-induced Vav1 activity is required for the accumulation of primed T cells into antigenic tissue. Blood 113(16): 3696-705.

Deckert, M., Tartare-Deckert, S., Couture, C., Mustelin, T. and Altman, A. (1996). Functional and physical interactions of Syk family kinases with the Vav proto-oncogene product. Immunity 5(6): 591-604.

Dekel, I., Russek, N., Jones, T., Mortin, M. A. and Katzav, S. (2000). Identification of the Drosophila melanogaster homologue of the mammalian signal transducer protein, Vav. FEBS Lett 472(1): 99-104.

Dennehy, K. M., Elias, F., Na, S. Y., Fischer, K. D., Hunig, T. and Luhder, F. (2007). Mitogenic CD28 signals require the exchange factor Vav1 to enhance TCR signaling at the SLP-76-Vav-Itk signalosome. J Immunol 178(3): 1363-71.

DerMardirossian, C. and Bokoch, G. M. (2005). GDls: central regulatory molecules in Rho GTPase activation. Trends Cell Biol 15(7): 356-63.

Dombroski, D., Houghtling, R. A., Labno, C. M., Precht, P., Takesono, A., Caplen, N. J., Billadeau, D. D., Wange, R. L., Burkhardt, J. K. and Schwartzberg, P. L. (2005). Kinaseindependent functions for Itk in TCR-induced regulation of Vav and the actin cytoskeleton. $J$ Immunol 174(3): 1385-92.

Doody, G. M., Bell, S. E., Vigorito, E., Clayton, E., McAdam, S., Tooze, R., Fernandez, C., Lee, I. J. and Turner, M. (2001). Signal transduction through Vav-2 participates in humoral immune responses and B cell maturation. Nat Immunol 2(6):542-7. 
Doody, G. M., Billadeau, D. D., Clayton, E., Hutchings, A., Berland, R., McAdam, S., Leibson, P. J. and Turner, M. (2000). Vav-2 controls NFAT-dependent transcription in B- but not T-lymphocytes. EMBO J 19(22):6173-84.

Doody, G. M., Justement, L. B., Delibrias, C. C., Matthews, R. J., Lin, J., Thomas, M. L. and Fearon, D. T. (1995). A role in B cell activation for CD22 and the protein tyrosine phosphatase SHP. Science 269(5221):242-4.

Dumont, C., Corsoni-Tadrzak, A., Ruf, S., de Boer, J., Williams, A., Turner, M., Kioussis, D. and Tybulewicz, V. L. (2009). Rac GTPases play critical roles in early T-cell development. Blood 113(17): 3990-8.

Eden, S., Rohatgi, R., Podtelejnikov, A. V., Mann, M. and Kirschner, M. W. (2002). Mechanism of regulation of WAVE1-induced actin nucleation by Rac1 and Nck. Nature 418(6899): 790-3.

Evans, G. A., Howard, O. M., Erwin, R. and Farrar, W. L. (1993). Interleukin-2 induces tyrosine phosphorylation of the vav proto-oncogene product in human T cells: lack of requirement for the tyrosine kinase Ick. Biochem J 294 ( Pt 2):339-42.

Fackler, O. T., Kremmer, E. and Mueller-Lantzsch, N. (1996). Evidence for the association of Nef protein with HIV-2 virions. Virus Res 46(1-2): 105-10.

Fackler, O. T., Luo, W., Geyer, M., Alberts, A. S. and Peterlin, B. M. (1999). Activation of Vav by Nef induces cytoskeletal rearrangements and downstream effector functions. Mol Cell 3(6): 729-39.

Fanto, M., Weber, U., Strutt, D. I. and Mlodzik, M. (2000). Nuclear signaling by Rac and Rho GTPases is required in the establishment of epithelial planar polarity in the Drosophila eye. Curr Biol 10(16): 979-88.

Fernandez-Zapico, M. E., Gonzalez-Paz, N. C., Weiss, E., Savoy, D. N., Molina, J. R., Fonseca, R., Smyrk, T. C., Chari, S. T., Urrutia, R. and Billadeau, D. D. (2005). Ectopic expression of VAV1 reveals an unexpected role in pancreatic cancer tumorigenesis. Cancer Cell 7(1):39-49.

Finco, T. S., Kadlecek, T., Zhang, W., Samelson, L. E. and Weiss, A. (1998). LAT is required for TCR-mediated activation of PLCgamma1 and the Ras pathway. Immunity 9(5):617-26. 
Fischer, K. D., Kong, Y. Y., Nishina, H., Tedford, K., Marengere, L. E., Kozieradzki, I., Sasaki, T., Starr, M., Chan, G., Gardener, S., Nghiem, M. P., Bouchard, D., Barbacid, M., Bernstein, A. and Penninger, J. M. (1998). Vav is a regulator of cytoskeletal reorganization mediated by the T-cell receptor. Curr Biol 8(10): 554-62.

Fischer, K. D., Zmuldzinas, A., Gardner, S., Barbacid, M., Bernstein, A. and Guidos, C. (1995). Defective T-cell receptor signalling and positive selection of Vav-deficient CD4+ CD8+ thymocytes. Nature 374(6521):474-7.

Foucault, I., Le Bras, S., Charvet, C., Moon, C., Altman, A. and Deckert, M. (2005). The adaptor protein $3 \mathrm{BP} 2$ associates with VAV guanine nucleotide exchange factors to regulate NFAT activation by the B-cell antigen receptor. Blood 105(3): 1106-13.

Fu, C., Turck, C. W., Kurosaki, T. and Chan, A. C. (1998). BLNK: a central linker protein in B cell activation. Immunity $\mathbf{9 ( 1 ) : 9 3 - 1 0 3 . ~}$

Fujii, H., Nakagawa, Y., Schindler, U., Kawahara, A., Mori, H., Gouilleux, F., Groner, B., Ihle, J. N., Minami, Y., Miyazaki, T. and et al. (1995). Activation of Stat5 by interleukin 2 requires a carboxyl-terminal region of the interleukin 2 receptor beta chain but is not essential for the proliferative signal transmission. Proc Natl Acad Sci U S A 92(12): 5482-6.

Fujikawa, K., Miletic, A. V., Alt, F. W., Faccio, R., Brown, T., Hoog, J., Fredericks, J., Nishi, S., Mildiner, S., Moores, S. L., Brugge, J., Rosen, F. S. and Swat, W. (2003). Vav1/2/3-null mice define an essential role for Vav family proteins in lymphocyte development and activation but a differential requirement in MAPK signaling in T and B cells. J Exp Med 198(10): 1595-608.

Fukumoto, R., Dundr, M., Nicot, C., Adams, A., Valeri, V. W., Samelson, L. E. and Franchini, G. (2007). Inhibition of T-cell receptor signal transduction and viral expression by the linker for activation of $\mathrm{T}$ cells-interacting $\mathrm{p} 12(\mathrm{I})$ protein of human T-cell leukemia/lymphoma virus type 1.J Viro/ 81(17): 9088-99.

Gakidis, M. A., Cullere, X., Olson, T., Wilsbacher, J. L., Zhang, B., Moores, S. L., Ley, K., Swat, W., Mayadas, T. and Brugge, J. S. (2004). Vav GEFs are required for beta2 integrindependent functions of neutrophils. J Cell Biol 166(2): 273-82.

Galandrini, R., Palmieri, G., Piccoli, M., Frati, L. and Santoni, A. (1999). Role for the Rac1 exchange factor Vav in the signaling pathways leading to NK cell cytotoxicity. J Immunol 162(6): 3148-52. 
Gao, C. and Blystone, S. D. (2009). A Pyk2-Vav1 complex is recruited to beta3-adhesion sites to initiate Rho activation. Biochem J 420(1):49-56.

Garcia, G. G. and Miller, R. A. (2009). Age-related changes in Ick-Vav signaling pathways in mouse CD4 T cells. Cell Immunol 259(1): 100-4.

Garcia-Bernal, D., Parmo-Cabanas, M., Dios-Esponera, A., Samaniego, R., Hernan, P. d. I. O. D. and Teixido, J. (2009). Chemokine-induced Zap70 kinase-mediated dissociation of the Vav1-talin complex activates alpha4beta1 integrin for T cell adhesion. Immunity 31(6): 95364.

Germani, A., Romero, F., Houlard, M., Camonis, J., Gisselbrecht, S., Fischer, S. and VarinBlank, N. (1999). hSiah2 is a new Vav binding protein which inhibits Vav-mediated signaling pathways. Mol Cell Biol 19(5):3798-807.

Geyeregger, R., Zeyda, M., Zlabinger, G. J., Waldhausl, W. and Stulnig, T. M. (2005). Polyunsaturated fatty acids interfere with formation of the immunological synapse. $J$ Leukoc Biol 77(5): 680-8.

Gismondi, A., Jacobelli, J., Strippoli, R., Mainiero, F., Soriani, A., Cifaldi, L., Piccoli, M., Frati, L. and Santoni, A. (2003). Proline-rich tyrosine kinase 2 and Rac activation by chemokine and integrin receptors controls NK cell transendothelial migration. J Immunol 170(6): 3065-73.

Gomez, M., Tybulewicz, V. and Cantrell, D. A. (2000). Control of pre-T cell proliferation and differentiation by the GTPase Rac-I. Nat Immunol 1(4):348-52.

Gomez, T. S., Hamann, M. J., McCarney, S., Savoy, D. N., Lubking, C. M., Heldebrant, M. P., Labno, C. M., McKean, D. J., McNiven, M. A., Burkhardt, J. K. and Billadeau, D. D. (2005). Dynamin 2 regulates T cell activation by controlling actin polymerization at the immunological synapse. Nat Immunol 6(3):261-70.

Graham, D. B., Robertson, C. M., Bautista, J., Mascarenhas, F., Diacovo, M. J., Montgrain, V., Lam, S. K., Cremasco, V., Dunne, W. M., Faccio, R., Coopersmith, C. M. and Swat, W. (2007). Neutrophil-mediated oxidative burst and host defense are controlled by a VavPLCgamma2 signaling axis in mice. J Clin Invest 117(11):3445-52. 
Graham, D. B., Zinselmeyer, B. H., Mascarenhas, F., Delgado, R., Miller, M. J. and Swat, W. (2009). ITAM signaling by Vav family Rho guanine nucleotide exchange factors regulates interstitial transit rates of neutrophils in vivo. PLoS One 4(2): e4652.

Groysman, M., Hornstein, I., Alcover, A. and Katzav, S. (2002). Vav1 and Ly-GDI two regulators of Rho GTPases, function cooperatively as signal transducers in T cell antigen receptor-induced pathways. J Biol Chem 277(51):50121-30.

Groysman, M., Russek, C. S. and Katzav, S. (2000). Vav, a GDP/GTP nucleotide exchange factor, interacts with GDIs, proteins that inhibit GDP/GTP dissociation. FEBS Lett 467(1): 75-80.

Gulbranson-Judge, A., Tybulewicz, V. L., Walters, A. E., Toellner, K. M., MacLennan, I. C. and Turner, M. (1999). Defective immunoglobulin class switching in Vav-deficient mice is attributable to compromised T cell help. Eur J Immuno/ 29(2):477-87.

Hall, A. B., Gakidis, M. A., Glogauer, M., Wilsbacher, J. L., Gao, S., Swat, W. and Brugge, J. S. (2006). Requirements for Vav guanine nucleotide exchange factors and Rho GTPases in FcgammaR- and complement-mediated phagocytosis. Immunity 24(3): 305-16.

Han, J., Das, B., Wei, W., Van Aelst, L., Mosteller, R. D., Khosravi-Far, R., Westwick, J. K., Der, C. J. and Broek, D. (1997). Lck regulates Vav activation of members of the Rho family of GTPases. Mol Cell Biol 17(3): 1346-53.

Harnois, T., Constantin, B., Rioux, A., Grenioux, E., Kitzis, A. and Bourmeyster, N. (2003). Differential interaction and activation of Rho family GTPases by p2 $10 \mathrm{bcr}$-abl and p190bcr-abl. Oncogene 22(41): 6445-54.

Hebeis, B., Vigorito, E., Kovesdi, D. and Turner, M. (2005). Vav proteins are required for Blymphocyte responses to LPS. Blood 106(2): 635-40.

Hehner, S. P., Li-Weber, M., Giaisi, M., Droge, W., Krammer, P. H. and Schmitz, M. L. (2000). Vav synergizes with protein kinase $C$ theta to mediate IL-4 gene expression in response to CD28 costimulation in T cells. J Immunol 164(7): 3829-36.

Henske, E. P., Short, M. P., Jozwiak, S., Bovey, C. M., Ramlakhan, S., Haines, J. L. and Kwiatkowski, D. J. (1995). Identification of VAV2 on 9q34 and its exclusion as the tuberous sclerosis gene TSC1. Ann Hum Genet 59(Pt 1):25-37.

Hermiston, M. L., Xu, Z. and Weiss, A. (2003). CD45: a critical regulator of signaling thresholds in immune cells. Annu Rev Immunol 21:107-37. 
Higuchi, T., Kanzaki, H., Fujimoto, M., Hatayama, H., Watanabe, H., Fukumoto, M., Kaneko, Y., Higashitsuji, H., Kishishita, M., Mori, T. and et al. (1995). Expression of vav proto-oncogene by nonhematopoietic trophoblast cells at the human uteroplacental interface. Biol Reprod 53(4): 840-6.

Hirasawa, N., Scharenberg, A., Yamamura, H., Beaven, M. A. and Kinet, J. P. (1995). A requirement for Syk in the activation of the microtubule-associated protein kinase/phospholipase A2 pathway by Fc epsilon R1 is not shared by a G protein-coupled receptor. J Biol Chem 270(18): 10960-7.

Hobert, O., Jallal, B., Schlessinger, J. and Ullrich, A. (1994). Novel signaling pathway suggested by $\mathrm{SH} 3$ domain-mediated p95vav/heterogeneous ribonucleoprotein $\mathrm{K}$ interaction. J Biol Chem 269(32): 20225-8.

Hobert, O., Schilling, J. W., Beckerle, M. C., Ullrich, A. and Jallal, B. (1996). SH3 domaindependent interaction of the proto-oncogene product Vav with the focal contact protein zyxin. Oncogene 12(7): 1577-81.

Hollmann, A., Aloyz, R., Baker, K., Dirnhofer, S., Owens, T., Sladek, R. and Tzankov, A. (2010). Vav-1 expression correlates with NFkappaB activation and CD40-mediated cell death in diffuse large B-cell lymphoma cell lines. Hematol Oncol 28(3): 142-50.

Holsinger, L. J., Graef, I. A., Swat, W., Chi, T., Bautista, D. M., Davidson, L., Lewis, R. S., Alt, F. W. and Crabtree, G. R. (1998). Defects in actin-cap formation in Vav-deficient mice implicate an actin requirement for lymphocyte signal transduction. Curr Bio/ 8(10):563-72.

Hornstein, I., Pikarsky, E., Groysman, M., Amir, G., Peylan-Ramu, N. and Katzav, S. (2003). The haematopoietic specific signal transducer Vav1 is expressed in a subset of human neuroblastomas. J Pathol 199(4): 526-33.

Houlard, M., Romero-Portillo, F., Germani, A., Depaux, A., Regnier-Ricard, F., Gisselbrecht, S. and Varin-Blank, N. (2005). Characterization of VIK-1: a new Vavinteracting Kruppel-like protein. Oncogene 24(1): 28-38.

Huang, J., Tilly, D., Altman, A., Sugie, K. and Grey, H. M. (2000). T-cell receptor antagonists induce Vav phosphorylation by selective activation of Fyn kinase. Proc Natl Acad Sci U S A 97(20): 10923-9. 
Huby, R. D., Carlile, G. W. and Ley, S. C. (1995). Interactions between the protein-tyrosine kinase ZAP-70, the proto-oncoprotein Vav, and tubulin in Jurkat T cells. J Biol Chem 270(51): 30241-4.

Jaffer, Z. M. and Chernoff, J. (2002). p21-activated kinases: three more join the Pak. Int J Biochem Cell Biol 34(7): 713-7.

Jagodic, M., Colacios, C., Nohra, R., Dejean, A. S., Beyeen, A. D., Khademi, M., Casemayou, A., Lamouroux, L., Duthoit, C., Papapietro, O., Sjoholm, L., Bernard, I., Lagrange, D., Dahlman, I., Lundmark, F., Oturai, A. B., Soendergaard, H. B., Kemppinen, A., Saarela, J., Tienari, P. J., Harbo, H. F., Spurkland, A., Ramagopalan, S. V., Sadovnick, D. A., Ebers, G. C., Seddighzadeh, M., Klareskog, L., Alfredsson, L., Padyukov, L., Hillert, J., Clanet, M., Edan, G., Fontaine, B., Fournie, G. J., Kockum, I., Saoudi, A. and Olsson, T. (2009). A role for VAV1 in experimental autoimmune encephalomyelitis and multiple sclerosis. Sci Transl Med 1(10): 10ra21.

Joazeiro, C. A., Wing, S. S., Huang, H., Leverson, J. D., Hunter, T. and Liu, Y. C. (1999). The tyrosine kinase negative regulator $\mathrm{c}$-Cbl as a RING-type, E2-dependent ubiquitin-protein ligase. Science 286(5438): 309-12.

Johansen, F. E. and Prywes, R. (1995). Serum response factor: transcriptional regulation of genes induced by growth factors and differentiation. Biochim Biophys Acta 1242(1): 1-10.

Katzav, S. (2004). Vav1: an oncogene that regulates specific transcriptional activation of T cells. Blood 103(7): 2443-51.

Katzav, S., Cleveland, J. L., Heslop, H. E. and Pulido, D. (1991). Loss of the amino-terminal helix-loop-helix domain of the vav proto-oncogene activates its transforming potential. Mol Cell Biol 11(4): 1912-20.

Katzav, S., Martin-Zanca, D. and Barbacid, M. (1989). vav, a novel human oncogene derived from a locus ubiquitously expressed in hematopoietic cells. EMBO J 8(8): 2283-90.

Katzav, S., Sutherland, M., Packham, G., Yi, T. and Weiss, A. (1994). The protein tyrosine kinase ZAP-70 can associate with the SH2 domain of proto-Vav. J Biol Chem 269(51): 3257985.

Kiener, P. A., Lioubin, M. N., Rohrschneider, L. R., Ledbetter, J. A., Nadler, S. G. and Diegel, M. L. (1997). Co-ligation of the antigen and Fc receptors gives rise to the selective 
modulation of intracellular signaling in B cells. Regulation of the association of phosphatidylinositol 3-kinase and inositol 5'-phosphatase with the antigen receptor complex. J Biol Chem 272(6): 3838-44.

Kim, H. H., Tharayil, M. and Rudd, C. E. (1998). Growth factor receptor-bound protein 2 SH2/SH3 domain binding to CD28 and its role in co-signaling. J Biol Chem 273(1):296-301.

Kintscher, C., Wuertenberger, S., Eylenstein, R., Uhlendorf, T. and Groemping, Y. (2010). Autoinhibition of GEF activity in Intersectin 1 is mediated by the short SH3-DH domain linker. Protein Sci 19(11): 2164-74.

Kon-Kozlowski, M., Pani, G., Pawson, T. and Siminovitch, K. A. (1996). The tyrosine phosphatase PTP1C associates with Vav, Grb2, and mSos1 in hematopoietic cells. J Biol Chem 271(7): 3856-62.

Kong, Y. Y., Fischer, K. D., Bachmann, M. F., Mariathasan, S., Kozieradzki, I., Nghiem, M. P., Bouchard, D., Bernstein, A., Ohashi, P. S. and Penninger, J. M. (1998). Vav regulates peptide-specific apoptosis in thymocytes. J Exp Med 188(11): 2099-111.

Konno, R., Fujiwara, H., Netsu, S., Odagiri, K., Shimane, M., Nomura, H. and Suzuki, M. (2007). Gene expression profiling of the rat endometriosis model. Am J Reprod Immunol 58(4): 330-43.

Koretzky, G. A., Abtahian, F. and Silverman, M. A. (2006). SLP76 and SLP65: complex regulation of signalling in lymphocytes and beyond. Nat Rev Immunol 6(1):67-78.

Korn, T., Fischer, K. D., Girkontaite, I., Kollner, G., Toyka, K. and Jung, S. (2003). Vav1deficient mice are resistant to MOG-induced experimental autoimmune encephalomyelitis due to impaired antigen priming. J Neuroimmunol 139(1-2): 17-26.

Krawczyk, C., Bachmaier, K., Sasaki, T., Jones, R. G., Snapper, S. B., Bouchard, D., Kozieradzki, I., Ohashi, P. S., Alt, F. W. and Penninger, J. M. (2000). Cbl-b is a negative regulator of receptor clustering and raft aggregation in T cells. Immunity 13(4):463-73.

Krawczyk, C., Oliveira-dos-Santos, A., Sasaki, T., Griffiths, E., Ohashi, P. S., Snapper, S., Alt, F. and Penninger, J. M. (2002). Vav1 controls integrin clustering and MHC/peptidespecific cell adhesion to antigen-presenting cells. Immunity 16(3):331-43. 
Krawczyk, C. M., Jones, R. G., Atfield, A., Bachmaier, K., Arya, S., Odermatt, B., Ohashi, P. S. and Penninger, J. M. (2005). Differential control of CD28-regulated in vivo immunity by the E3 ligase Cbl-b.J Immunol 174(3): 1472-8.

Ksionda, O., Saveliev, A., Kochl, R., Rapley, J., Faroudi, M., Smith-Garvin, J. E., Wulfing, C., Rittinger, K., Carter, T. and Tybulewicz, V. L. (2012). Mechanism and function of Vav1 localisation in TCR signalling. J Cell Sci 125(Pt 22):5302-14.

Kuhne, M. R., Ku, G. and Weiss, A. (2000). A guanine nucleotide exchange factorindependent function of Vav1 in transcriptional activation. J Biol Chem 275(3): 2185-90.

Kupfer, A. and Singer, S. J. (1989). The specific interaction of helper T cells and antigenpresenting B cells. IV. Membrane and cytoskeletal reorganizations in the bound T cell as a function of antigen dose. J Exp Med 170(5): 1697-713.

Kwon, J., Qu, C. K., Maeng, J. S., Falahati, R., Lee, C. and Williams, M. S. (2005). Receptorstimulated oxidation of SHP-2 promotes T-cell adhesion through SLP-76-ADAP. EMBO J 24(13):2331-41.

Lawson, B. R., Manenkova, Y., Ahamed, J., Chen, X., Zou, J. P., Baccala, R., Theofilopoulos, A. N. and Yuan, C. (2007). Inhibition of transmethylation down-regulates CD4 T cell activation and curtails development of autoimmunity in a model system. $J$ Immunol 178(8): 5366-74.

Lazer, G., Idelchuk, Y., Schapira, V., Pikarsky, E. and Katzav, S. (2009). The haematopoietic specific signal transducer Vav1 is aberrantly expressed in lung cancer and plays a role in tumourigenesis. J Pathol 219(1):25-34.

Lazer, G., Pe'er, L., Schapira, V., Richard, S. and Katzav, S. (2007). The association of Sam68 with Vav1 contributes to tumorigenesis. Cell Signal 19(12):2479-86.

Lee, B. S., Lee, S. H., Feng, P., Chang, H., Cho, N. H. and Jung, J. U. (2005). Characterization of the Kaposi's sarcoma-associated herpesvirus K1 signalosome. J Virol 79(19): 12173-84.

Levkowitz, G., Waterman, H., Zamir, E., Kam, Z., Oved, S., Langdon, W. Y., Beguinot, L., Geiger, B. and Yarden, Y. (1998). C-Cbl/Sli-1 regulates endocytic sorting and ubiquitination of the epidermal growth factor receptor. Genes Dev 12(23): 3663-74. 
Li, R., Wei, F., Yu, J., Li, H., Ren, X. and Hao, X. (2009). IDO inhibits T-cell function through suppressing Vav1 expression and activation. Cancer Biol Ther 8(14): 1402-8.

Li, X., Sandoval, D., Freeberg, L. and Carter, R. H. (1997). Role of CD19 tyrosine 391 in synergistic activation of B lymphocytes by coligation of CD19 and membrane Ig. J Immunol 158(12): 5649-57.

Liu, J. Y., Seno, H., Miletic, A. V., Mills, J. C., Swat, W. and Stappenbeck, T. S. (2009). Vav proteins are necessary for correct differentiation of mouse cecal and colonic enterocytes. $J$ Cell Sci 122(Pt 3): 324-34.

Llorca, O., Arias-Palomo, E., Zugaza, J. L. and Bustelo, X. R. (2005). Global conformational rearrangements during the activation of the GDP/GTP exchange factor Vav3. EMBO $J \mathbf{2 4 ( 7 ) : ~}$ $1330-40$.

Lopez-Lago, M., Lee, H., Cruz, C., Movilla, N. and Bustelo, X. R. (2000). Tyrosine phosphorylation mediates both activation and downmodulation of the biological activity of Vav. Mol Cell Biol 20(5): 1678-91.

Lustig, A., Carter, A., Bertak, D., Enika, D., Vandanmagsar, B., Wood, W., Becker, K. G., Weeraratna, A. T. and Taub, D. D. (2009). Transcriptome analysis of murine thymocytes reveals age-associated changes in thymic gene expression. Int J Med Sci 6(1):51-64.

Mahana, W., Zhao, T. M., Teller, R., Robinson, M. A. and Kindt, T. J. (1998). Genes in the pX region of human T cell leukemia virus I influence Vav phosphorylation in T cells. Proc Natl Acad Sci U S A 95(4): 1782-7.

Maignan, S., Guilloteau, J. P., Fromage, N., Arnoux, B., Becquart, J. and Ducruix, A. (1995). Crystal structure of the mammalian Grb2 adaptor. Science 268(5208): 291-3.

Malhotra, S., Kovats, S., Zhang, W. and Coggeshall, K. M. (2009). Vav and Rac activation in B cell antigen receptor endocytosis involves Vav recruitment to the adapter protein LAB. $J$ Biol Chem 284(52): 36202-12.

Manetz, T. S., Gonzalez-Espinosa, C., Arudchandran, R., Xirasagar, S., Tybulewicz, V. and Rivera, J. (2001). Vav1 regulates phospholipase cgamma activation and calcium responses in mast cells. Mol Cell Biol 21(11):3763-74. 
Marengere, L. E., Mirtsos, C., Kozieradzki, I., Veillette, A., Mak, T. W. and Penninger, J. M. (1997). Proto-oncoprotein Vav interacts with c-Cbl in activated thymocytes and peripheral T cells. J Immunol 159(1): 70-6.

Margolis, B., Hu, P., Katzav, S., Li, W., Oliver, J. M., Ullrich, A., Weiss, A. and Schlessinger, J. (1992). Tyrosine phosphorylation of vav proto-oncogene product containing SH2 domain and transcription factor motifs. Nature 356(6364): 71-4.

Matsuguchi, T., Inhorn, R. C., Carlesso, N., Xu, G., Druker, B. and Griffin, J. D. (1995). Tyrosine phosphorylation of p95Vav in myeloid cells is regulated by GM-CSF, IL-3 and steel factor and is constitutively increased by p210BCR/ABL. EMBO J 14(2): 257-65.

Michel, F. and Acuto, O. (2002). CD28 costimulation: a source of Vav-1 for TCR signaling with the help of SLP-76? Sci STKE 2002(144): pe35.

Michel, F., Grimaud, L., Tuosto, L. and Acuto, O. (1998). Fyn and ZAP-70 are required for Vav phosphorylation in T cells stimulated by antigen-presenting cells. J Biol Chem 273(48): 31932-8.

Michel, F., Mangino, G., Attal-Bonnefoy, G., Tuosto, L., Alcover, A., Roumier, A., Olive, D. and Acuto, O. (2000). CD28 utilizes Vav-1 to enhance TCR-proximal signaling and NF-AT activation. J Immunol 165(7): 3820-9.

Miletic, A. V., Graham, D. B., Montgrain, V., Fujikawa, K., Kloeppel, T., Brim, K., Weaver, B., Schreiber, R., Xavier, R. and Swat, W. (2007). Vav proteins control MyD88-dependent oxidative burst. Blood 109(8): 3360-8.

Miller, C. L., Burkhardt, A. L., Lee, J. H., Stealey, B., Longnecker, R., Bolen, J. B. and Kieff, E. (1995). Integral membrane protein 2 of Epstein-Barr virus regulates reactivation from latency through dominant negative effects on protein-tyrosine kinases. Immunity 2(2): 15566.

Mimura, T., Minota, S., Nojima, Y., Morino, N., Hamasaki, K., Furuya, H. and Yazaki, Y. (1997). Constitutive tyrosine phosphorylation of the vav proto-oncogene product in MRL/Mp-Ipr/lpr mice.J Jmmunol 158(6):2977-83.

Ming, W., Li, S., Billadeau, D. D., Quilliam, L. A. and Dinauer, M. C. (2007). The Rac effector p67phox regulates phagocyte NADPH oxidase by stimulating Vav1 guanine nucleotide exchange activity. Mol Cell Biol 27(1):312-23. 
Miranti, C. K., Leng, L., Maschberger, P., Brugge, J. S. and Shattil, S. J. (1998). Identification of a novel integrin signaling pathway involving the kinase Syk and the guanine nucleotide exchange factor Vav1. Curr Bio/ 8(24): 1289-99.

Mitin, N., Betts, L., Yohe, M. E., Der, C. J., Sondek, J. and Rossman, K. L. (2007). Release of autoinhibition of ASEF by APC leads to CDC42 activation and tumor suppression. Nat Struct Mol Biol 14(9): 814-23.

Miura-Shimura, Y., Duan, L., Rao, N. L., Reddi, A. L., Shimura, H., Rottapel, R., Druker, B. J., Tsygankov, A., Band, V. and Band, H. (2003). Cbl-mediated ubiquitinylation and negative regulation of Vav. J Biol Chem 278(40): 38495-504.

Moller, A., Dienz, O., Hehner, S. P., Droge, W. and Schmitz, M. L. (2001). Protein kinase C theta cooperates with Vav1 to induce JNK activity in T-cells. J Biol Chem 276(23): 20022-8.

Monks, C. R., Freiberg, B. A., Kupfer, H., Sciaky, N. and Kupfer, A. (1998). Threedimensional segregation of supramolecular activation clusters in T cells. Nature 395(6697): $82-6$.

Montaner, S., Perona, R., Saniger, L. and Lacal, J. C. (1998). Multiple signalling pathways lead to the activation of the nuclear factor kappaB by the Rho family of GTPases. J Biol Chem 273(21): 12779-85.

Movilla, N. and Bustelo, X. R. (1999). Biological and regulatory properties of Vav-3, a new member of the Vav family of oncoproteins. Mol Cell Biol 19(11): 7870-85.

Murayama, K., Shirouzu, M., Kawasaki, Y., Kato-Murayama, M., Hanawa-Suetsugu, K., Sakamoto, A., Katsura, Y., Suenaga, A., Toyama, M., Terada, T., Taiji, M., Akiyama, T. and Yokoyama, S. (2007). Crystal structure of the rac activator, Asef, reveals its autoinhibitory mechanism. J Biol Chem 282(7):4238-42.

Mustelin, T., Vang, T. and Bottini, N. (2005). Protein tyrosine phosphatases and the immune response. Nat Rev Immunol 5(1):43-57.

Myung, P. S., Derimanov, G. S., Jordan, M. S., Punt, J. A., Liu, Q. H., Judd, B. A., Meyers, E. E., Sigmund, C. D., Freedman, B. D. and Koretzky, G. A. (2001). Differential requirement for SLP-76 domains in T cell development and function. Immunity 15(6): 1011-26. 
Nagano, K., Bornhauser, B. C., Warnasuriya, G., Entwistle, A., Cramer, R., Lindholm, D. and Naaby-Hansen, S. (2006). PDGF regulates the actin cytoskeleton through hnRNP-Kmediated activation of the ubiquitin E3-ligase MIR.EMBO J 25(9): 1871-82.

Nishida, M., Nagata, K., Hachimori, Y., Horiuchi, M., Ogura, K., Mandiyan, V., Schlessinger, J. and Inagaki, F. (2001). Novel recognition mode between Vav and Grb2 SH3 domains. EMBO J 20(12):2995-3007.

Nishihara, H., Maeda, M., Oda, A., Tsuda, M., Sawa, H., Nagashima, K. and Tanaka, S. (2002). DOCK2 associates with CrkL and regulates Rac1 in human leukemia cell lines. Blood 100(12):3968-74.

Norman, K. R., Fazzio, R. T., Mellem, J. E., Espelt, M. V., Strange, K., Beckerle, M. C. and Maricq, A. V. (2005). The Rho/Rac-family guanine nucleotide exchange factor VAV-1 regulates rhythmic behaviors in C. elegans. Cell 123(1): 119-32.

Nunes, J. A., Collette, Y., Truneh, A., Olive, D. and Cantrell, D. A. (1994). The role of p21 ras in CD28 signal transduction: triggering of CD28 with antibodies, but not the ligand B7-1, activates p21 ras.J Exp Med 180(3): 1067-76.

O'Rourke, A. M., Shao, H. and Kaye, J. (1998). A role for p21ras/MAP kinase in TCRmediated activation of LFA-1. J Immunol 161(11):5800-3.

Okumura, K., Kaneko, Y., Nonoguchi, K., Nishiyama, H., Yokoi, H., Higuchi, T., Itoh, K., Yoshida, O., Miki, T. and Fujita, J. (1997). Expression of a novel isoform of Vav, Vav-T, containing a single Src homology 3 domain in murine testicular germ cells. Oncogene 14(6): 713-20.

Onodera, H., Motto, D. G., Koretzky, G. A. and Rothstein, D. M. (1996). Differential regulation of activation-induced tyrosine phosphorylation and recruitment of SLP-76 to Vav by distinct isoforms of the CD45 protein-tyrosine phosphatase. J Biol Chem 271(36): 2222530.

Ota, Y. and Samelson, L. E. (1997). The product of the proto-oncogene c-cbl: a negative regulator of the Syk tyrosine kinase. Science 276(5311):418-20.

Pani, G., Fischer, K. D., Mlinaric-Rascan, I. and Siminovitch, K. A. (1996). Signaling capacity of the T cell antigen receptor is negatively regulated by the PTP1C tyrosine phosphatase. J Exp Med 184(3): 839-52. 
Pearce, A. C., McCarty, O. J., Calaminus, S. D., Vigorito, E., Turner, M. and Watson, S. P. (2007). Vav family proteins are required for optimal regulation of PLCgamma2 by integrin alphallbbeta3. Biochem J 401(3): 753-61.

Pearce, A. C., Senis, Y. A., Billadeau, D. D., Turner, M., Watson, S. P. and Vigorito, E. (2004). Vav1 and vav3 have critical but redundant roles in mediating platelet activation by collagen. J Biol Chem 279(52): 53955-62.

Penninger, J. M., Fischer, K. D., Sasaki, T., Kozieradzki, I., Le, J., Tedford, K., Bachmaier, K., Ohashi, P. S. and Bachmann, M. F. (1999). The oncogene product Vav is a crucial regulator of primary cytotoxic T cell responses but has no apparent role in CD28-mediated co-stimulation. Eur J Immunol 29(5): 1709-18.

Phillipson, M., Heit, B., Parsons, S. A., Petri, B., Mullaly, S. C., Colarusso, P., Gower, R. M., Neely, G., Simon, S. I. and Kubes, P. (2009). Vav1 is essential for mechanotactic crawling and migration of neutrophils out of the inflamed microvasculature. J Immuno/ 182(11):68708.

Pires de Miranda, M., Alenquer, M., Marques, S., Rodrigues, L., Lopes, F., Bustelo, X. R. and Simas, J. P. (2008). The Gammaherpesvirus m2 protein manipulates the Fyn/Vav pathway through a multidocking mechanism of assembly. PLoS One 3(2): e1654.

Poppe, D., Tiede, I., Fritz, G., Becker, C., Bartsch, B., Wirtz, S., Strand, D., Tanaka, S., Galle, P. R., Bustelo, X. R. and Neurath, M. F. (2006). Azathioprine suppresses ezrin-radixinmoesin-dependent T cell-APC conjugation through inhibition of Vav guanosine exchange activity on Rac proteins. J Immunol 176(1):640-51.

Prieto-Sanchez, R. M., Hernandez, J. A., Garcia, J. L., Gutierrez, N. C., San Miguel, J., Bustelo, X. R. and Hernandez, J. M. (2006). Overexpression of the VAV proto-oncogene product is associated with B-cell chronic lymphocytic leukaemia displaying loss on $13 \mathrm{q} . \mathrm{Br} J$ Haematol 133(6): 642-5.

Prisco, A., Vanes, L., Ruf, S., Trigueros, C. and Tybulewicz, V. L. (2005). Lineage-specific requirement for the $\mathrm{PH}$ domain of Vav1 in the activation of CD4+ but not CD8+ T cells. Immunity 23(3): 263-74.

Puga, I., Rao, A. and Macian, F. (2008). Targeted cleavage of signaling proteins by caspase 3 inhibits T cell receptor signaling in anergic T cells. Immunity 29(2): 193-204. 
Quaranta, M. G., Mattioli, B., Spadaro, F., Straface, E., Giordani, L., Ramoni, C., Malorni, W. and Viora, M. (2003). HIV-1 Nef triggers Vav-mediated signaling pathway leading to functional and morphological differentiation of dendritic cells. FASEB J 17(14): 2025-36.

Quevedo, C., Sauzeau, V., Menacho-Marquez, M., Castro-Castro, A. and Bustelo, X. R. (2010). Vav3-deficient mice exhibit a transient delay in cerebellar development. Mol Biol Cell 21(6): 1125-39.

Raab, M., da Silva, A. J., Findell, P. R. and Rudd, C. E. (1997). Regulation of Vav-SLP-76 binding by ZAP-70 and its relevance to TCR zeta/CD3 induction of interleukin-2. Immunity 6(2): 155-64.

Ramos-Morales, F., Romero, F., Schweighoffer, F., Bismuth, G., Camonis, J., Tortolero, M. and Fischer, S. (1995). The proline-rich region of Vav binds to Grb2 and Grb3-3. Oncogene 11(8): 1665-9.

Rao, A., Luo, C. and Hogan, P. G. (1997). Transcription factors of the NFAT family: regulation and function. Annu Rev Immunol 15: 707-47.

Rapley, J., Tybulewicz, V. L. and Rittinger, K. (2008). Crucial structural role for the PH and C1 domains of the Vav1 exchange factor. EMBO Rep 9(7):655-61.

Rauch, S., Pulkkinen, K., Saksela, K. and Fackler, O. T. (2008). Human immunodeficiency virus type 1 Nef recruits the guanine exchange factor Vav1 via an unexpected interface into plasma membrane microdomains for association with p21-activated kinase 2 activity. $J$ Virol 82(6): 2918-29.

Reynolds, L. F., de Bettignies, C., Norton, T., Beeser, A., Chernoff, J. and Tybulewicz, V. L. (2004). Vav1 transduces T cell receptor signals to the activation of the Ras/ERK pathway via LAT, Sos, and RasGRP1.J Biol Chem 279(18): 18239-46.

Reynolds, L. F., Smyth, L. A., Norton, T., Freshney, N., Downward, J., Kioussis, D. and Tybulewicz, V. L. (2002). Vav1 transduces T cell receptor signals to the activation of phospholipase C-gamma1 via phosphoinositide 3-kinase-dependent and -independent pathways. J Exp Med 195(9): 1103-14.

Rhee, S. G. (2001). Regulation of phosphoinositide-specific phospholipase C. Annu Rev Biochem 70:281-312. 
Rodrigues, L., Pires de Miranda, M., Caloca, M. J., Bustelo, X. R. and Simas, J. P. (2006). Activation of Vav by the gammaherpesvirus M2 protein contributes to the establishment of viral latency in B lymphocytes. J Virol 80(12):6123-35.

Romero, F., Dargemont, C., Pozo, F., Reeves, W. H., Camonis, J., Gisselbrecht, S. and Fischer, S. (1996). p95vav associates with the nuclear protein Ku-70. Mol Cell Biol 16(1): 3744.

Ruiz, S., Santos, E. and Bustelo, X. R. (2007). RasGRF2, a guanosine nucleotide exchange factor for Ras GTPases, participates in T-cell signaling responses. Mol Cell Biol 27(23): 81 27-42.

Ruiz, S., Santos, E. and Bustelo, X. R. (2009). The use of knockout mice reveals a synergistic role of the Vav1 and Rasgrf2 gene deficiencies in lymphomagenesis and metastasis. PLoS One 4(12): e8229.

Saito, E., Fujimoto, M., Hasegawa, M., Komura, K., Hamaguchi, Y., Kaburagi, Y., Nagaoka, T., Takehara, K., Tedder, T. F. and Sato, S. (2002). CD19-dependent B lymphocyte signaling thresholds influence skin fibrosis and autoimmunity in the tight-skin mouse. J Clin Invest 109(11): 1453-62.

Salmond, R. J., McNeill, L., Holmes, N. and Alexander, D. R. (2008). CD4+ T cell hyperresponsiveness in CD45 transgenic mice is independent of isoform. Int Immunol 20(7): 81927.

Salojin, K. V., Zhang, J. and Delovitch, T. L. (1999). TCR and CD28 are coupled via ZAP-70 to the activation of the Vav/Rac-1-/PAK-1/p38 MAPK signaling pathway. J Immunol 163(2): 84453.

Salojin, K. V., Zhang, J., Meagher, C. and Delovitch, T. L. (2000). ZAP-70 is essential for the T cell antigen receptor-induced plasma membrane targeting of SOS and Vav in T cells. J Biol Chem 275(8): 5966-75.

Sanzone, S., Zeyda, M., Saemann, M. D., Soncini, M., Holter, W., Fritsch, G., Knapp, W., Candotti, F., Stulnig, T. M. and Parolini, O. (2003). SLAM-associated protein deficiency causes imbalanced early signal transduction and blocks downstream activation in T cells from X-linked lymphoproliferative disease patients. J Biol Chem 278(32): 29593-9. 
Sato, S., Jansen, P. J. and Tedder, T. F. (1997). CD19 and CD22 expression reciprocally regulates tyrosine phosphorylation of Vav protein during B lymphocyte signaling. Proc Natl Acad SciU S A 94(24): 13158-62.

Sattler, M., Pride, Y. B., Quinnan, L. R., Verma, S., Malouf, N. A., Husson, H., Salgia, R., Lipkowitz, S. and Griffin, J. D. (2002). Differential expression and signaling of CBL and CBL-B in BCR/ABL transformed cells. Oncogene 21(9): 1423-33.

Sauzeau, V., Horta-Junior, J. A., Riolobos, A. S., Fernandez, G., Sevilla, M. A., Lopez, D. E., Montero, M. J., Rico, B. and Bustelo, X. R. (2010a). Vav3 is involved in GABAergic axon guidance events important for the proper function of brainstem neurons controlling cardiovascular, respiratory, and renal parameters. Mol Biol Cell 21 (23):4251-63.

Sauzeau, V., Jerkic, M., Lopez-Novoa, J. M. and Bustelo, X. R. (2007). Loss of Vav2 protooncogene causes tachycardia and cardiovascular disease in mice. Mol Biol Cell 18(3): 943-52.

Sauzeau, V., Sevilla, M. A., Montero, M. J. and Bustelo, X. R. (2010b)The Rho/Rac exchange factor Vav2 controls nitric oxide-dependent responses in mouse vascular smooth muscle cells. J Clin Invest 120(1):315-30.

Sauzeau, V., Sevilla, M. A., Rivas-Elena, J. V., de Alava, E., Montero, M. J., Lopez-Novoa, J. M. and Bustelo, X. R. (2006). Vav3 proto-oncogene deficiency leads to sympathetic hyperactivity and cardiovascular dysfunction. Nat Med 12(7): 841-5.

Saveliev, A., Vanes, L., Ksionda, O., Rapley, J., Smerdon, S. J., Rittinger, K. and Tybulewicz, V. L. (2009). Function of the nucleotide exchange activity of vav1 in T cell development and activation. Sci Signal 2(101): ra83.

Schaeffer, H. J. and Weber, M. J. (1999). Mitogen-activated protein kinases: specific messages from ubiquitous messengers. Mol Cell Biol 19(4): 2435-44.

Schiller, M. R., Chakrabarti, K., King, G. F., Schiller, N. I., Eipper, B. A. and Maciejewski, M. W. (2006). Regulation of RhoGEF activity by intramolecular and intermolecular SH3 domain interactions. J Biol Chem 281 (27): 18774-86.

Schuebel, K. E., Bustelo, X. R., Nielsen, D. A., Song, B. J., Barbacid, M., Goldman, D. and Lee, I. J. (1996). Isolation and characterization of murine vav2, a member of the vav family of proto-oncogenes. Oncogene 13(2): 363-71. 
Schuebel, K. E., Movilla, N., Rosa, J. L. and Bustelo, X. R. (1998). Phosphorylationdependent and constitutive activation of Rho proteins by wild-type and oncogenic Vav-2. $E M B O J$ 17(22): 6608-21.

Sekine, Y., Yamamoto, C., Ikeda, O., Muromoto, R., Nanbo, A., Oritani, K., Yoshimura, A. and Matsuda, T. (2009). The protein content of an adaptor protein, STAP-2 is controlled by E3 ubiquitin ligase Cbl. Biochem Biophys Res Commun 384(2): 187-92.

Serfling, E., Berberich-Siebelt, F., Chuvpilo, S., Jankevics, E., Klein-Hessling, S., Twardzik, T. and Avots, A. (2000). The role of NF-AT transcription factors in T cell activation and differentiation. Biochim Biophys Acta 1498(1): 1-18.

Shigematsu, H., Iwasaki, H., Otsuka, T., Ohno, Y., Arima, F. and Niho, Y. (1997). Role of the vav proto-oncogene product (Vav) in erythropoietin-mediated cell proliferation and phosphatidylinositol 3-kinase activity. J Biol Chem 272(22): 14334-40.

Simmons, A., Gangadharan, B., Hodges, A., Sharrocks, K., Prabhakar, S., Garcia, A., Dwek, R., Zitzmann, N. and McMichael, A. (2005). Nef-mediated lipid raft exclusion of UbcH7 inhibits $\mathrm{Cbl}$ activity in T cells to positively regulate signaling. Immunity 23(6):621-34.

Smyth, L. A., Williams, O., Huby, R. D., Norton, T., Acuto, O., Ley, S. C. and Kioussis, D. (1998). Altered peptide ligands induce quantitatively but not qualitatively different intracellular signals in primary thymocytes. Proc Natl Acad Sci U S A 95(14):8193-8.

Snapper, S. B., Rosen, F. S., Mizoguchi, E., Cohen, P., Khan, W., Liu, C. H., Hagemann, T. L., Kwan, S. P., Ferrini, R., Davidson, L., Bhan, A. K. and Alt, F. W. (1998). Wiskott-Aldrich syndrome protein-deficient mice reveal a role for WASP in T but not B cell activation. Immunity 9(1): 81-91.

Song, J. S., Haleem-Smith, H., Arudchandran, R., Gomez, J., Scott, P. M., Mill, J. F., Tan, T. H. and Rivera, J. (1999). Tyrosine phosphorylation of Vav stimulates IL-6 production in mast cells by a Rac/c-Jun N-terminal kinase-dependent pathway. J Immunol 163(2): 802-10.

Sosinowski, T., Pandey, A., Dixit, V. M. and Weiss, A. (2000). Src-like adaptor protein (SLAP) is a negative regulator of T cell receptor signaling. J Exp Med 191(3): 463-74.

Spurrell, D. R., Luckashenak, N. A., Minney, D. C., Chaplin, A., Penninger, J. M., Liwski, R. S., Clements, J. L. and West, K. A. (2009). Vav1 regulates the migration and adhesion of dendritic cells. J Immunol 183(1):310-8. 
Stebbins, C. C., Watzl, C., Billadeau, D. D., Leibson, P. J., Burshtyn, D. N. and Long, E. O. (2003). Vav1 dephosphorylation by the tyrosine phosphatase SHP-1 as a mechanism for inhibition of cellular cytotoxicity. Mol Cell Biol 23(17):6291-9.

Su, I. H., Dobenecker, M. W., Dickinson, E., Oser, M., Basavaraj, A., Marqueron, R., Viale, A., Reinberg, D., Wulfing, C. and Tarakhovsky, A. (2005). Polycomb group protein ezh2 controls actin polymerization and cell signaling. Cell 121(3):425-36.

Suzuki-Inoue, K., Kato, Y., Inoue, O., Kaneko, M. K., Mishima, K., Yatomi, Y., Yamazaki, Y., Narimatsu, H. and Ozaki, Y. (2007). Involvement of the snake toxin receptor CLEC-2, in podoplanin-mediated platelet activation, by cancer cells. J Biol Chem 282(36): 25993-6001 .

Swat, W., Xavier, R., Mizoguchi, A., Mizoguchi, E., Fredericks, J., Fujikawa, K., Bhan, A. K. and Alt, F. W. (2003). Essential role for Vav1 in activation, but not development, of gammadelta T cells. Int Immunol 15(2): 215-21.

Tamir, I., Dal Porto, J. M. and Cambier, J. C. (2000). Cytoplasmic protein tyrosine phosphatases SHP-1 and SHP-2: regulators of B cell signal transduction. Curr Opin Immunol 12(3): 307-15.

Tarakhovsky, A., Turner, M., Schaal, S., Mee, P. J., Duddy, L. P., Rajewsky, K. and Tybulewicz, V. L. (1995). Defective antigen receptor-mediated proliferation of B and T cells in the absence of Vav. Nature 374(6521): 467-70.

Tedford, K., Nitschke, L., Girkontaite, I., Charlesworth, A., Chan, G., Sakk, V., Barbacid, M. and Fischer, K. D. (2001). Compensation between Vav-1 and Vav-2 in B cell development and antigen receptor signaling. Nat Immuno/ 2(6):548-55.

Teramoto, H., Salem, P., Robbins, K. C., Bustelo, X. R. and Gutkind, J. S. (1997). Tyrosine phosphorylation of the vav proto-oncogene product links FcepsilonRI to the Rac1-JNK pathway. J Biol Chem 272(16): 10751-5.

Thien, C. B. and Langdon, W. Y. (1998). c-Cbl: a regulator of T cell receptor-mediated signalling. Immunol Cell Biol 76(5):473-82.

Thrasher, A. J. (2002). WASp in immune-system organization and function. Nat Rev Immunol 2(9): 635-46.

Toker, A. (2002). Phosphoinositides and signal transduction. Cell Mol Life Sci 59(5): 761-79. 
Treisman, R. (1994). Ternary complex factors: growth factor regulated transcriptional activators. Curr Opin Genet Dev 4(1): 96-101.

Trenkle, T., McClelland, M., Adlkofer, K. and Welsh, J. (2000). Major transcript variants of VAV3, a new member of the VAV family of guanine nucleotide exchange factors. Gene 245(1): 139-49.

Tuosto, L., Michel, F. and Acuto, O. (1996). p95vav associates with tyrosine-phosphorylated SLP-76 in antigen-stimulated T cells. J Exp Med 184(3): 1161-6.

Turner, M. and Billadeau, D. D. (2002). VAV proteins as signal integrators for multi-subunit immune-recognition receptors. Nat Rev Immunol 2(7):476-86.

Turner, M., Mee, P. J., Walters, A. E., Quinn, M. E., Mellor, A. L., Zamoyska, R. and Tybulewicz, V. L. (1997). A requirement for the Rho-family GTP exchange factor Vav in positive and negative selection of thymocytes. Immunity 7(4): 451-60.

Tybulewicz, V. L. (2005). Vav-family proteins in T-cell signalling. Curr Opin Immunol 17(3): 267-74.

Tybulewicz, V. L., Ardouin, L., Prisco, A. and Reynolds, L. F. (2003). Vav1: a key signal transducer downstream of the TCR. Immunol Rev 192:42-52.

Utomo, A., Hirahashi, J., Mekala, D., Asano, K., Glogauer, M., Cullere, X. and Mayadas, T. N. (2008). Requirement for Vav proteins in post-recruitment neutrophil cytotoxicity in IgG but not complement C3-dependent injury. J Immunol 180(9): 6279-87.

Valitutti, S., Dessing, M., Aktories, K., Gallati, H. and Lanzavecchia, A. (1995). Sustained signaling leading to $T$ cell activation results from prolonged $T$ cell receptor occupancy. Role of T cell actin cytoskeleton. J Exp Med 181(2):577-84.

Van Aelst, L., and C. D'Souza-Schorey (1997). Rho GTPases and signaling networks. Genes Dev 11:2295-322.

van Oers, N. S., Killeen, N. and Weiss, A. (1994). ZAP-70 is constitutively associated with tyrosine-phosphorylated TCR zeta in murine thymocytes and lymph node T cells. Immunity 1(8):675-85.

van Oers, N. S. and Weiss, A. (1995). The Syk/ZAP-70 protein tyrosine kinase connection to antigen receptor signalling processes. Semin Immunol 7(4): 227-36. 
Van Seuningen, I., Ostrowski, J., Bustelo, X. R., Sleath, P. R. and Bomsztyk, K. (1995). The $\mathrm{K}$ protein domain that recruits the interleukin 1-responsive $\mathrm{K}$ protein kinase lies adjacent to a cluster of c-Src and Vav SH3-binding sites. Implications that $\mathrm{K}$ protein acts as a docking platform. J Biol Chem 270(45):26976-85.

Vigorito, E., Billadeu, D. D., Savoy, D., McAdam, S., Doody, G., Fort, P. and Turner, M. (2003). RhoG regulates gene expression and the actin cytoskeleton in lymphocytes. Oncogene 22(3): 330-42.

Vigorito, E., Gambardella, L., Colucci, F., McAdam, S. and Turner, M. (2005). Vav proteins regulate peripheral B-cell survival. Blood 106(7): 2391-8.

Vigorito, E., Kovesdi, D. and Turner, M. (2006). Synergistic activation of PKD by the B cell antigen receptor and CD1 9 requires PI3K, Vav1 and PLCgamma. Cell Signal 18(9): 1455-60.

Villalba, M., Bi, K., Rodriguez, F., Tanaka, Y., Schoenberger, S. and Altman, A. (2001). Vav1/Rac-dependent actin cytoskeleton reorganization is required for lipid raft clustering in T cells. J Cell Biol 155(3): 331-8.

Walmsley, M. J., Ooi, S. K., Reynolds, L. F., Smith, S. H., Ruf, S., Mathiot, A., Vanes, L., Williams, D. A., Cancro, M. P. and Tybulewicz, V. L. (2003). Critical roles for Rac1 and Rac2 GTPases in B cell development and signaling. Science 302(5644): 459-62.

Wang, S., Diao, H., Guan, Q., Jevnikar, A. M. and Du, C. (2007). Enhanced cardiac allograft survival by Vav1-Rac signaling blockade in a mouse model. Transpl Immunol 18(1):53-61.

Weckbecker, G., Bruns, C., Fischer, K. D., Heusser, C., Li, J., Metzler, B., Morris, R. E., Nuesslein-Hildesheim, B., Raulf, F., Wieczorek, G. and Zenke, G. (2007). Strongly reduced alloreactivity and long-term survival times of cardiac allografts in Vav1- and Vav1/Vav2knockout mice. Transpl Int 20(4): 353-64.

Wells, J. A. (1991). Systemic mutational analyses of protein-protein interfaces. Methods Enzymol 202, 390-411.

Weng, W. K., Jarvis, L. and LeBien, T. W. (1994). Signaling through CD19 activates Vav/mitogen-activated protein kinase pathway and induces formation of a CD19/Vav/phosphatidylinositol 3-kinase complex in human B cell precursors. J Biol Chem 269(51):32514-21. 
Wilkinson, F. L., Holaska, J. M., Zhang, Z., Sharma, A., Manilal, S., Holt, I., Stamm, S., Wilson, K. L. and Morris, G. E. (2003). Emerin interacts in vitro with the splicing-associated factor, YT521-B. Eur J Biochem 270(11): 2459-66.

Wilson, R., Ainscough, R., Anderson, K., Baynes, C., Berks, M., Bonfield, J., Burton, J., Connell, M., Copsey, T., Cooper, J. and et al. (1994). $2.2 \mathrm{Mb}$ of contiguous nucleotide sequence from chromosome III of C. elegans. Nature 368(6466):32-8.

Worthylake, D. K., Rossman, K. L. and Sondek, J. (2000). Crystal structure of Rac1 in complex with the guanine nucleotide exchange region of Tiam1. Nature 408(6813): 682-8.

Wu, C., Zhang, L., Bourne, P. A., Reeder, J. E., di Sant'Agnese, P. A., Yao, J. L., Na, Y. and Huang, J. (2006). Protein tyrosine phosphatase PTP1B is involved in neuroendocrine differentiation of prostate cancer. Prostate 66(11): 1125-35.

Wu, J., Katzav, S. and Weiss, A. (1995). A functional T-cell receptor signaling pathway is required for p95vav activity. Mol Cell Biol 15(8): 4337-46.

Wu, J., Motto, D. G., Koretzky, G. A. and Weiss, A. (1996). Vav and SLP-76 interact and functionally cooperate in IL-2 gene activation. Immunity 4(6): 593-602.

Wu, J., Zhao, Q., Kurosaki, T. and Weiss, A. (1997). The Vav binding site (Y315) in ZAP-70 is critical for antigen receptor-mediated signal transduction. J Exp Med 185(10): 1877-82.

Wulf, G. M., Adra, C. N. and Lim, B. (1993). Inhibition of hematopoietic development from embryonic stem cells by antisense vav RNA.EMBO J 12(13): 5065-74.

Xavier, R., Brennan, T., Li, Q., McCormack, C. and Seed, B. (1998). Membrane compartmentation is required for efficient T cell activation. Immunity 8(6): 723-32.

Yabana, N. and Shibuya, M. (2002). Adaptor protein APS binds the NH2-terminal autoinhibitory domain of guanine nucleotide exchange factor Vav3 and augments its activity. Oncogene 21(50): 7720-9.

Ye, Z. S. and Baltimore, D. (1994). Binding of Vav to Grb2 through dimerization of Src homology 3 domains. Proc Natl Acad Sci U S A 91 (26): 12629-33.

Yohe, M. E., Rossman, K. and Sondek, J. (2008). Role of the C-terminal SH3 domain and Nterminal tyrosine phosphorylation in regulation of Tim and related Dbl-family proteins. Biochemistry 47(26): 6827-39. 
Yu, B., Martins, I. R., Li, P., Amarasinghe, G. K., Umetani, J., Fernandez-Zapico, M. E., Billadeau, D. D., Machius, M., Tomchick, D. R. and Rosen, M. K. (2010). Structural and energetic mechanisms of cooperative autoinhibition and activation of Vav1. Cell 140(2): 24656.

Yuzawa, S., Yokochi, M., Hatanaka, H., Ogura, K., Kataoka, M., Miura, K., Mandiyan, V., Schlessinger, J. and Inagaki, F. (2001). Solution structure of Grb2 reveals extensive flexibility necessary for target recognition. J Mol Biol 306(3): 527-37.

Zhang, R., Alt, F. W., Davidson, L., Orkin, S. H. and Swat, W. (1995). Defective signalling through the T- and B-cell antigen receptors in lymphoid cells lacking the vav protooncogene. Nature 374(6521):470-3.

Zhang, W., Irvin, B. J., Trible, R. P., Abraham, R. T. and Samelson, L. E. (1999). Functional analysis of LAT in TCR-mediated signaling pathways using a LAT-deficient Jurkat cell line. Int Immunol 11(6): 943-50.

Zhang, W., Sloan-Lancaster, J., Kitchen, J., Trible, R. P. and Samelson, L. E. (1998). LAT: the ZAP-70 tyrosine kinase substrate that links T cell receptor to cellular activation. Cell 92(1): 83-92.

Zhang, W., Trible, R. P. and Samelson, L. E. (1998). LAT palmitoylation: its essential role in membrane microdomain targeting and tyrosine phosphorylation during $\mathrm{T}$ cell activation. Immunity 9(2): 239-46.

Zhao, Q., Williams, B. L., Abraham, R. T. and Weiss, A. (1999). Interdomain B in ZAP-70 regulates but is not required for ZAP-70 signaling function in lymphocytes. Mol Cell Biol 19(1): 948-56.

Zhou, Z., Yin, J., Dou, Z., Tang, J., Zhang, C. and Cao, Y. (2007). The calponin homology domain of Vav1 associates with calmodulin and is prerequisite to T cell antigen receptorinduced calcium release in Jurkat T lymphocytes. J Biol Chem 282(32): 23737-44.

Zhu, J. and McKeon, F. (2000). Nucleocytoplasmic shuttling and the control of NF-AT signaling. Cell Mol Life Sci 57(3): 411-20.

Zmuidzinas, A., Fischer, K. D., Lira, S. A., Forrester, L., Bryant, S., Bernstein, A. and Barbacid, M. (1995). The vav proto-oncogene is required early in embryogenesis but not for hematopoietic development in vitro. EMBO J 14(1): 1-11. 
Zugaza, J. L., Caloca, M. J. and Bustelo, X. R. (2004). Inverted signaling hierarchy between RAS and RAC in T-lymphocytes. Oncogene 23(34):5823-33.

Zugaza, J. L., Lopez-Lago, M. A., Caloca, M. J., Dosil, M., Movilla, N. and Bustelo, X. R. (2002). Structural determinants for the biological activity of Vav proteins. J Biol Chem 277(47): 45377-92. 



\section{Anexo I}

Vectores de expresión adicionales utilizados en este trabajo. El nombre, tipo de vector y proteína codificada aparecen indicados.

\begin{tabular}{|c|c|c|}
\hline Nombre & Tipo de vector & Proteína codificada \\
\hline pKES27 & pMEX & $\operatorname{Vav} 1^{\mathrm{Y} 3 \times \mathrm{F}+\Delta 835-845}$ \\
\hline pMB35 & pGEX 6P-1 & GST-CSH3 ${ }^{\text {P833L }}$ \\
\hline pMB52 & pEGFP-C2 & EGFP-Vav1 AAAP \\
\hline pMB50 & pEGFP-C2 & EGFP-Vav1 ${ }^{\text {P651L }}$ \\
\hline pMB53 & pEGFP-C2 & EGFP-Vav1 ${ }^{\text {AAAP+P651L }}$ \\
\hline pMB54 & pEGFP-C2 & EGFP-Vav1 ${ }^{\mathrm{AAAP}+{ }_{\Delta} 835-845}$ \\
\hline pMB51 & pEGFP-C2 & EGFP-Vav1 $^{\mathrm{P} 651 \mathrm{~L}+{ }_{\Delta} 835-845}$ \\
\hline pMB55 & pEGFP-C2 & EGFP-Vav1 ${ }^{\text {AAAP+P651L+ } \Delta 835-845}$ \\
\hline pMB69 & pEGFP-C2 & EGFP-Vav1 ${ }^{\text {NEmut }+{ }_{\Delta} 835-845}$ \\
\hline pMB70 & pEGFP-C2 & EGFP-Vav1 $1^{\text {VKmut }+{ }_{\Delta} 835-845}$ \\
\hline pMB71 & pEGFP-C2 & EGFP-Vav1 $1^{\text {RDmut }+{ }_{\Delta} 835-845}$ \\
\hline pMB72 & pEGFP-C2 & EGFP-Vav1 $1^{\text {NE+RDmut }+{ }_{\alpha} 835-845}$ \\
\hline pMB73 & pEGFP-C2 & EGFP-Vav1 ${ }^{\text {NEVKRDmut }+{ }_{\Delta} 835-845}$ \\
\hline pMB74 & pEGFP-C2 & EGFP-Vav1 ${ }^{T 384 A+{ }_{\Delta} 835-845}$ \\
\hline pMB75 & pEGFP-C2 & EGFP-Vav1 ${ }^{\mathrm{L388A+}{ }_{\Delta} 835-845}$ \\
\hline pMB90 & pEGFP-C2 & EGFP-Vav1 $1^{\mathrm{V} 373 \mathrm{~A}+{ }_{\Delta} 835-845}$ \\
\hline PMB91 & pEGFP-C2 & EGFP-Vav1 $1^{\text {K374A+ }{ }_{\Delta} 835-845}$ \\
\hline pMB92 & pEGFP-C2 & EGFP-Vav1 ${ }^{\mathrm{R} 375 \mathrm{~A}+{ }_{\Delta} 835-845}$ \\
\hline pMB93 & pEGFP-C2 & EGFP-Vav1 ${ }^{\mathrm{D} 376 \mathrm{~A}+{ }_{\Delta} 835-845}$ \\
\hline pMB98 & pEGFP-C2 & EGFP-Vav1 $1^{\text {R375A }}$ \\
\hline pMB99 & pEGFP-C2 & EGFP-Vav1 $1^{\text {D376A }}$ \\
\hline pMB77 & pEGFP-C2 & EGFP-Vav1 ${ }^{\text {D792A }}$ \\
\hline pMB86 & pEGFP-C2 & EGFP-Vav1 ${ }^{\mathrm{F} 793 \mathrm{~A}}$ \\
\hline pMB87 & pEGFP-C2 & EGFP-Vav1 ${ }^{\text {C794A }}$ \\
\hline pMB78 & pEGFP-C2 & EGFP-Vav1 ${ }^{\text {R796A }}$ \\
\hline pMB88 & pEGFP-C2 & EGFP-Vav $1^{\mathrm{K} 804 \mathrm{~A}}$ \\
\hline pMB89 & pEGFP-C2 & EGFP-Vav1 ${ }^{\mathrm{N} 835 \mathrm{~A}}$ \\
\hline pMB58 & pEGFP-C2 & EGFP-Vav1 $1^{\text {R790A }}$ \\
\hline pMB59 & pEGFP-C2 & EGFP-Vav1 $1^{\text {Y791A }}$ \\
\hline pMB60 & pEGFP-C2 & EGFP-Vav1 $1^{\text {D797A }}$ \\
\hline pMB61 & pEGFP-C2 & EGFP-Vav1 ${ }^{\text {R798A }}$ \\
\hline pMB62 & pEGFP-C2 & EGFP-Vav1 ${ }^{\text {S799A }}$ \\
\hline pMB63 & pEGFP-C2 & EGFP-Vav1 ${ }^{\mathrm{E} 805 \mathrm{~A}}$ \\
\hline pMB64 & pEGFP-C2 & EGFP-Vav1 ${ }^{\text {G806A }}$ \\
\hline pMB65 & pEGFP-C2 & EGFP-Vav1 $1^{\mathrm{Q} 817 \mathrm{~A}}$ \\
\hline pMB66 & pEGFP-C2 & EGFP-Vav1 ${ }^{\mathrm{Q} 818 \mathrm{~A}}$ \\
\hline pMB67 & pEGFP-C2 & EGFP-Vav1 ${ }^{\text {Y826A }}$ \\
\hline pMB68 & pEGFP-C2 & EGFP-Vav1 ${ }^{\text {G827A }}$ \\
\hline
\end{tabular}




\section{Anexo I (continuación)}

\begin{tabular}{|c|c|c|}
\hline Nombre & Tipo de vector & Proteína codificada \\
\hline pMB79 & pEGFP-C2 & EGFP-Vav1 1837A \\
\hline pMB80 & pEGFP-C2 & EGFP-Vav1 $1^{\text {E838A }}$ \\
\hline pMB81 & pEGFP-C2 & EGFP-Vav1 ${ }^{\mathrm{E} 839 \mathrm{~A}}$ \\
\hline pMB82 & pEGFP-C2 & EGFP-Vav1 D840A \\
\hline pMB83 & pEGFP-C2 & EGFP-Vav1 ${ }^{\mathrm{S} 842 \mathrm{~A}}$ \\
\hline pMB84 & pEGFP-C2 & EGFP-Vav1 ${ }^{\mathrm{E} 843 \mathrm{~A}}$ \\
\hline pMB94 & pEGFP-C2 & EGFP-Vav1 DFCmut \\
\hline pMB100 & pEGFP-C2 & EGFP-Vav1 DFC-Rmut \\
\hline pMB101 & pEGFP-C2 & EGFP-Vav1 YVEEDmut \\
\hline pMB104 & pEGFP-C2 & EGFP-Vav1 1FC-R+YVEEDmut \\
\hline pMB111 & pEGFP-C2 & EGFP-Vav1 1 $376 \mathrm{~A}+\mathrm{DFC}-\mathrm{Rmut}$ \\
\hline pMB109 & pEGFP-C2 & EGFP-Vav1 1376A+DFC-R+YVEEDmut \\
\hline pMB108 & pGEX 6P-1 & GST-CSH3 ${ }^{\text {DFC-Rmut }}$ \\
\hline pMB130 & pGEX 6P-1 & GST-CSH3 $3^{\text {YVEEDmut }}$ \\
\hline pMB131 & pGEX 6P-1 & GST-CSH3 DFC-R+YVEEDmut \\
\hline pMB115 & pGEX 6P-1 & GST-SH3 ${ }^{\text {DFC-R+P833Lmut }}$ \\
\hline pMB141 & pGEX 6P-1 & GST-SH3 $3^{\text {P833L+YVEEDmut }}$ \\
\hline pMB142 & pGEX 6P-1 & GST-SH3 DFC-Rmut+P833L+YVEEDmut \\
\hline pJRC64 & pEF1-Myc-His A & Vav1 ${ }^{\mathrm{Y} 541 \mathrm{~F}}$ \\
\hline pMB13 & pEF1-Myc-His A & Vav1 $1^{\mathrm{Y} 174 \mathrm{~F}+\mathrm{Y} 541 \mathrm{~F}}$ \\
\hline pMB23 & pEF1-Myc-His A & Vav1 ${ }^{\text {Y541E }}$ \\
\hline pMB124 & pEF1-Myc-His A & Vav1 ${ }^{\text {Y174F+Y541E }}$ \\
\hline pJRC65 & pEF1-Myc-His A & Vav1 ${ }^{\text {Y544F }}$ \\
\hline pMB14 & pEF1-Myc-His A & Vav1 ${ }^{\mathrm{Y} 174 \mathrm{~F}+\mathrm{Y} 544 \mathrm{~F}}$ \\
\hline pMB24 & pEF1-Myc-His A & Vav1 $1^{\text {Y544E }}$ \\
\hline pMB31 & pEF1-Myc-His A & Vav1 $1^{Y 174 F+Y 544 E}$ \\
\hline pMB41 & pGEX 6P-1 & GST-CSH3 $^{\text {Y836F }}$ \\
\hline pMB36 & pGEX 6P-1 & GST-CSH3 ${ }^{\text {Y836E }}$ \\
\hline pKES23 & pcDNA3 & Vav1 $^{\mathrm{Y} 142 \mathrm{~F}}$ \\
\hline pMB120 & pcDNA3 & Vav1 ${ }^{\mathrm{Y} 160 \mathrm{~F}}$ \\
\hline pMB38 & $\mathrm{pEF} 1 / \mathrm{myc}-\mathrm{His} \mathrm{A}$ & Vav1 ${ }^{\mathrm{Y} 3 \mathrm{xF}+\mathrm{Y} 836 \mathrm{~F}}$ \\
\hline pMB28 & pEF1/myc-His A & Vav1 ${ }^{\mathrm{Y} 142 \mathrm{E}}$ \\
\hline pMB29 & $\mathrm{pEF} 1 / \mathrm{myc}-\mathrm{His} \mathrm{A}$ & Vav1 ${ }^{\mathrm{Y} 160 \mathrm{E}}$ \\
\hline pMB30 & pEF1/myc-His A & Vav1 ${ }^{\text {Y174E }}$ \\
\hline pKES24 & pcDNA3 & Vav1 $1^{\mathrm{Y} 142 \mathrm{~F}+\mathrm{Y} 174 \mathrm{~F}}$ \\
\hline pKES25 & pcDNA3 & Vav1 $1^{\mathrm{Y} 160 \mathrm{~F}+\mathrm{Y} 174 \mathrm{~F}}$ \\
\hline pMB37 & pEF1/myc-His A & Vav1 ${ }^{\mathrm{Y} 160 F+\mathrm{Y} 174 \mathrm{E}}$ \\
\hline pMB45 & $\mathrm{pEF} 1 / \mathrm{myc}-\mathrm{His} \mathrm{A}$ & Vav1 ${ }^{\mathrm{Y} 160 \mathrm{E}+\mathrm{Y} 174 \mathrm{E}}$ \\
\hline
\end{tabular}




\section{Anexo II}

Lista de oligonucleótidos utilizados para introducir mutaciones puntuales o combinadas en el cDNA de Vav1. D, directo; $R$, reverso.

\begin{tabular}{|c|c|c|}
\hline Mutación & & Oligo \\
\hline \multirow{2}{*}{ Y174F } & D & $\begin{array}{l}\text { 5'-GCA GAG GGG GAC GAG ATC TTC GAG GAC CTA ATG } \\
\text { CGC TTG-3' }\end{array}$ \\
\hline & $\mathrm{R}$ & $\begin{array}{l}\text { 5'-CAA GCG CAT TAG GTC CTC GAA GAT CTC GTC CCC } \\
\text { CTC TGC-3' }\end{array}$ \\
\hline \multirow{2}{*}{ P833L } & $\mathrm{D}$ & $\begin{array}{l}\text { 5'-CGG CCG GAT CGG CTG GTT CCC TTC TAA CTA TGT } \\
\text { GGA GGA AG-3' }\end{array}$ \\
\hline & $\mathrm{R}$ & $\begin{array}{l}\text { 5'-CTT CCT CCA CAT AGT TAG AAG GGA ACC AGC CGA } \\
\text { TCC GGC CG-3' }\end{array}$ \\
\hline \multirow{2}{*}{ AAAP } & $\mathrm{D}$ & $\begin{array}{l}\text { 5'-GGA ATA CTA TGG GAT CGC TGC TGC ACC TGG AGC- } \\
3 \text {,' }\end{array}$ \\
\hline & $\mathrm{R}$ & $\begin{array}{l}\text { 5'-GCT CCA GGT GCA GCA GCG ATC CCA TAG TAT TCC- } \\
3 \text { ' }\end{array}$ \\
\hline \multirow{2}{*}{ P651L } & $\mathrm{D}$ & 5'-GTC GGC TGG TTT CTC TGT AAC AGA GTG C-3' \\
\hline & $\mathrm{R}$ & 5'-GCA CTC TGT TAC AGA GAA ACC AGC CGA C-3' \\
\hline \multirow{2}{*}{ NEmut } & $\mathrm{D}$ & $\begin{array}{l}\text { 5'-GGG ACC TGG CAC AGT GCG TGG CCG CGG TCA AGA } \\
\text { GGG ACA ATG AAA CC-3' }\end{array}$ \\
\hline & $\mathrm{R}$ & $\begin{array}{l}\text { 5'-GGT TTC ATT GTC CCT CTT GAC CGC GGC CAC GCA } \\
\text { CTG TGC CAG GTC CC-3' }\end{array}$ \\
\hline \multirow{2}{*}{ VKmut } & $\mathrm{D}$ & $\begin{array}{l}\text { 5'-CTG GCA CAG TGC GTG AAC GAG GCC GCG AGG GAC } \\
\text { AAT GAA ACC CTA CGG-3' }\end{array}$ \\
\hline & $\mathrm{R}$ & $\begin{array}{l}\text { 5'-CCG TAG GGT TTC ATT GTC CCT CGC GGC CTC GTT } \\
\text { CAC GCA CTG TGC CAG-3', }\end{array}$ \\
\hline \multirow{2}{*}{ RDmut } & $\mathrm{D}$ & $\begin{array}{l}\text { 5'-GCA CAG TGC GTG AAC GAG GTC AAG GCG GCC AAT } \\
\text { GAA ACC CTA CGG CAG ATC AC-3' }\end{array}$ \\
\hline & $\mathrm{R}$ & $\begin{array}{l}\text { 5'-GTG ATC TGC CGT AGG GTT TCA TTG GCC GCC TTG } \\
\text { ACC TCG TTC ACG CAC TGT GC-3' }\end{array}$ \\
\hline \multirow{2}{*}{$\mathrm{NE}+\mathrm{RDmut}$} & $\mathrm{D}$ & $\begin{array}{l}\text { 5'-GGG ACC TGG CAC AGT GCG TGG CCG CGG TCA AGG } \\
\text { CGG CCA ATG AAA CC-3' }\end{array}$ \\
\hline & $\mathrm{R}$ & $\begin{array}{l}5^{\prime} \text {-GGT TTC ATT GGC CGC CTT GAC CGC GGC CAC GCA } \\
\text { CTG TGC CAG GTC CC-3' }\end{array}$ \\
\hline \multirow{2}{*}{ NEVKRDmut } & $\mathrm{D}$ & $\begin{array}{l}\text { 5'-CTG GCA CAG TGC GTG GCC GCG GCC GCG GCG GCC } \\
\text { AAT GAA ACC CTA CGG-3' }\end{array}$ \\
\hline & $\mathrm{R}$ & $\begin{array}{l}\text { 5'-CCG TAG GGT TTC ATT GGC CGC CGC GGC CGC GGC } \\
\text { CAC GCA CTG TGC CAG-3' }\end{array}$ \\
\hline \multirow{2}{*}{ T384A } & $\mathrm{D}$ & $\begin{array}{l}\text { 5'-GGG ACA ATG AAA CCC TAC GGC AGA TCG CAA ACT } \\
\text { TTC AGC TGT CCA TTG AGA AC-3' }\end{array}$ \\
\hline & $\mathrm{R}$ & $\begin{array}{l}\text { 5'-GTT CTC AAT GGA CAG CTG AAA GTT TGC GAT CTG } \\
\text { CCG TAG GGT TTC ATT GTC CC-3' }\end{array}$ \\
\hline
\end{tabular}




\section{Anexo II (continuación)}

\begin{tabular}{|c|c|c|}
\hline Mutación & & Oligo \\
\hline \multirow{2}{*}{ L388A } & $\mathrm{D}$ & $\begin{array}{l}\text { 5'-GGC AGA TCA CAA ACT TTC AGG CGT CCA TTG AGA } \\
\text { ACC TGG ACC-3' }\end{array}$ \\
\hline & $\mathrm{R}$ & $\begin{array}{l}\text { 5'-GGT CCA GGT TCT CAA TGG ACG CCT GAA AGT TTG } \\
\text { TGA TCT GCC-3' }\end{array}$ \\
\hline \multirow{2}{*}{ V373A } & $\mathrm{D}$ & $\begin{array}{l}\text { 5'-GGC ACA GTG CGT GAA CGA GGC CAA GAG GGA } \\
\text { CAA TGA AAC CCT AC-3' }\end{array}$ \\
\hline & $\mathrm{R}$ & $\begin{array}{l}\text { 5'-GTA GGG TTT CAT TGT CCC TCT TGG CCT CGT TCA } \\
\text { CGC ACT GTG CC-3' }\end{array}$ \\
\hline \multirow{2}{*}{ K374A } & $\mathrm{D}$ & $\begin{array}{l}\text { 5'-GGC ACA GTG CGT GAA CGA GGT CGC GAG GGA CAA } \\
\text { TGA AAC CC-3' }\end{array}$ \\
\hline & $\mathrm{R}$ & $\begin{array}{l}\text { 5'-GGG TTT CAT TGT CCC TCG CGA CCT CGT TCA CGC } \\
\text { ACT GTG CC-3' }\end{array}$ \\
\hline \multirow{2}{*}{ R375A } & $\mathrm{D}$ & $\begin{array}{l}\text { 5'-CAG TGC GTG AAC GAG GTC AAG GCG GAC AAT GAA } \\
\text { ACC CTA CGG-3' }\end{array}$ \\
\hline & $\mathrm{R}$ & $\begin{array}{l}\text { 5'-CCG TAG GGT TTC ATT GTC CGC CTT GAC CTC GTT } \\
\text { CAC GCA CTG-3' }\end{array}$ \\
\hline \multirow{2}{*}{ D376A } & $\mathrm{D}$ & $\begin{array}{l}\text { 5'-GTG AAC GAG GTC AAG AGG GCC AAT GAA ACC CTA } \\
\text { CGG CAG-3' }\end{array}$ \\
\hline & $\mathrm{R}$ & $\begin{array}{l}\text { 5'-CTG CCG TAG GGT TTC ATT GGC CCT CTT GAC CTC } \\
\text { GTT CAC-3' }\end{array}$ \\
\hline \multirow{2}{*}{ D792A } & $\mathrm{D}$ & $\begin{array}{l}\text { 5'-GCA CTG CCA AAG CCC GCT ACG CCT TCT GTG CCC } \\
\text { GGG ACA GGT C-3' }\end{array}$ \\
\hline & $\mathrm{R}$ & $\begin{array}{l}\text { 5'- GAC CTG TCC CGG GCA CAG AAG GCG TAG CGG GCT } \\
\text { TTG GCA GTG C -3' }\end{array}$ \\
\hline \multirow{2}{*}{ F793A } & D & $\begin{array}{l}\text { 5'- CTG CCA AAG CCC GCT ACG ACG CCT GTG CCC GGG } \\
\text { ACA GGT CGG -3' }\end{array}$ \\
\hline & $\mathrm{R}$ & $\begin{array}{l}\text { 5'- CCG ACC TGT CCC GGG CAC AGG CGT CGT AGC GGG } \\
\text { CTT TGG CAG -3' }\end{array}$ \\
\hline \multirow{2}{*}{ C794A } & D & $\begin{array}{l}\text { 5'-CCA AAG CCC GCT ACG ACT TCG CTG CCC GGG ACA } \\
\text { GGT CGG AAC-3' }\end{array}$ \\
\hline & $\mathrm{R}$ & $\begin{array}{l}\text { 5'-GTT CCG ACC TGT CCC GGG CAG CGA AGT CGT AGC } \\
\text { GGG CTT TGG-3' }\end{array}$ \\
\hline \multirow{2}{*}{ R796A } & $\mathrm{D}$ & $\begin{array}{l}\text { 5'-CGC TAC GAC TTC TGT GCC GCG GAC AGG TCG GAA } \\
\text { CTG TCC C-3' }\end{array}$ \\
\hline & $\mathrm{R}$ & $\begin{array}{l}\text { 5'-GGG ACA GTT CCG ACC TGT CCG CGG CAC AGA AGT } \\
\text { CGT AGC G-3' }\end{array}$ \\
\hline \multirow{2}{*}{ K804A } & $\mathrm{D}$ & $\begin{array}{l}\text { 5'-GGA CAG GTC GGA ACT GTC CCT TGC GGA GGG TGA } \\
\text { TAT CAT CAA GAT C-3' }\end{array}$ \\
\hline & $\mathrm{R}$ & $\begin{array}{l}5^{\prime} \text {-GAT CTT GAT GAT ATC ACC CTC CGC AAG GGA CAG } \\
\text { TTC CGA CCT GTC C-3' }\end{array}$ \\
\hline
\end{tabular}




\section{Anexo II (continuación)}

\begin{tabular}{|c|c|c|}
\hline Mutación & & Oligo \\
\hline \multirow{2}{*}{ N835A } & $\mathrm{D}$ & $\begin{array}{l}\text { 5'- CGG ATC GGC TGG TTC CCT TCT GCC TAT GTG GAG } \\
\text { GAA GAC TAT TC -3' }\end{array}$ \\
\hline & $\mathrm{R}$ & $\begin{array}{l}\text { 5'- GAA TAG TCT TCC TCC ACA TAG GCA GAA GGG AAC } \\
\text { CAG CCG ATC CG -3' }\end{array}$ \\
\hline \multirow{2}{*}{ R790A } & $\mathrm{D}$ & $\begin{array}{l}\text { 5'- GTA TTT TGG CAC TGC CAA AGC CGC CTA CGA CTT } \\
\text { CTG TGC CCG GGA C -3' }\end{array}$ \\
\hline & $\mathrm{R}$ & $\begin{array}{l}\text { 5'- GTC CCG GGC ACA GAA GTC GTA GGC GGC TTT GGC } \\
\text { AGT GCC AAA ATA C -3' }\end{array}$ \\
\hline \multirow{2}{*}{ Y791A } & $\mathrm{D}$ & $\begin{array}{l}\text { 5'- GCA CTG CCA AAG CCC GCG CCG ACT TCT GTG CCC } \\
\text { GGG -3' }\end{array}$ \\
\hline & $\mathrm{R}$ & $\begin{array}{l}\text { 5'- CCC GGG CAC AGA AGT CGG CGC GGG CTT TGG CAG } \\
\text { TGC -3' }\end{array}$ \\
\hline \multirow{2}{*}{ D797A } & D & $\begin{array}{l}\text { 5'- CGC TAC GAC TTC TGT GCC CGG GCC AGG TCG GAA } \\
\text { CTG TCC CTT AAG -3' }\end{array}$ \\
\hline & $\mathrm{R}$ & $\begin{array}{l}\text { 5'- CTT AAG GGA CAG TTC CGA CCT GGC CCG GGC ACA } \\
\text { GAA GTC GTA GCG -3' }\end{array}$ \\
\hline \multirow{2}{*}{ R798A } & $\mathrm{D}$ & $\begin{array}{l}\text { 5'- CTA CGA CTT CTG TGC CCG GGA CGC GTC GGA ACT } \\
\text { GTC CCT TAA GGA G -3' }\end{array}$ \\
\hline & $\mathrm{R}$ & $\begin{array}{l}\text { 5'- CTC CTT AAG GGA CAG TTC CGA CGC GTC CCG GGC } \\
\text { ACA GAA GTC GTA G -3' }\end{array}$ \\
\hline \multirow{2}{*}{ S799A } & $\mathrm{D}$ & $\begin{array}{l}\text { 5'- GAC TTC TGT GCC CGG GAC AGG GCG GAA CTG TCC } \\
\text { CTT AAG GAG G -3' }\end{array}$ \\
\hline & $\mathrm{R}$ & $\begin{array}{l}\text { 5'- CCT CCT TAA GGG ACA GTT CCG CCC TGT CCC GGG } \\
\text { CAC AGA AGT C -3' }\end{array}$ \\
\hline \multirow{2}{*}{ E805A } & $\mathrm{D}$ & $\begin{array}{l}\text { 5'- GTC GGA ACT GTC CCT TAA GGC GGG TGA TAT CAT } \\
\text { CAA GAT CC -3' }\end{array}$ \\
\hline & $\mathrm{R}$ & $\begin{array}{l}\text { 5'- GGA TCT TGA TGA TAT CAC CCG CCT TAA GGG ACA } \\
\text { GTT CCG AC -3' }\end{array}$ \\
\hline \multirow{2}{*}{ G806A } & D & $\begin{array}{l}\text { 5'- GAA CTG TCC CTT AAG GAG CGT GAT ATC ATC AAG } \\
\text { ATC C -3' }\end{array}$ \\
\hline & $\mathrm{R}$ & $\begin{array}{l}\text { 5'- GGA TCT TGA TGA TAT CAC GCT CCT TAA GGG ACA } \\
\text { GTT C -3' }\end{array}$ \\
\hline \multirow{2}{*}{ Q817A } & $\mathrm{D}$ & $\begin{array}{l}\text { 5'- GAT CCT CAA TAA GAA GGG ACG GCA AGG CTG } \\
\text { GTG GCG TGG GG -3' }\end{array}$ \\
\hline & $\mathrm{R}$ & $\begin{array}{l}\text { 5'- CCC CAC GCC ACC AGC CTT GCC GTC CCT TCT TAT } \\
\text { TGA GGA TC -3' }\end{array}$ \\
\hline \multirow{2}{*}{ Q818A } & D & $\begin{array}{l}\text { 5'- CTC AAT AAG AAG GGA CAG CGA GGC TGG TGG } \\
\text { CGT GGG GAG -3' }\end{array}$ \\
\hline & $\mathrm{R}$ & $\begin{array}{l}\text { 5'- CTC CCC ACG CCA CCA GCC TCG CTG TCC CTT CTT } \\
\text { ATT GAG -3' }\end{array}$ \\
\hline
\end{tabular}




\section{Anexo II (continuación)}

\begin{tabular}{|c|c|c|}
\hline Mutación & & Oligo \\
\hline \multirow[b]{2}{*}{ Y826A } & $\mathrm{D}$ & $\begin{array}{l}\text { 5'-CTG GTG GCG TGG GGA GAT CCG CGG CCG GAT CGG } \\
\text { CTG GTT C-3' }\end{array}$ \\
\hline & $\mathrm{R}$ & $\begin{array}{l}\text { 5'-GAA CCA GCC GAT CCG GCC GCG GAT CTC CCC ACG } \\
\text { CCA CCA G-3' }\end{array}$ \\
\hline \multirow{2}{*}{ G827A } & D & $\begin{array}{l}\text { 5'-CTG GTG GCG TGG GGA GAT CTA CCG CCG GAT CGG } \\
\text { CTG GTT CCC TTC-3' }\end{array}$ \\
\hline & $\mathrm{R}$ & $\begin{array}{l}\text { 5'-GAA GGG AAC CAG CCG ATC CGG CGG TAG ATC TCC } \\
\text { CCA CGC CAC CAG-3' }\end{array}$ \\
\hline \multirow{2}{*}{ V837A } & D & $\begin{array}{l}\text { 5'-CGG CTG GTT CCC TTC TAA CTA TGC GGA GGA AGA } \\
\text { CTA TTC CGA ATA TTG-3' }\end{array}$ \\
\hline & $\mathrm{R}$ & $\begin{array}{l}\text { 5'-CAA TAT TCG GAA TAG TCT TCC TCC GCA TAG TTA } \\
\text { GAA GGG AAC CAG CCG-3' }\end{array}$ \\
\hline \multirow{2}{*}{ E838A } & D & $\begin{array}{l}\text { 5'-CTG GTT CCC TTC TAA CTA TGT GGC GGA AGA CTA } \\
\text { TTC CGA ATA TTG-3' }\end{array}$ \\
\hline & $\mathrm{R}$ & $\begin{array}{l}\text { 5'-CAA TAT TCG GAA TAG TCT TCC GCC ACA TAG TTA } \\
\text { GAA GGG AAC CAG-3' }\end{array}$ \\
\hline \multirow{2}{*}{ E839A } & D & $\begin{array}{l}\text { 5'-CCT TCT AAC TAT GTG GAG GCA GAC TAT TCC GAA } \\
\text { TAT TGC-3' }\end{array}$ \\
\hline & $\mathrm{R}$ & $\begin{array}{l}\text { 5'-GCA ATA TTC GGA ATA GTC TGC CTC CAC ATA GTT } \\
\text { AGA AGG-3' }\end{array}$ \\
\hline \multirow{2}{*}{ D840A } & $\mathrm{D}$ & $\begin{array}{l}\text { 5'-CTT CTA ACT ATG TGG AGG AAG CCT ATT CCG AAT } \\
\text { ATT GCT GAG C-3' }\end{array}$ \\
\hline & $\mathrm{R}$ & $\begin{array}{l}\text { 5'-GCT CAG CAA TAT TCG GAA TAG GCT TCC TCC ACA } \\
\text { TAG TTA GAA G-3' }\end{array}$ \\
\hline \multirow{2}{*}{ S842A } & D & $\begin{array}{l}\text { 5'-CTA TGT GGA GGA AGA CTA TGC CGA ATA TTG CTG } \\
\text { AGC CTG-3' }\end{array}$ \\
\hline & $\mathrm{R}$ & $\begin{array}{l}\text { 5'-CAG GCT CAG CAA TAT TCG GCA TAG TCT TCC TCC } \\
\text { ACA TAG-3' }\end{array}$ \\
\hline \multirow{2}{*}{ E843A } & D & $\begin{array}{l}\text { 5'-GTG GAG GAA GAC TAT TCC GCA TAT TGC TGA GCC } \\
\text { TGG TGC-3' }\end{array}$ \\
\hline & $\mathrm{R}$ & $\begin{array}{l}\text { 5'-GCA CCA GGC TCA GCA ATA TGC GGA ATA GTC TTC } \\
\text { CTC CAC-3' }\end{array}$ \\
\hline \multirow{2}{*}{ DFCmut } & $\mathrm{D}$ & $\begin{array}{l}\text { 5'-GCA CTG CCA AAG CCC GCT ACG CCG CCG CAG CCC } \\
\text { GGG ACA GGT CGG AAC TG-3' }\end{array}$ \\
\hline & $\mathrm{R}$ & $\begin{array}{l}\text { 5'-CAG TTC CGA CCT GTC CCG GGC TGC GGC GGC GTA } \\
\text { GCG GGC TTT GGC AGT GC-3' }\end{array}$ \\
\hline \multirow{2}{*}{ DFC-Rmut } & $\mathrm{D}$ & $\begin{array}{l}\text { 5'-CGC TAC GCC GCC GCA GCC GCG GAC AGG TCG GAA } \\
\text { CTG TCC C-3' }\end{array}$ \\
\hline & $\mathrm{R}$ & $\begin{array}{l}\text { 5'-GGG ACA GTT CCG ACC TGT CCG CGG CTG CGG CGG } \\
\text { CGT AGC G-3' }\end{array}$ \\
\hline
\end{tabular}




\section{Anexo II (continuación)}

\begin{tabular}{|c|c|c|}
\hline Mutación & & Oligo \\
\hline \multirow{2}{*}{ YVEEDmut } & D & $\begin{array}{l}\text { 5'-CGG ATC GGC TGG TTC CCT TCT AAC GCA GCG GCG } \\
\text { GCA GCC TAT TCC GAA TAT TG-3' }\end{array}$ \\
\hline & $\mathrm{R}$ & $\begin{array}{l}\text { 5'-CAA TAT TCG GAA TAG GCT GCC GCC GCT GCG TTA } \\
\text { GAA GGG AAC CAG CCG ATC CG-3' }\end{array}$ \\
\hline \multirow{2}{*}{$\begin{array}{l}\text { P833L+YVEED } \\
\text { mut }\end{array}$} & D & $\begin{array}{l}\text { 5'-CGG ATC GGC TGG TTC CCT TCT AAC GCA GCG GCG } \\
\text { GCA GCC TAT TCC GAA TAT TG-3' }\end{array}$ \\
\hline & $\mathrm{R}$ & $\begin{array}{l}\text { 5'-CAA TAT TCG GAA TAG GCT GCC GCC GCT GCG TTA } \\
\text { GAA GGG AAC CAG CCG ATC CG-3' }\end{array}$ \\
\hline \multirow[b]{2}{*}{ Y541F } & $\mathrm{D}$ & $\begin{array}{l}\text { 5'-GGC ACA TTC TAC CAG GGA TTT CGC TGT TAC AGG } \\
\text { TGC CGG-3' }\end{array}$ \\
\hline & $\mathrm{R}$ & $\begin{array}{l}\text { 5'-CCG GCA CCT GTA ACA GCG AAA TCC CTG GTA GAA } \\
\text { TGT GCC-3' }\end{array}$ \\
\hline \multirow{2}{*}{ Y541E } & D & $\begin{array}{l}\text { 5'-GGC ACA TTC TAC CAG GGA GAG CGC TGT TAC AGG } \\
\text { TGC CGG-3' }\end{array}$ \\
\hline & $\mathrm{R}$ & $\begin{array}{l}\text { 5'-CCG GCA CCT GTA ACA GCG CTC TCC CTG GTA GAA } \\
\text { TGT GCC-3' }\end{array}$ \\
\hline \multirow{2}{*}{ Y544F } & D & $\begin{array}{l}\text { 5'-GGC ACA TTC TAC CAG TTT GAA CGC TGT TAC AGG- } \\
\text { 3, }\end{array}$ \\
\hline & $\mathrm{R}$ & $\begin{array}{l}\text { 5'-CCT GTA ACA GCG TTC AAA CTG GTA GAA TGT GCC- } \\
\text { 3', }\end{array}$ \\
\hline \multirow[b]{2}{*}{ Y544E } & $\mathrm{D}$ & $\begin{array}{l}\text { 5'-GGC ACA TTC TAC CAG GGA GAA CGC TGT TAC AGG- } \\
\text { 3, }\end{array}$ \\
\hline & $\mathrm{R}$ & $\begin{array}{l}\text { 5'-CCT GTA ACA GCG TTC TCC CTG GTA GAA TGT GCC- } \\
\text { 3, }\end{array}$ \\
\hline \multirow{2}{*}{ Y836F } & $\mathrm{D}$ & $\begin{array}{l}\text { 5'-CGG CTG GTT CCC TTC TAA CTT TGT GGA GGA AGA } \\
\text { CTA TTC CG-3' }\end{array}$ \\
\hline & $\mathrm{R}$ & $\begin{array}{l}\text { 5'-CGG AAT AGT CTT CCT CCA CAA AGT TAG AAG GGA } \\
\text { ACC AGC CG-3' }\end{array}$ \\
\hline \multirow{2}{*}{ Y836E } & D & $\begin{array}{l}\text { 5'-GGC TGG TTC CCT TCT AAC GAG GTG GAG GAA GAC } \\
\text { TAT TCC-3' }\end{array}$ \\
\hline & $\mathrm{R}$ & $\begin{array}{l}\text { 5'-GGA ATA GTC TTC CTC CAC CTC GTT AGA AGG GAA } \\
\text { CCA GCC-3' }\end{array}$ \\
\hline \multirow{2}{*}{$\mathrm{Y} 142 \mathrm{~F}$} & D & $\begin{array}{l}\text { 5'- CTG AAC GAC GAA GAT ATT TTC AGT GGC CTT TCA } \\
\text { GAC CAG -3' }\end{array}$ \\
\hline & $\mathrm{R}$ & $\begin{array}{l}\text { 5'- CTG GTC TGA AAG GCC ACT GAA AAT ATC TTC GTC } \\
\text { GTT CAG -3' }\end{array}$ \\
\hline \multirow{2}{*}{ Y160F } & D & $\begin{array}{l}\text { 5'- GAG GAA GAC GAG GAC CTT TTT GAC TGC GTG } \\
\text { GAA AAT GAG -3' }\end{array}$ \\
\hline & $\mathrm{R}$ & $\begin{array}{l}\text { 5'- CTC ATT TTC CAC GCA GTC AAA AAG GTC CTC GTC } \\
\text { TTC CTC -3' }\end{array}$ \\
\hline
\end{tabular}




\section{Anexo II (continuación)}

\begin{tabular}{|c|l|l|}
\hline Mutación & \multicolumn{2}{|c|}{ Oligo } \\
\hline \multirow{3}{*}{ Y142E } & D $\begin{array}{l}\text { 5'- GCG AGA CTT GCT GCT TCT ATA ACT CTC ACC GGA } \\
\text { AAG TCT GGT CTA AC -3' }\end{array}$ \\
\cline { 2 - 3 } & R & $\begin{array}{l}\text { 5'- CAA TCT GGT CTG AAA GGC CAC TCT CAA TAT CTT } \\
\text { CGT CGT TCA GAG CG -3' }\end{array}$ \\
\hline \multirow{3}{*}{ Y160E } & D & $\begin{array}{l}\text { 5'- CGT CTC CTT CTG CTC CTG GAA CTC CTG ACG CAC } \\
\text { CTT TTA CTC CTC -3' }\end{array}$ \\
\cline { 2 - 3 } & R & $\begin{array}{l}\text { 5'- CTC CTC ATT TTC CAC GCA GTC CTC AAG GTC CTC } \\
\text { GTC TTC CTC TGC -3' }\end{array}$ \\
\hline Y174E & D & $\begin{array}{l}\text { 5'- CTC CGT CTC CCC CTG CTC TAG CTC CTC CTG GAT } \\
\text { TAC GCG AAC CTC -3' }\end{array}$ \\
\cline { 2 - 3 } & R & $\begin{array}{l}\text { 5'- CTC CAA GCG CAT TAG GTC CTC CTC GAT CTC GTC } \\
\text { CCC CTC TGC CTC -3' }\end{array}$ \\
\hline
\end{tabular}




\section{Abreviaturas}

Ac

ADN

ADNc

Alk

A-loop

AP-1

APC

APS/SH2B2

ARN

ARNm

Arp2/3

ATF2

BCAP

BCR

$\mathrm{Brc} / \mathrm{Abl}$

Blnk

BSA

Btk

CD2

CD3

CD4

CD8

CD19

CD22

CD28

CD45
Región acídica.

Ácido dexoxirribonucléico.

ADN complementario.

Anaplastic lymphoma kinase. Quinasa de linfomas anaplásicos.

Activation loop. Búcle de activación.

Activator protein 1. Proteína activadora 1.

Antigen presenting cell. Célula presentadora de antígenos.

Adaptor protein 2. Proteína adaptadora 2.

Ácido ribonuléico.

ARN mensajero.

Actin related proteins 2 and 3. Proteínas relacionadas con actina 2 y 3 .

Activating transcription factor 2. Factor de transcripción activador 2.

B-cell adaptor for phosphoinositide 3-kinase. Proteína adaptadora de PI3K en células $\mathrm{B}$.

B-cell receptor. Receptor de células B.

Breaking cluster region / Abelson fusion gene. Gen de fusión del gen de región de ruptura del cromosoma 22 y el gen Abelson del cromosoma 9.

B-cell linker protein. Proteína conectora de células B.

Bovine serum albumin. Albúmina sérica bovina.

Bruton's tyrosine kinase. Proteína tirosina quinasa de Bruton.

Cluster of differentiation 2. Grupo de diferenciación 2.

Cluster of differentiation 3. Grupo de diferenciación 3.

Cluster of differentiation 4. Grupo de diferenciación 4.

Cluster of differentiation 8. Grupo de diferenciación 8.

Cluster of differentiation 19. Grupo de diferenciación 19.

Cluster of differentiation 22. Grupo de diferenciación 22.

Cluster of differentiation 28. Grupo de diferenciación 28.

Cluster of differentiation 45. Grupo de diferenciación 45. 
CD58

Cdc42

$\mathrm{CH}$

CLEC-2

$\mathrm{CSH} 3$

Csk

C-terminal

DAG

DAPI

DEAE-dextrano

$\mathrm{DH}$

DMEM

DMSO

DTT

$\mathrm{ECL}$

EGF

EGFP

EGF-R

EM

EpoR

Erk

FAK

FBS

Fc $\gamma R$

FceR

Gads

GAP

GDI
Cluster of differentiation 58. Grupo de diferenciación 58.

Cell division control protein 42 homolog. Proteína de control del ciclo celular 42.

Calponin homology domain. Dominio de homología a Calponina.

C-type lectin domain family 2. Dominio lectina tipo C familia 2.

C-terminal Src homology 3 domain. Dominio de homología a Src tipo 3 Cterminal.

C-Src tyrosine kinase. Tirosina quinasa de proteínas Src tipo C.

Carboxilo terminal.

Diacilglicerol.

4',6-Diamidino-2-fenilindol diclorhidrato

Dietilaminoetil dextrano.

Dbl homology domain. Dominio de homología a Dbl.

Dulbecco's Modified Eagle Medium. Medio Eagle modificado por Dulbecco.

Dimetil sulfóxido.

Ditiotreitol

Enhanced chemiluminescent substrate. Sustrato quimioluminiscente.

Epidermal growth factor. Factor de crecimiento epidérmico

External Green Fluorescent Protein. Proteína verde fluorescente externa.

Epidermal growth factor receptor. Receptor del factor de crecimiento epidérmico

Electron Microscopy. Microscopía electrónica.

Erythropoyetin Receptor. Receptor de eritropoyetina.

Extracellular signal-Regulated Kinase. Quinasa regulada por señales extracelulares.

Focal Adhesion Kinase. Quinasa de adhesión focal.

Fetal Bovine Serum. Suero fetal bovino.

Fcy receptor. Receptor de Fcy.

Fcع receptor. Receptor de Fcع.

Grb2-Related Adaptor Downstream of Shc. Proteína adaptadora ligada a Grb2.

GTPase Activating Protein. Proteína activadora de GTPasas.

GDP Dissociation Inhibitor. Inhibidor de la disociación de GDP. 
GEF

GEM

GPVI

Grb2, Grb3-3

GTP

GST

HEPES

HGF-R

HLA

hnRNP

HRP

HTVL-1

ICAM-1

IGF-R

$\lg M$

IL-2

IL-2R

IL-3

IL-4

IL-6

IL-10

IP

IPTG

I-R

ITAMs
Guanosine Exchange Factor. Factor de intercambio de núcleotidos de guanina.

Glycosphingolipid Enriched Microdomains. Microdominios enriquecidos con glicoesfingolípidos.

Glycoprotein VI. Glicoproteína VI.

Growth factor Receptor-Bound protein 2 and 3-3. Proteína unida al receptor del factor de crecimiento 2 y 3-3.

Guanosine Triphosphate. Guanosina trifosfato.

Glutation S-transferasa.

4-(2-hydroxyethyl)-1-piperazineethanesulfonic acid. Ácido 4-(2-hidroxiethil)-1 piperacinetanosulfónico.

Hepatocyte Growth Factor Receptor. Receptor del factor de crecimiento de hepatocitos.

Human Leukocyte Antigen. Antigeno de leucocitos humanos.

Heterogeneous Nuclear Ribonucleoproteins. Ribonuleoproteínas nucleares heterogeneas.

Horseradish peroxidase. Peroxidasa de rábano.

Human T-lymphotropic Virus 1. Virus humano linfotrópico de células T.

Intercellular Adhesion Molecule 1. Molécula de adhesión intracelular 1.

Insulin-like Growth Factor Receptor. Receptor del factor de crecimiento similar a insulina.

Inmunoglobulina M.

Interleucina-2.

Receptor de Interleucina-2.

Interleucina-3.

Interleucina-4.

Interleucina-6.

Interleucina-10.

Inmunoprecipitación.

Isopropil- $\beta-D-$-tiogalactopiranósido.

Insulin Receptor. Receptor de insulina.

Immunoreceptor tyrosine-based activated motifs. Motivos de activación basados 
en tirosinas de los inmunorreceptores.

Itk

JAK

JNK

Lat

LAT2

LB

Lck

LFA-1

LPS

MAPK

MHC

MTOC

Nck

NF-AT

NF-KB

NK

NMR

NOX2

NSH3

$\mathrm{N}$-terminal

PAK

PBS

PCR

PD

PDGF

PDGF-R
IL2-inducible T-cell kinase. Quinasa de células T inducible por IL-2.

Janus kinase. Quinasa de Janus.

c-Jun N-terminal kinase. Quinasa N-terminal de c-Jun.

Linker of Activated T-cells. Proteína de unión de linfocitos T activados.

Linker of Activated T-cells 2. Proteína de unión de linfocitos T activados tipo 2.

Luria Bertani medium. Medio de Luria Bertani.

Lymphocyte-specific protein tyrosine kinase. Proteína tirosina quinasa específica de linfocitos.

Lymphocyte function-associated antigen 1. Antígeno asociado a la función linfocitaria tipo 1.

Lipopolisacárido.

Mitogen-activated tyrosine kinase. Tirosina quinasa activada por mitógenos.

Major Histocompatibility Complex. Complejo mayor de histocompatibilidad.

Microtubule-organizing Centre. Centro de organización de microtúbulos.

Non-catalytic region of tyrosine kinase adaptor proteína 1. Región no catalítica de la proteína adaptadora tirosina quinasa 1.

Nuclear Factor of Activated T-cells. Factor nuclear de linfocitos T activados.

Nuclear factor кB. Factor Nuclear кB.

Natural Killer cells. Células naturales asesinas.

Nuclear Magnetic Resonance. Resonancia nuclear magnética.

Nicotinamide Adenine Dinucleotide Phosphate-oxidase. Oxidasa nicotinamida adenina dinucleótido fosfato.

$\mathrm{N}$-terminal Src homology 3 domain. Dominio N-terminal de homología a Src tipo3.

Amino terminal.

p21 activated kinase. Quinasa activada por p21.

Phosphate buffered saline. Tampón fosfato salino.

Polymerase chain reaction. Reacción en cadena de la polimerasa.

Pull-down.

Platelet derived growth factor. Factor de crecimiento derivado de plaquetas.

Platelet derived growth factor receptor. Receptor del factor de crecimiento 
derivado de plaquetas.

PGN Proteoglicano.

$\mathrm{PH}$

PI

PI(4)P

$\mathrm{PI}(3,4) \mathrm{P}_{2}$

$\mathrm{PI}(3,4,5) \mathrm{P}_{3}$ o $\mathrm{PIP}_{3} \quad$ Phosphatidylinositol-3,4,5-triphosphate. Fosfatidilinositol-3,4,5-trifosfato.

$\mathrm{PI}(4,5) \mathrm{P}_{2}$ o $\mathrm{PIP}_{2} \quad$ Phosphatidylinositol-4,5-bisphosphate. Fosfatidilinositol-4,5-bisfosfato.

PI3K

PIP5K

PKC

PKD

PLC

PTK

PTPasa

PRR

RasGRP

RIPA

ROS

rpm

RPMI-1640

SBS

SDS-PAGE

$\mathrm{SH} 2$

$\mathrm{SH} 3$

SRF

TBS-T

Pleckstrin homology domain. Dominio de homología a pleckstrina.

Phosphatidylinositol. Fosfatidilinositol.

Phosphatidylinositol-4-phosphate. Fosfatidilinositol-4-fosfato.

Phosphatidylinositol-3,4-bisphosphate. Fosfatidilinositol-3,4-bisfosfato.

Phosphatidylinositol 3-kinase. Fosfatidilinositol 3-quinasa.

Phosphatidylinositol-4-phosphate 5-kinase. Fosfatidilinositol-4-fosfato 5quinasa.

Protein kinase C. Proteína quinasa $C$.

Protein kinase C. Proteína quinasa C.

Phospholipase C. Fosfolipasa C.

Protein Tyrosine Kinase. Proteína tirosina quinasa.

Proteína tirosina fosofatasa.

Proline Rich Region. Región rica en prolinas.

RAS guanyl nucleotide-releasing protein. Proteína liberadora de nublótidos de guanina de Ras.

Radio immunoprecipitation assay buffer. Tampón en ensayos de inmunoprecipitación.

Reactive Oxygen Species. Especies reactivas de oxígeno.

Revolutions per minute. Revoluciones por minuto.

Roswell Park Memorial Institute Medium 1640. Medio del Instituto Roswell Park Memorial.

SH3 Binding Site. Sitio de unión a SH3.

Sodium dodecyl sulfate polyacrylamide gel electrophoresis. Electroforesis en gel de poliacrilamida con dodecilsulfato sódico.

Type 2 Src homology domain. Dominio de homología a Src de tipo 2.

Type 3 Src homology domain. Dominio de homología a Src de tipo 3.

Serum response factor. Factor de respuesta a suero.

Tris-Buffered Saline and Tween 20. Tampón Tris salino con Tween 20. 
Tiam1

$\mathrm{VIH}-1$

WASP

WAVE

WB

WT

Zap70

ZF o C1
T-cell lymphoma invasion and metastasis-inducing protein 1. Proteína promotora de metastasis e invasión en linfomas de células T tipo 1.

Tumor Necrosis Factor $\alpha$. Factor de necrosis tumoral $\alpha$.

Virus de Inmunodeficiencia Humano tipo 1.

Wiskott-Aldrich syndrome protein. Proteína del síndrome de Wiskott-Aldrich.

WASP family verprolin-homologous protein. Proteína homóloga a verprolina de la familia WASP.

Western-Blot.

Wild Type. Versión silvestre.

Zeta-chain-associated protein kinase 70. Proteína quinasa asociada a la cadena zeta.

Zinc Finger domain. Dominio en dedos de Zinc. 


\section{Índice de Figuras}

Figura 1. Esquema del ciclo de activación de las GTPasas de la familia Rho/Rac.

Figura 2. Estructura de dominios de los miembros de la familia Vav y la variante transcripcional Vav-T. $\quad 5$

$\begin{array}{lr}\text { Figura 3. Modelo actual de activación de las proteínas Vav. } & \mathbf{9}\end{array}$

Figura 4. Modelo estructural de la interacción Vav1/Rac1.

Figura 5. Interacciones de los distintos dominios de la proteína Vav1 con otras proteínas. $\quad \mathbf{1 2}$

Figura 6. Representación esquemática de la maduración de los linfocitos T. $\quad 24$

Figura 7. Ruta de Vav1 en linfocitos T.

$\begin{array}{ll}\text { Figura 8. Ruta de señalización de Vav1 bajo el receptor de células T (TCR). } & \mathbf{2 7}\end{array}$

Figura 9. El dominio CSH3 inhibe la actividad biológica de Vav1.

Figura 10. Efecto de Vav1 $1^{835-845}$ sobre la activación de NF-AT en linfocitos. 63

Figura 11. La deleción parcial del dominio CSH3 promueve la activación in vivo de las proteínas Vav.

Figura 12. La inhibición mediada por el CSH3 es una característica común de los miembros de la familia Vav.

Figura 13. El dominio CSH3 inhibe a Vav1 en cis debido a su interacción con otras regiones de la proteína.

Figura 14. El dominio CSH3 de Vav1 no interacciona ni con la región rica en prolinas (PRR) ni con el dominio NSH3.

Figura 15. El CSH3 inhibe a Vav1 a través de su interacción con las regiones DH y PH.

Figura 16. Estructura de microscopía electrónica $(E M)$ de la proteína $6 x H i s-V a v 11^{1-144}$ no fosforilada.

Figura 17. Análisis de la conservación filogenética de los residuos de la región CH-Ac-DH-PH-ZF de Vav1.

Figura 18. Caracterización de los residuos de la hélice $\alpha 6$ del $\mathrm{DH}$ que contribuyen a la estabilidad de la interacción inhibitoria CSH3/Vav1.

Figura 19. La hélice $\alpha 6$ participa en la estabilidad de la interacción inhibitoria CSH3/Vav1.

Figura 20. La mutación del residuo $\mathrm{D} 376 \mathrm{~A}$ de la hélice $\alpha 6$ incrementa la actividad de la proteína Vav1.

Figura 21. El CSH3 de Vav1 utiliza una combinación de residuos para interaccionar con el núcleo central de la proteína.

Figura 22. El CSH3 de Vav1 utiliza dos regiones diferentes para interaccionar con los dominios $\mathrm{DH}$ y $\mathrm{PH}$.

Figura 23. Los dos sitios de unión del CSH3 son necesarios participan en al interacción inhibitoria CSH3/Vav1.

Figura 24. El dominio CSH3 de Vav1 utiliza las regiones DFC-R e YVEED para interactuar 
con los dominios $\mathrm{DH}$ y $\mathrm{PH}$, respectivamente.

Figura 25. Identificación de los sitios de fosforilación de la proteína Vav1.

Figura 26. Contribución de los residuos del ZF y del CSH3 a la activación de Vav1 in vivo.

Figura 27. Relación entre los sitios de fosforilación de Vav1 y la interacción intramolecular del CSH3 con la región $\mathrm{DH}-\mathrm{PH}$.

Figura 28. Fosforilación cruzada entre los residuos de las regiones Ac, ZF y CSH3.

Figura 29. Representación esquemática de la influencia de la fosforilación de unos residuos sobre otros.

Figura 30. Efecto de los residuos de la región Ac sobre las respuestas celulares asociadas a la activación de Vav1 en linfocitos.

Figura 31. Efecto sinérgico de los residuos de la región Ac sobre la activación de NF-AT mediada por la activación de Vav1 en linfocitos.

Figura 32. Efecto de $\mathrm{Y}^{160}$ sobre las respuestas celulares asociadas a la activación de Vav1 en linfocitos.

Figura 33. Efecto sinérgico de los residuos de la región acídica y la $Y^{836}$ sobre las respuestas celulares asociadas a la activación de Vav1 en linfocitos.

Figura 34. Esquema resumen de los efectos de las mutaciones de las tirosinas de la región Ac sobre la actividad catalítica y funciones efectoras de Vav1 en linfocitos.

Figura 35. Efecto de los residuos del dominio ZF sobre la activación de NF-AT mediada por la activación de Vav1 en linfocitos.

Figura 36. Esquema resumen de los efectos de las mutaciones de las tirosinas del dominio ZF sobre la actividad catalítica y funciones efectoras de Vav1 en linfocitos.

Figura 37. Efecto de la $\mathrm{Y}^{836}$ del dominio $\mathrm{CSH} 3$ sobre la activación de NF-AT mediada por la activación de Vav1 en linfocitos.

Figura 38. Esquema resumen de los efectos de las mutaciones de la $\mathrm{Y}^{836}$ del dominio CSH3 sobre la actividad catalítica y funciones efectoras de Vav1 en linfocitos.

Figura 39. Estado de fosforilación de Vav1 en células Jurkat deficientes en Zap70, Lck y CD45.

Figura 40. Efectos de la ausencia de Zap70 y Lck sobre respuestas celulares asociadas a Vav1 en linfocitos.

Figura 41. Efecto de la ausencia de la proteína Lat sobre la cinética de fosforilación de la proteína Vav1.

Figura 42. Efectos de la ausencia de Lat sobre respuestas celulares asociadas a Vav1 en linfocitos.

Figura 43. Efectos de la ausencia de SIp76 y PLC $\gamma 1$ sobre la fosforilación y respuestas celulares de Vav1.

Figura 44. Efecto de la ausencia de las proteínas del complejo Vav1/SIp76/PLC $\gamma 1$ sobre el estado de fosforilación de las mismas.

Figura 45. Nuevo modelo propuesto para la regulación de la familia de proteínas Vav.

Figura 46. Esquema representativo de la cascada secuencial de fosforilación que lleva a la 
Figura 47. Esquema comparativo de los modelos de activación de la proteína Vav1 anterior y posterior a este estudio. 



\section{Agradecimientos}

Y llegado el final del camino, es hora de hacer balance. Estos años en el laboratorio me han servido para aprender a pensar científicamente y a realizar muchas técnicas pero también a conocer mis límites, pedir ayuda cuando la necesito, tener paciencia, tolerar más los momentos de frustración y valorar las cosas en su justa medida. Todo esto creo que me será muy útil en el futuro no sólo para mi carrera científica sino también para mi vida en general. $Y$ este camino no hubiese sido el mismo sin una serie de personas que han compartido conmigo mis penas y mis glorias y a los que estoy profundamente agradecida.

Xosé, muchas gracias por abrirme las puertas de tu laboratorio. Gracias por guiarme en este camino e ir siempre muchos pasos por delante de mí, ha sido un gran ayuda. Gracias también por no poner límites ni científicos ni económicos a mi tesis y por brindarme la oportunidad de continuar el trabajo que un día tu comenzaste. Ya sabes que, al menos a ti y a mi, sí que nos importa Vav1.

Gracias a todos los que han colaborado en este trabajo, desde el Dr. José Couceiro que peleó con los anticuerpos fosfoespecíficos hasta la Dra. Eva Torreira y el Dr. Óscar Llorca que hicieron un gran trabajo con la EM. Muchas gracias a la mejor técnico que se puede tener, Maite Blázquez, por tener siempre una mano libre para mí, por estar pendiente, por las riñas con cariño y por dejarme ser tu otra María. Muchas gracias a los miembros presentes y pasados del Laboratorio 2 por aguantarme cuando me pongo pesada, soportar mis manías y resolver mis dudas, de todos he aprendido algo. Gracias Mauri, por tus ánimos constantes, por nuestras colaboraciones, por decirme lo que no quiero oir, por las canciones de cultivos y por los ratos de terapia, ya sabes que los dos corremos la misma suerte. Gracias Vir, por ser mi hermana pequeña en el laboratorio, por los ratos de diversión dentro y fuera, por ser un público fácil para mis comentarios graciosos, por escuchar mis teorías surrealistas y por ser mi cómplice en tantos momentos. Gracias Carmen, por ser la hermana mayor, por tus consejos, por tus regañinas y por hacerme pensar el porqué de las cosas. Gracias Vincent, por contagiarme tu pasión científica y responder a todas mis preguntas con gran paciencia. Gracias Mariajo, por tu sabiduría con las Jurkat, las DT40, los ensayos de luciferasa... por todo lo que sabes y los consejos que me has dado tanto sobre los experimentos como sobre lo que hay alrededor.

Gracias a todos los becarios de otros laboratorios que han caminado a mi lado, por las segundas opiniones sobre los experimentos y sobre todo por ser paño de lágrimas cuando ha hecho falta. Gracias Yure y Cris, mis chicas del 9, y Laura, mi uruguaya favorita, por todo, por 
estar ahí dentro y fuera de $\mathrm{CIC}$, habeis sido un buen espejo donde mirarme y unas grandes amigas. Gracias también, Dani y Nacho, por compartir conmigo risas y momentos de desahogo. Gracias Antoñito, por tu optimismo desproporcionado, por estar siempre dispuesto a distraerme, por tener más confianza en mi que yo misma y por no enfadarte cuando te doy caña.

Si de algo me he dado cuenta en estos años de tesis es que tengo una familia maravillosa, del primero al último. Gracias mamá, por haber hecho este camino antes que yo, por estar siempre al otro lado del teléfono, por no dejarme caer, por recordarme quién soy y de donde vengo, y por enseñarnos a tomar nuestras propias decisiones y a sumir responsabilidades. Gracias por tu cariño, tu comprensión, tu flexibilidad y por entender mis ausencias. Gracias papá, por soportar estoicamente que tu hija te saliese bióloga, sé que ha sido duro. Gracias por contagiarme tu curiosidad científica, por enseñarme la importancia de buscar la verdad, por los trucos de magia en el laboratorio, por responder a mis preguntas incesantes, por saber de todo y sino ayudarme a descubrirlo, por nuestras discusiones científicas, por tus halagos a terceros y porque sé que aunque no te perciba siempre estás ahí. Gracias Pablín, por ser más que un hermano un compañero de viaje, por consultarme a cada paso, por valorar mi opinión aunque sea a escondidas, por darme cariño a tu manera y por apoyarme siempre. Gracias güelita, por ser el mejor ejemplo que puedo tener, por enserñarme el valor del esfuerzo, por no consentirme, por tus refranes y tus frases acertadas en cada momento, por recordarme lo que realmente importa, por tu positividad hasta límites insospechados y por ser el mejor oasis donde descansar. Gracias tía Inma por ser más que una madrina mi segunda madre, porque siempre estás cuando te necesito. Gracias tíos y primines, por entender que no esté siempre, por apoyarme siempre y confiar en mi.

Gracias a mis amigos, que aunque os cueste entender lo que hago siempre estais ahí cuando os necesito y por no tener en cuenta mis ausencias. Gracias Noe y Ana, por ser las mejores amigas que puedo tener, por sentiros tan cerca aunque esteis tan lejos, por no darme la razón cuando no la tengo, por soportar mis defectos y quererme a pesar de ellos, y por estar siempre dispuestas a salir corriendo en mi ayuda. Gracias Javi y Manu, por no dudar en coger el coche y venir a verme, por estar en las buenas y en las malas, y por aguantarme durante estos años que sé que no han sido fáciles. Gracias a los hermanos, a Mar-Cha y a mi "familia del pueblo" por ser un espacio de protección, por permitirme ser auténtica, por enseñarme tanto, por escucharme sin juzgar y por tener siempre la puerta abierta ya que nunca se sabe cuando voy a volver.

Gracias a todos. 

